\title{
VOICES OF SUCCESSFUL WOMEN ADVANCED TECHNOLOGICAL EDUCATION GRADUATES: COUNTERNARRATIVES
}

\author{
A Dissertation submitted to the faculty of \\ San Francisco State University \\ In partial fulfillment of \\ As \\ 35 \\ 2015 \\ EDD \\ Doctor of Education \\ - P38 \\ In
}

Educational Leadership

by

Courtney Nicole Rudd Paulger

San Francisco, California

May 2015 
Copyright by

Courtney Nicole Rudd Paulger

2015 


\section{CERTIFICATION OF APPROVAL}

I certify that I have read Voices of Successful Women Advanced Technological Education Graduates: Counternarratives by Courtney Nicole Rudd Paulger and that in my opinion this work meets the criteria for approving a dissertation submitted in partial fulfillment of the requirements for the degree: Doctor of Education in Educational Leadership at San Francisco State University.

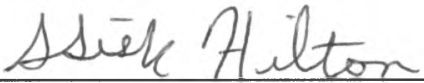

Dr. Stephanie Sisk-Hilton, Ph.D.

Associate Professor, College of Education

San Francisco State University

Dy. Jamal Cooks, Ph.D.

Associate Professor, College of Education

San Francisco State University

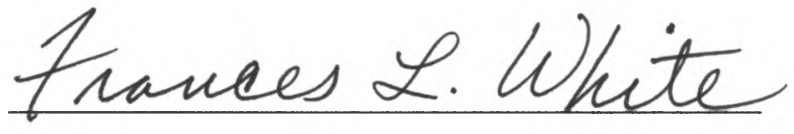

Dr. Frances L. White, Ph.D.

Former Superintendent/President

College of Marin 


\title{
VOICES OF SUCCESSFUL WOMEN ADVANCED TECHNOLOGICAL EDUCATION GRADUATES: COUNTERNARRATIVES
}

\author{
Courtney Nicole Rudd Paulger \\ San Francisco, California
}

2015

Only 26 percent of graduates earning sub-baccalaureate degrees from Advanced Technological Education (ATE) programs are women, which has declined from 31\% since 2006 (Patton, 2011; Smith, Wingate, \& Gullickson, 2014). Funded by the National Science Foundation, ATE programs are typically in community colleges and have the goal of training technicians in cutting edge advanced technology disciplines critical to the economic and domestic security of the United States (Maricopa Community College, 2014). This qualitative research study focused on women's experiences in ATE programs with the main research question: How do successful women graduates from the ATE programs describe barriers and supports to their success? Six women ATE graduates were interviewed using an in-depth phenomenological methodology. Six main themes emerged from the data; the women ATE graduates revealed two barriers to their success: 1) Race/ethnicity and gender: The double bind and 2) (Un)becoming a woman. In contrast, the women participants shared four sources of support: STEM identity (and its accompanying microaffirmations), patchwork of support, resilience, and self-efficacy. These results are significant because of the dearth of research on women earning sub-baccalaureate degrees from ATE programs (Patton, 2011; Smith et al., 2014; Westine, Gullickson, \& Wingate, 2010). While most research uses a deficit based-approach, this study uses a success-based lens to recognize that some women do succeed in ATE education. Recommendations outline practice and policy strategies for ATE programs and partners as well as future research directions. By understanding the successes and barriers to success for women in ATE, this study fills a critical gap in the research on women and STEM education.

I certify that the abstract is a correct representation of the content of this dissertation

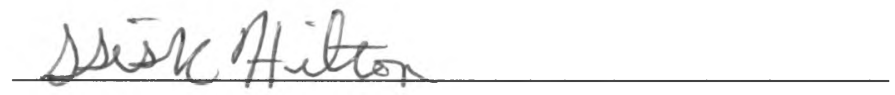

Chair, Dissertation Committee

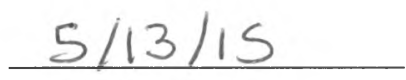

Date 


\section{ACKNOWLEDGEMENTS}

I would like to first thank my husband, Ryan, for his enduring love and encouragement throughout the Ed.D coursework and the dissertation process. You supported me, reminded me to believe in my aspirations, this work, and myself. You were loving and patient with the rollercoaster of ups and downs throughout this process, even until the last day of dissertation submission. Thank you to my family and friends: without your support and guidance, I could never have completed this work. To my father, thank you for your support and for encouraging me push myself to my highest potential. I am appreciative of my committee for sharing their extensive knowledge and support: to Dr. Sisk-Hilton for coaching me to better develop myself as a writer, practitioner, and scholar and for being the best dissertation chair and mentor I could ever have imagined. Thank you to Dr. White for her guidance and mentorship in addition to her sharing the wealth of knowledge and dedication to community colleges. Thank you to Dr. Cooks for his mentorship and for opening my eyes to the depths of this work and the field of qualitative data collection and analysis. Special thanks to Dr. Badway, for the opportunity to join the ATE Pipeline to Pathways project and for your enduring support and respect. I am thankful to members of the NSF ATE Pipeline to Pathways team for support, sharing experiences, and collaboration. NOTE: This material is partially supported by the National Science Foundation under Grant No. DUE 1003589. Any opinions, findings, conclusions or recommendations expressed in this material are those of the author and do 
not necessarily reflect the views of the National Science Foundation. Special thanks to Dr. Badway, for the opportunity to join the ATE Pipeline to Pathways project and for your enduring support and respect. I am thankful to members of the NSF ATE Pipeline to Pathways team for support, sharing experiences, and collaboration. NOTE: This material is partially supported by the National Science Foundation under Grant No. DUE 1003589. Any opinions, findings, conclusions or recommendations expressed in this material are those of the author and do not necessarily reflect the views of the National Science Foundation. To the Ed.D. 2012 family -and we did it! Thanks to all for the support, conversations, hugs, yummy snacks, and laughs - love you! To Stacey, Patricia, Cary, Betsy, and Lindsay: thank you for your enduring respect and support, especially as I navigated the dissertation process - I am lucky to have you in my life! This dissertation is dedicated to the study participants; I thank you for opening up and sharing your life stories, dreams, truths, and challenges with me. I only hope that I portrayed your life experiences in an authentic and respectful way that effectively expresses how extraordinary you are as individuals. 


\section{TABLE OF CONTENTS}

LIST OF TABLES ......................................................................................................... viii

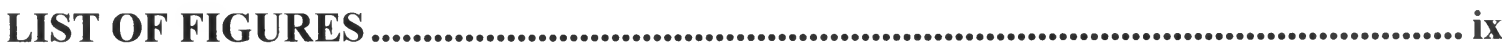

LIST OF APPENDICES ........................................................................................................... $x$

Chapter One: Purpose of the Study ............................................................................................. 1

Research Context .......................................................................................................................... 4

Research Question ...................................................................................................................... 5

Conceptual Framework …............................................................................................................. 6

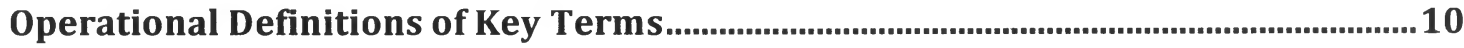

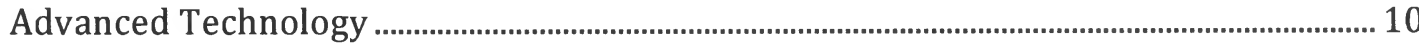

Advanced Technological Education Projects .................................................................................... 11

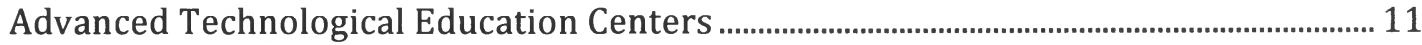

Advanced Technological Education (ATE) Program ...................................................................... 12

Science Identity .......................................................................................................................................... 13

STEM .................................................................................................................................................. 13

Justification for the Study and Significance .......................................................................13

Chapter Two: Literature Review .................................................................................................. 15

The Role of Community Colleges in STEM Career Preparation.....................................17

Advanced Technological Education: STEM in Community Colleges ...............................18

Advanced Technology Education Centers........................................................................................ 20

Advanced Technology Education Projects....................................................................................... 22

Advanced Technology Education: Gender Equity ...............................................................23

The Gender Achievement Gap in STEM .................................................................................27

External Barriers ........................................................................................................................28

Societal Barriers ……………………………………………………………………………………….... 28

Educational and Organizational Factors ............................................................................................ 30

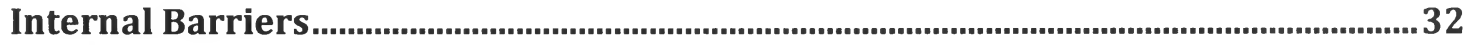

Self-efficacy .............................................................................................................................................. 33

Science Identity ........................................................................................................................................... 37

Conclusions and Implications ........................................................................................ 40

Chapter Three: Methodology ....................................................................................................... 42

Phenomenology Methodology .................................................................................................42

Participant Selection ......................................................................................................................44

Statement of Ethical Considerations..........................................................................................47

Research Procedures and Data Collection ...........................................................................48

Data Analysis...................................................................................................................................51

Internal Validity ........................................................................................................................53

Limitations................................................................................................................................54

Chapter Four: Report of Findings ...........................................................................556

STEM Identity: "Science Is Really Cool" ..........................................................................62

Self-efficacy: "There is Pretty Much Nothing That I Can't Do" .........................................70 
Self-efficacy as a Barrier: "I Never Saw Myself Where I Am" ...................................................... 74

Resilience: "I Wouldn't Be Where I Am." ........................................................................................... 78

Gender: (Un)becoming a Woman .......................................................................................83

Race/Ethnicity \& Gender: The Double Bind .......................................................................... 90

Patchwork of Support: "Someone Cared About Me." ..........................................................95

Other Themes ................................................................................................................................................. 104

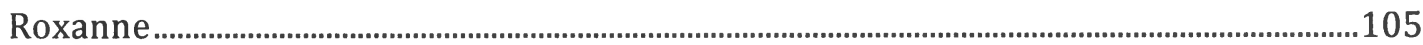

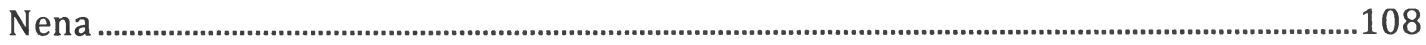

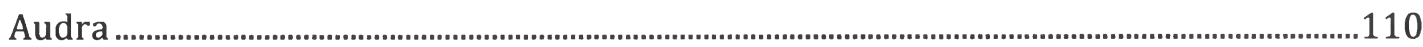

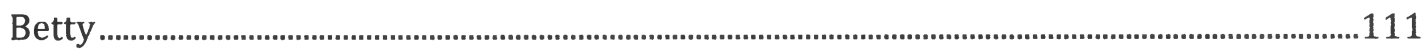

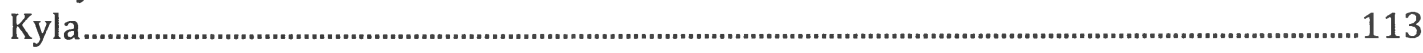

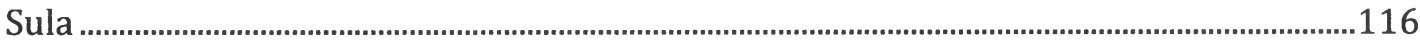

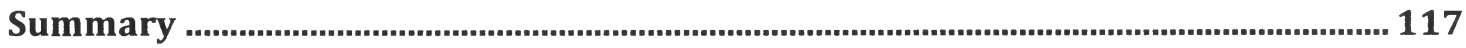

Chapter Five: Discussion and Recommendations..................................................... 119

Confirming and Extending Prior Research .............................................................................. 121

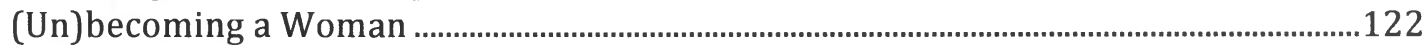

Race/Ethnicity \& Gender: The Double Bind ..............................................................................123

STEM Identity (and its accompanying STEM Fluency and Microaffirmations) ...............125

Patchwork of Support (and its accompanying Resilience) ....................................................128

Recommendations for Policy and Practice ........................................................................... 130

Recommendation \# 1: Gender Sensitivity Training For ATE Students and Staff ............130

Recommendation 2: Implement strategies to increase women's success in ATE .........132

Recommendations for Future Research ........................................................................... 133

Future Research Direction \#1: More Research on Women in ATE Overall ......................134

Future Research Direction \#2: Longitudinal Research on Women ATE Graduates .....135

Future Research Direction \#3: Employ a Mixed-Methods Approach..................................136

Conclusion........................................................................................................................................ 137

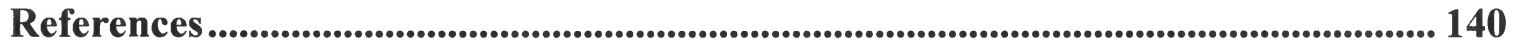

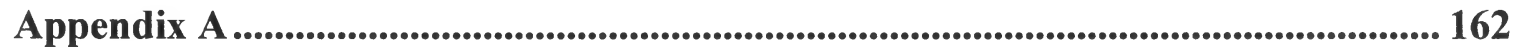

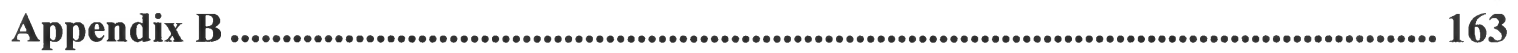

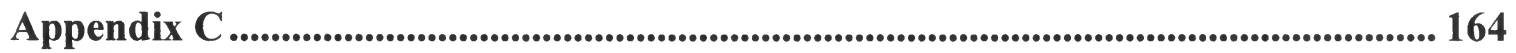




\section{LIST OF TABLES}

Table

1. Race/ethnicity and gender demographics of ATE students

2. Demographic data of study participants...................................47

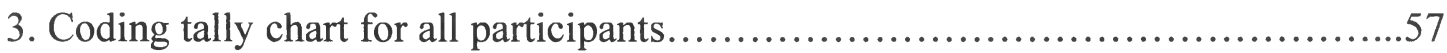

C1. Extensive participant demographics table.................................. 164 


\section{LIST OF FIGURES}

Figure

Page

1. Conceptual framework.....................................................

2. Logic model....................................................................... 16

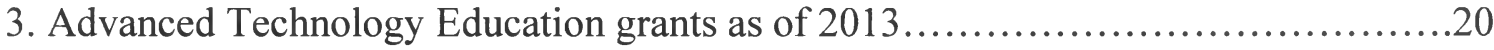

4. Current ATE centers across the United States....................................22

5. Participation rate of women in two-year colleges with ATE programs................24

6. Participation rate of women in ATE programs. ..................................25

7. Pie charts representing frequency of the six main themes across participants.........61

8. The four main themes described as supports by women ATE graduates..............120

9. The two main themes explained as barriers by women ATE graduates...............120 


\section{LIST OF APPENDICES}

$\begin{array}{lll}\text { Appendix } & \text { Page }\end{array}$

A. Email to principal investigators to request nominations for participants............. 162

B. Recruiting email to potential participants..................................... 163

C. Extensive participant demographics......................................... 164 
Voices of Successful Women Advanced Technological Education Graduates: Counternarratives

\section{Chapter One: Purpose of the Study}

Despite the growth of science, technology, engineering, and mathematics (STEM) related jobs and the economic benefits of these careers, the number of women entering them is decreasing (Bayer Corporation, 2012; Robelen, 2012). Of the best twenty-five jobs in the twenty-first century, sixty percent are in STEM-related fields (US News Staff, 2012). These positions offer job security, stability, and upward mobility, yet most go unfilled by women (Bayer Corporation, 2012; Darling-Hammond, 2010; Garibay, 2012). Many of these STEM-based occupations require a sub-baccalaureate degree (defined as an associate's degree or a technical certificate) earned in six months to two years at a community college (Costello, 2012; Grandgenett, Ostler, Jeanetta, \& Surface, 2010; President's Council of Advisors on Science and Technology, 2012). However, women are not equal beneficiaries of these advantages: there was a five-percent decline in the number of women earning STEM-related sub-baccalaureate degrees at community colleges between 2006 and 2013 (Bayer Corporation, 2012; Costello, 2012; President's Council of Advisors on Science and Technology, 2012; Smith et al., 2014). Meanwhile, the rates of women graduating with sub-baccalaureate degrees from community colleges 
has been fairly stable, ranging from 59\% in 2006 to 57\% in 2011 (Costello, 2012; Smith et al., 2014).

Recent research has documented myriad potential causes for the underrepresentation of women earning sub-baccalaureate degrees in STEM fields, (Calabrese Barton et al., 2013; Costello, 2012; Espinosa, 2011; Riegle-Crumb, King, Grodsky, \& Muller, 2012). Explanations for the deficit of women range from a lack of women role models to "stereotype threat" (characterized as a situation-specific anxiety either of being judged on the basis of stereotypes, or of performing in a way that confirms those stereotypes) (Marra, Rodgers, Shen, \& Bogue, 2009; Oakes, 1990; Shapiro \& Williams, 2012; Steele, 2010, p. 7). Another explanation for the STEM gender gap is that, in comparison to male students, most women underachieve relative to their capabilities in STEM courses and on standardized tests, even though they overachieve in reading courses (Riegle-Crumb et al., 2012). Sociocultural barriers, leading to conflicting self-perceptions and identities in women, also contribute to their underrepresentation in STEM fields (Ceci \& Williams, 2011; Espinosa, 2011; Thompson \& Windschitl, 2005).

The impact of STEM educational and organizational deficits on women is well described and may be an underlying cause of the underrepresentation of women in STEM (Hill, Corbett, \& St. Rose, 2010; Maltese \& Tai, 2011; Moss-Racusin, Dovidio, Brescoll, Graham, \& Handelsman, 2012). Examples of educational/organizational deficits include 
STEM curriculum, professors, program services and pedagogical approaches (Bettinger \& Long, 2005; Moss-Racusin et al., 2012; Scholer, 1998). For instance, according to the work of Moss-Racusin and colleagues (2012), women students experience gender bias from STEM professors who often choose to mentor and to hire male students. Furthermore, women students face exclusion and isolation in STEM courses and labs, and they report that male professors and colleagues exhibit antagonistic and intimidating behaviors toward them (Ceci, Williams, \& Barnett, 2009; Grossman \& Porche, 2013; Rosenthal, London, Levy, \& Lobel, 2011). These interactions, along with a paucity of women professors and peers, negatively impact women generally and lead to attrition in STEM programs (Betz \& Sekaquaptewa, 2012; Ramsey, Betz, \& Sekaquaptewa, 2013).

The genderization of STEM fields is a central social justice issue for women (Hill et al., 2010; Robelen, 2012; Vecchiarelli, Taormina, Simon, \& Anderson, 2009).

Completion of STEM sub-baccalaureate degrees offers women job security, opportunities for job advancement, civic participation, and satisfying lives typically correlated with postsecondary degree attainment (Darling-Hammond, 2010; Espinosa, 2011; Garibay, 2012; Johnson, Brown, Carlone, \& Cuevas, 2011). Research estimates that from 2008 to 2018, STEM-based job opportunities will continue to grow by thirty-percent, whereas non-STEM jobs are projected to only grow by ten-percent (Costello, 2012). Furthermore, women with careers in STEM fields typically earn significantly higher salaries than women with non-STEM careers (Hill et al., 2010). While the "gender wage gap" persists 
in STEM fields, women's salaries are fourteen-percent less than men with jobs in STEMfields, compared to twenty-one percent less than men in non-STEM fields (Hill et al., 2010; Robelen, 2012; U.S. Bureau of Labor Statistics, 2009; Vecchiarelli et al., 2009). Careers in STEM may offer a direct path for women to increase career stability, salary, and job satisfaction.

While some studies have documented factors that derail women from persisting in STEM education generally, few studies describe the experience of successful women community college STEM graduates (Allison \& Cossette, 2007; Hagedorn \& Purnamasari, 2012; Hoffman, Starobin, Laanan, \& Rivera, 2010; Packard, Gagnon, LaBelle, Jeffers, \& Lynn, 2011; Reyes, 2011; Starobin, Chen, Kollasch, Baul, \& Laanan, 2014; Starobin \& Laanan, 2008). As Maltese and Tai (2011) describe, a STEM student's persistence and graduation results from a "complex interplay of factors" (p. 901). The reasons for women's success in STEM programs are less well understood and deserve further study. The objective of this study is to understand the supports and barriers to success, as identified by women who have graduated from innovative STEM community college initiatives, Advanced Technological Education programs.

\section{Research Context}

The context of this study involves participants in Advanced Technological Education (ATE) programs, a National Science Foundation (NSF) sponsored initiative that seeks to drive innovation and foster the development of STEM education for 
technicians in advanced technology industries (Maricopa Community College, 2014; National Science Foundation, 2012). This ATE initiative specifically values underrepresented students. There are currently 292 active ATE projects and centers throughout the United States, typically located in two-year community colleges (Maricopa Community College, 2014; Wingate, Westine, \& Gullickson, 2010). Specifically, ATE projects partner with community colleges to offer STEM subbaccalaureate degrees and/or certificates and train students with cutting edge, high technology techniques (Smith et al., 2014). Gender diversification in ATE is especially critical because, despite the focus on increasing participation of underrepresented groups, as of 2014 only 26 percent of ATE graduates are women (Maricopa Community College, 2014; Westine et al., 2010). This study focused on women graduates from ATE programs as a lens into larger questions about women in STEM programs.

\section{Research Question}

This study seeks to explore the following research question: How do successful women graduates from Advanced Technological Education (ATE) programs in community colleges describe barriers and supports to their success? This research focuses on the stories of successful women graduates from community colleges in ATE projects and centers across the United States. This educational problem is critical to investigate because it disproportionately affects women in two key ways: 1) Women are hindered from access to STEM fields due to genderization (defined as the masculine 
characterizations in STEM fields) and 2) Consequently, women do not derive the benefits and economic security associated with STEM careers. As STEM fields continue to be dominated by white males, despite the increase in women graduating with non-STEM degrees from higher educational institutions, STEM faculty and administrators overlook gender equity issues central to these disciplines (Garibay, 2012; Hill et al., 2010; Robelen, 2012). Furthermore, the diverse perspectives, backgrounds, and experiences of women may potentially broaden approaches to scientific innovation, discovery, and complex societal scientific challenges (Ong, Wright, Espinosa, \& Orfield, 2011). Increasing the number of women in community college ATE programs has the potential to diversify STEM fields and to deconstruct the genderization of these fields (Espinosa, 2011; Garibay, 2012; Johnson et al., 2011).

\section{Conceptual Framework}

The aim of this study is to highlight the self-described barriers and supports of successful women graduates of ATE programs. This research is grounded in the conceptual framework (see Figure 1) that reveals the interplay between two types of external factors: 1) Societal 2) Educational/Organizational, and two types of internal factors: 1) Self-efficacy 2) Science identity. Figure 1 shows these four factors and the way in which each factor exists in as a dichotomy; the factor can be perceived as a support or a barrier to success for women ATE graduates. 


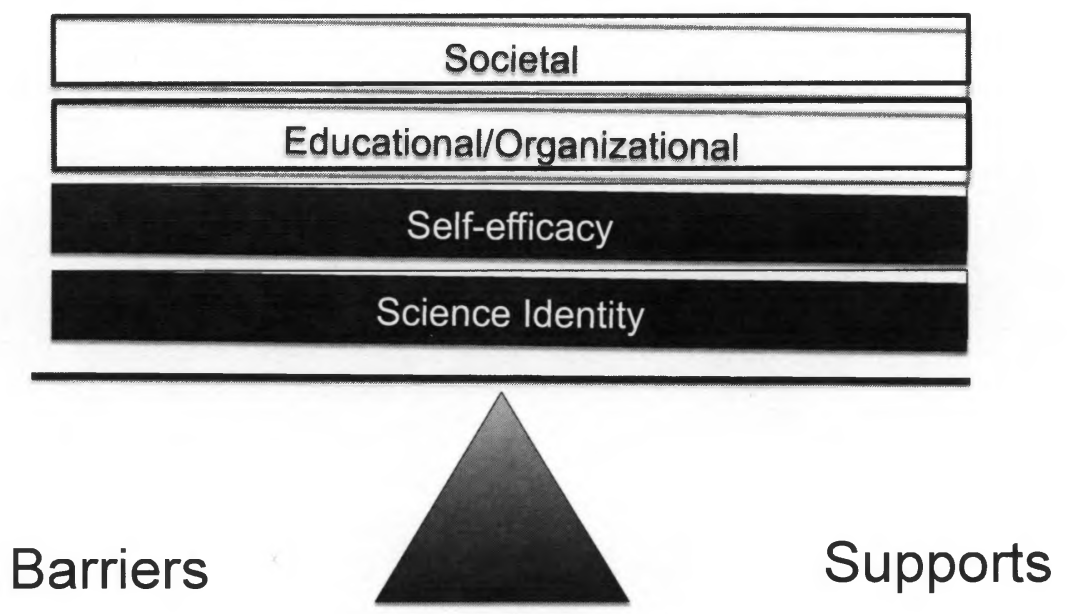

Figure 1. Conceptual framework for this study: the dichotomy of internal and external factors. These factors exist in a tension, either serving as a support as a barrier to success for women ATE graduates.

The first layer of the conceptual framework represents the internal factors, defined as behavioral and psychosocial aspects of women ATE graduates: 1) Science identity (a construct encompassing a person's ability to see oneself as a competent and confident scientist) 2) Self-efficacy (a theoretical construct that specifically describes a person's self-perceptions about his/her abilities to achieve high levels of performance) (Duckworth \& Gross, 2014; Perkins-Gough \& Duckworth, 2013; Tough, 2012). This conceptual framework demonstrates that successful women ATE graduates are iteratively constructing and co-constructing the two internal factors: self-efficacy and science identity. 
These internal factors can be construed as supports or barriers to the successful woman ATE graduate. When emerging as supports, these factors boost women's sense of self as a scientist and belief in their ability to achieve their goals. For instance, women continuously build science identity by pursuing science courses, extracurricular activities, science media, thus strengthening science identity (Calabrese Barton et al., 2013; Johnson et al., 2011). Self efficacy is a central support component, since students with high self efficacy are more likely to achieve goals, even in the face of adversity (Duckworth \& Gross, 2014; Duckworth, Peterson, Matthews, \& Kelly, 2007; Tough, 2012). The two internal constructs of self-efficacy and science identity, when acting as supports, can collectively contribute to the success of women ATE graduates.

In contrast, these internal factors that at times serve as supports can also effectively act as barriers. Several research studies of women in STEM shows that science identity can be a barrier that hinders the woman's ability to fulfill her academic or professional STEM capacity and abilities (Calabrese Barton et al., 2013; Johnson et al., 2011; Thompson \& Windschitl, 2005). There is a growing body of research suggesting that women's social identities are in conflict with the identities promoted within science class; specifically, women students do not find STEM courses to be relevant or engaging with respect to their self and social identities (Carlone, Scott, \& Lowder, 2014; Guertin, 2015; Jackson \& Suizzo, 2015). In addition, students reported that their own low levels of self-efficacy were barriers to their pursuit of STEM; 
confirming research shows that low self-efficacy can affect student performance on academic tests, internships, and commitment to career goals (Brown \& Burnham, 2012; Marra et al., 2009; Trujillo \& Tanner, 2014; Williams \& George-Jackson, 2014).

The second layer of this conceptual framework are the external factors (defined as societal \& structural factors influencing the success of a woman ATE graduate): 1) Societal factors (defined as the milieu and culture of the academy as well as broader societal stereotypes and norms that are reflected in institutional and hegemonic structures) 2) Educational/organizational factors (defined as aspects of educational organizations and other professional workplaces or organizations; these can be at the high-school level, community college level, higher-education, work organizations, or professional memberships).

Just as the behavioral factors exist as a dichotomy, so do the external factors: societal and educational/organizational factors can serve as supports or barriers. Societal factors can hinder women's success in STEM: the dominant archetype in science is still masculine and Caucasian and this proves increasingly difficult because women don't have sufficient role models in society and can have significant effects on women's ability to persist and graduate in STEM fields (Betz \& Sekaquaptewa, 2012; Espinosa, 2011; Griffith, 2010; Rosenthal, Levy, London, Lobel, \& Bazile, 2013; Young, Rudman, Buettner, \& McLean, 2013). Examples of educational/organizational factors emerge as supports include peer study groups and positive mentorship relationships with professors 
(Beltman \& Schaeben, 2012; Buday, Stake, \& Peterson, 2012; Guertin, 2015; Hill et al., 2010; Young et al., 2013). However, other educational/organizational factors can act as barriers to women ATE students. For instance, women students face exclusion and isolation in STEM courses and labs, and they report that male professors and colleagues exhibit antagonistic and intimidating behaviors toward them (Ceci et al., 2009; Grossman \& Porche, 2013; Moss-Racusin et al., 2012; Riegle-Crumb \& King, 2010; Rosenthal et al., 2011; Watermeyer, 2012).

\section{Operational Definitions of Key Terms}

In this section, operational definitions are offered for the key terms in this study: Advanced technology, Advanced Technological Education (ATE) program, Advanced Technological Education (ATE) projects, Advanced Technological Education (ATE) centers, science identity, and STEM.

\section{Advanced Technology}

For the purposes of this study, advanced technology is defined as emerging technologies that are underdeveloped but show great potential to have instrumental value for society (Bekelman \& Hahn, 2013; Locke \& Wellhausen, 2014). Often, advanced technologies are emergent and well-developed but have a small user base (Locke \& Wellhausen, 2014). Also known as "high technology," for purposes of this study, only advanced technology will be used as a key term (Sarangee \& Echambadi, 2014). Advanced technology encompasses a wide range of technologies, including space 
technology, agricultural technology, information technology, environmental technology, forensics, nanotechnology, cyber security, construction technology geospatial technology, marine technology, and manufacturing technology (Bekelman \& Hahn, 2013; Coda Zabetta, Barisic, Peltola, Sarkki, \& Jantti, 2013; De Weck, Reed, Sarma, \& Schmidt, 2014; Kessel et al., 2013; Locke \& Wellhausen, 2014; Von Solms \& Van Niekerk, 2013; Wilkinson, 2013).

\section{Advanced Technological Education Projects}

Advanced Technological Education (ATE) projects are often housed in community colleges and typically focus on one or more approaches to improving advanced technological education such as: curricular enhancements, professional development improvements, research, and/or laboratorial build-outs (Henderson, Fynewever, Petcovic, \& Bierema, 2011; Patton \& Internet Scout Research Group, 2013). ATE projects are typically smaller grants and are reduced in capacity in comparison to ATE centers (Maricopa Community College, 2014).

\section{Advanced Technological Education Centers}

Advanced Technological Education (ATE) centers have a greater capacity and scope than ATE projects. The primary goal of ATE centers is to focus on a region of the United States and a regional industry field in order to form robust partnerships across an array of stakeholders in advanced technological education, including industries, higher education institutions, P-12 schools, government, and non-profits (Badway, Somerville, 
\& Anderegg, 2010; Maricopa Community College, 2014; Patton \& Internet Scout Research Group, 2013). These centers also work to disseminate curriculum, best practices, and current research in industry-specific topics across the region; effectively serving as a region's top resource on all ATE-related matters (Henderson et al., 2011; Maricopa Community College, 2014; Patton \& Internet Scout Research Group, 2013).

\section{Advanced Technological Education (ATE) Program}

The Advanced Technological Education (ATE) program is an initiative funded by the National Science Foundation with the primary focus on two-year community college technician education in advanced technology fields that are critical to the United States' economy and national security (Maricopa Community College, 2014; National Science Foundation, 2012; Patton \& Internet Scout Research Group, 2013). The ATE programs accomplish this by offering grants to establish ATE projects and ATE centers that ultimately develop advanced technology curriculum, training, and professional development (National Science Foundation, 2012; Patton \& Internet Scout Research Group, 2013). ATE projects and centers work collaboratively on local, regional, and national scales to form partnerships between advanced technology industry, non-profits, two-year and four-year academic institutions, to promote ATE curriculum development, teacher professional development, and outreach to students (Maricopa Community College, 2014; National Science Foundation, 2012). The "ATE program" and "ATE" are terms to be used interchangeably to refer to the ATE program, its ATE projects, ATE 
centers and its scope.

\section{Science Identity}

For the purposes of this paper, science identity is defined as the active, iterative development of being acknowledged, and of acknowledging oneself, as a competent and confident scientist (Calabrese Barton et al., 2013; Carlone \& Johnson, 2007; Holmegaard, Madsen, \& Ulriksen, 2014; Johnson et al., 2011; Tan \& Barton, 2008; Williams \& George-Jackson, 2014). Science identity formation results from a complex negotiation of social interactions, self-perceptions, norms, dominant discourses, and collective past experiences (Calabrese Barton et al., 2013; Malone \& Barabino, 2009; Tan \& Barton, 2008).

\section{STEM}

STEM is an acronym for the four disciplines of science, technology, engineering, and math. It was created in 2000 by the National Science Foundation to describe any policy, event or curriculum in one or more of the STEM fields and is primarily used in education disciplines (Bybee, 2013). For the purposes of this study, STEM is an "umbrella term" that refers to education, curriculum, schooling, students, professors in one or more of the STEM fields (Kumtepe \& Genc-Kumtepe, 2013, p. 141).

\section{Justification for the Study and Significance}

This study offers a platform to share the narratives of women whose stories and successes are counter to the mainstream narrative of men succeeding in STEM education 
and careers (Clandinin \& Connelly, 2000; Giroux, 1996). Regardless of ATE and STEM achievement, there remains an underrepresentation of women in STEM postsecondary education and STEM-related jobs (Bielby, Posselt, Jaquette, \& Bastedo, 2014; Brandt, 2014; Kanny, Sax, \& Riggers-Piehl, 2014; Marra et al., 2009; Moss-Racusin et al., 2012). Accordingly, the voices of these women offered counternarratives of women in advanced technology education (Giroux, 1996). This research is important since it informs researchers and practitioners regarding factors that contribute to the success of women in earning ATE-related degrees. This study is a contribution to the field of ATE and STEM education, particularly the study of the underrepresentation of women in advanced technology. This study proposes a useful framework for understanding women's success in ATE programs for practitioners and scholars to refer to when seeking to promote women's representation in STEM fields. 


\section{Chapter Two: Literature Review}

The structure of this is framed by the logic model (see Figure 2) I created to address I created to address the central research question: How do successful women graduates from Advanced Technological Education (ATE) programs in community colleges describe barriers and supports to their success?

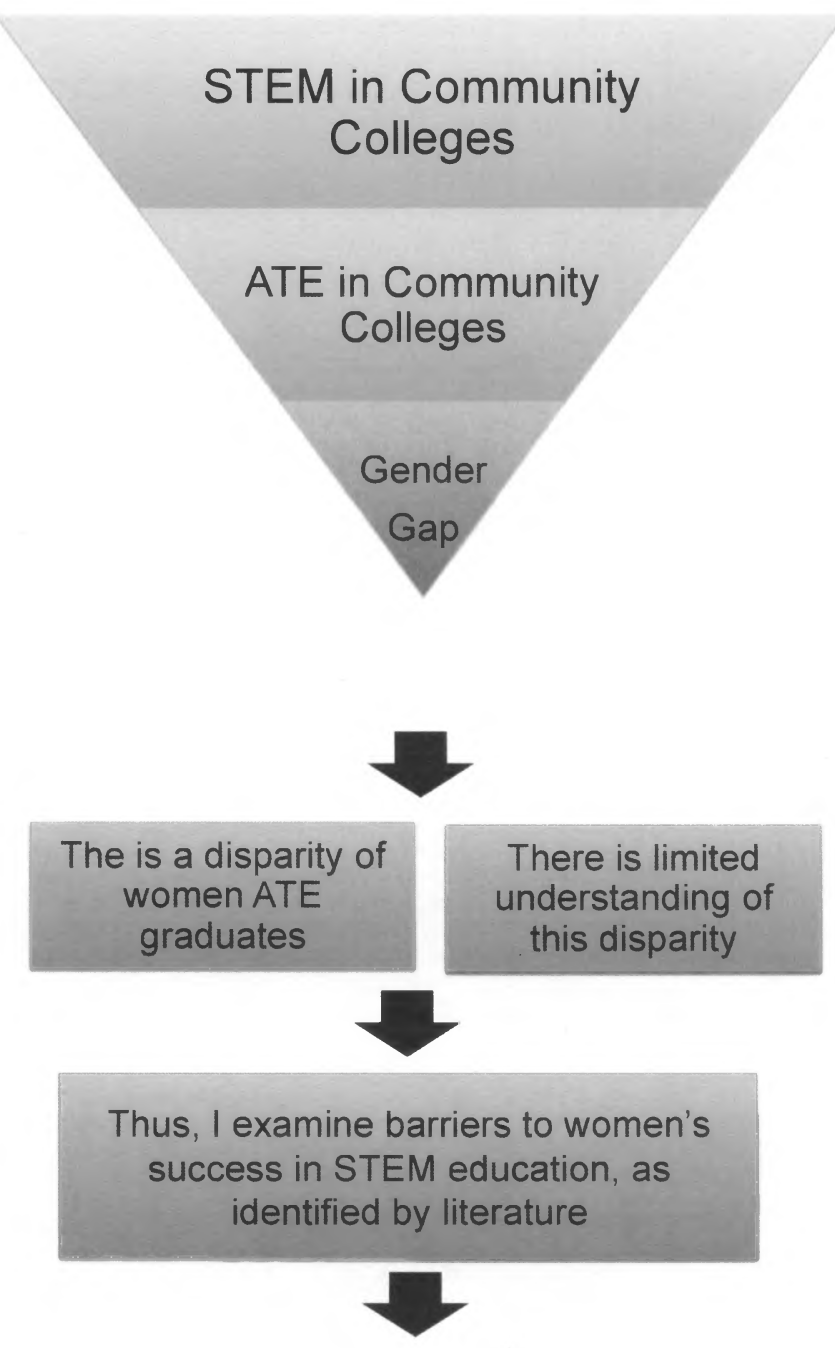




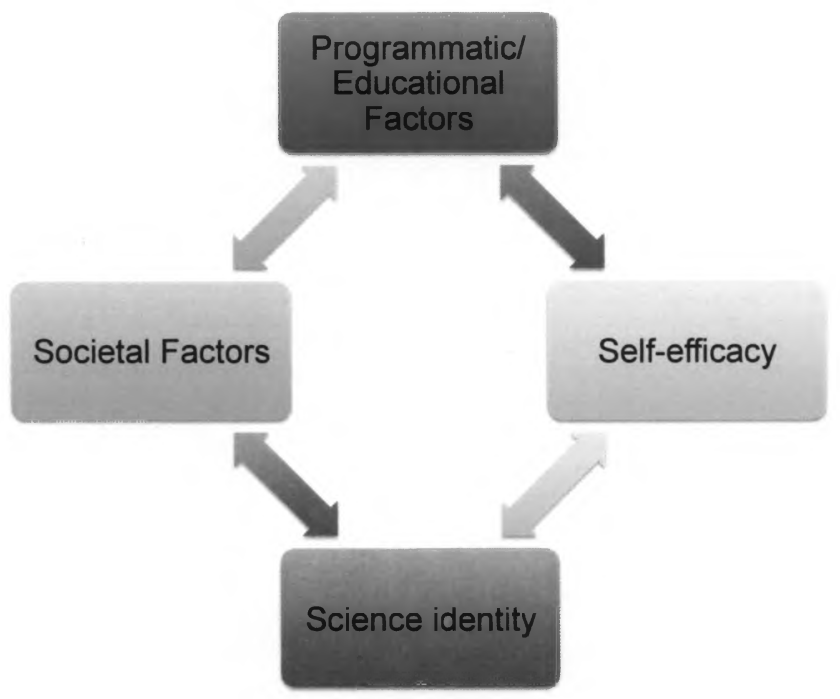

Figure 2. Logic model: identifying and understanding the barriers identified for women ATE graduates. This logic model serves as a framework for the discussion in Chapter Two.

In this chapter, I first broadly discuss STEM in community colleges. Then, I narrow the discussion to the role of ATE career preparation in community colleges (see Figure 2). Then, I discuss the gender gap of women in STEM and more specifically, ATE programs. Since limited studies are available on ATE gender equity, I consider the available literature on the STEM gender gap. I frame the remaining discussion on the internal and external barriers identified by literature, which are visually represented in the conceptual framework of this study (see Figure 1) and the logic model of this chapter (see Figure 2). Based on this literature review, the reason for women's success in STEM fields, particularly ATE, is understudied. This chapter concludes with a summary and discussion of the ways in which this research study will address the gap in research. 


\section{The Role of Community Colleges in STEM Career Preparation}

Community colleges are open-access institutions that offer developmental education, non-credit and for-credit pre-baccalaureate education, technical programs, and transfer options to four-year universities (Badway, Bell, \& Grubb, 2003; Grubb, 2013; Hagedorn \& Purnamasari, 2012; Levin \& Kater, 2012). Of all higher education institutions, community colleges are unique in the ability to offer a blend of comprehensive academic and support services for students of all ages and backgrounds (Badway et al., 2003; Levin \& Kater, 2012). These two-year institutions offer "diverse learning options," and act as a cornerstone for young adults and mature adults to gain job training and retraining, and are a critical academic institution for students to obtain qualifications that offer mobility and stability (Carnevale, 2000). A significant number of women students enroll in community college because of the affordable tuition, open admissions, convenient locations, and flexible course schedules (Packard et al., 2011). Many women students in community colleges have dependent children or family members; approximately ten percent of these are women students are single parents of dependent children (Miller, Gault, \& Thorman, 2011). Various aspects of community colleges attract women students, such as extended childcare services, financial aid, contextualized developmental courses, academic counseling, and other support services (Costello, 2012). 
Community colleges are a key place for students to enter the STEM career pathway since 20-percent of STEM careers require an associate's degree or technical certificate earned from a 2-year community college (Hoffman et al., 2010; Tsapogas, 2004). STEM community college pathways offer essential higher education opportunities for women students because of their open access, low cost, and convenient course schedules and locations (Levin \& Kater, 2012; Packard et al., 2011; Starobin \& Laanan, 2008). An understudied aspect of community colleges is the array of STEM educational opportunities, where women can earn a sub-baccalaureate associate's STEM degree in two years or STEM technical certificates in several months (Costello, 2012).

\section{Advanced Technological Education: STEM in Community Colleges}

To answer the growing need for better technological education and accessible pathways for underrepresented students into STEM fields of study in community colleges, the National Science Foundation created the Advanced Technological Education (ATE) initiative as a result of the Science and Advanced Technology Act (SATA) of 1992 (Costello, 2012; Maricopa Community College, 2014; National Science Foundation, 2012; Patton, 2011). The initiative increases support for community colleges to educate and prepare the STEM technicians to join advanced technology industries integral to U.S. security and economic growth (Henderson et al., 2011; Maricopa Community College, 2014; Patton, 2011). The ultimate outcome for the SATA act and ATE initiative was to increase the quantity and quality of advanced technology education 
and therefore the number of qualified workers entering U.S. advanced technology industries (Patton \& Internet Scout Research Group, 2013).

The ATE program focus is to improve ATE teacher preparation and professional development, recruitment and graduation of ATE students, and increasing the rigor of ATE education for technicians (Badway et al., 2010; McKinsey \& Company, 2009; Patton, 2011; Wingate et al., 2010). The goals of ATE programs also include graduating well-prepared technicians, engaging in dialogue on industry hiring protocols, developing and improving ATE curricula (Maricopa Community College, 2014; Patton \& Internet Scout Research Group, 2013). Since many industries and jobs in ATE programs are still emerging, ATE projects and centers also conduct research on promising practices in technician education, outreach to secondary schools to increase awareness of STEM technician careers, and innovative curriculum to train technicians (Patton \& Internet Scout Research Group, 2013).

In the 2013 Fiscal Year, NSF awarded \$64 million dollars to ATE programs and centers for 292 active grants (see Figure 3) (Patton \& Internet Scout Research Group, 2013). Since the start of ATE program, NSF has awarded grants to over 40 centers and 900 projects in the United States (Patton \& Internet Scout Research Group, 2013). The grants fund ATE projects and ATE centers that seek to impact students, community colleges, educators, and local industry to meet the growing demand of advanced technology-related workforce development (Maricopa Community College, 2014; Smith 
et al., 2014; Wingate et al., 2010). However, the scope and strategies of ATE projects versus centers varies widely.

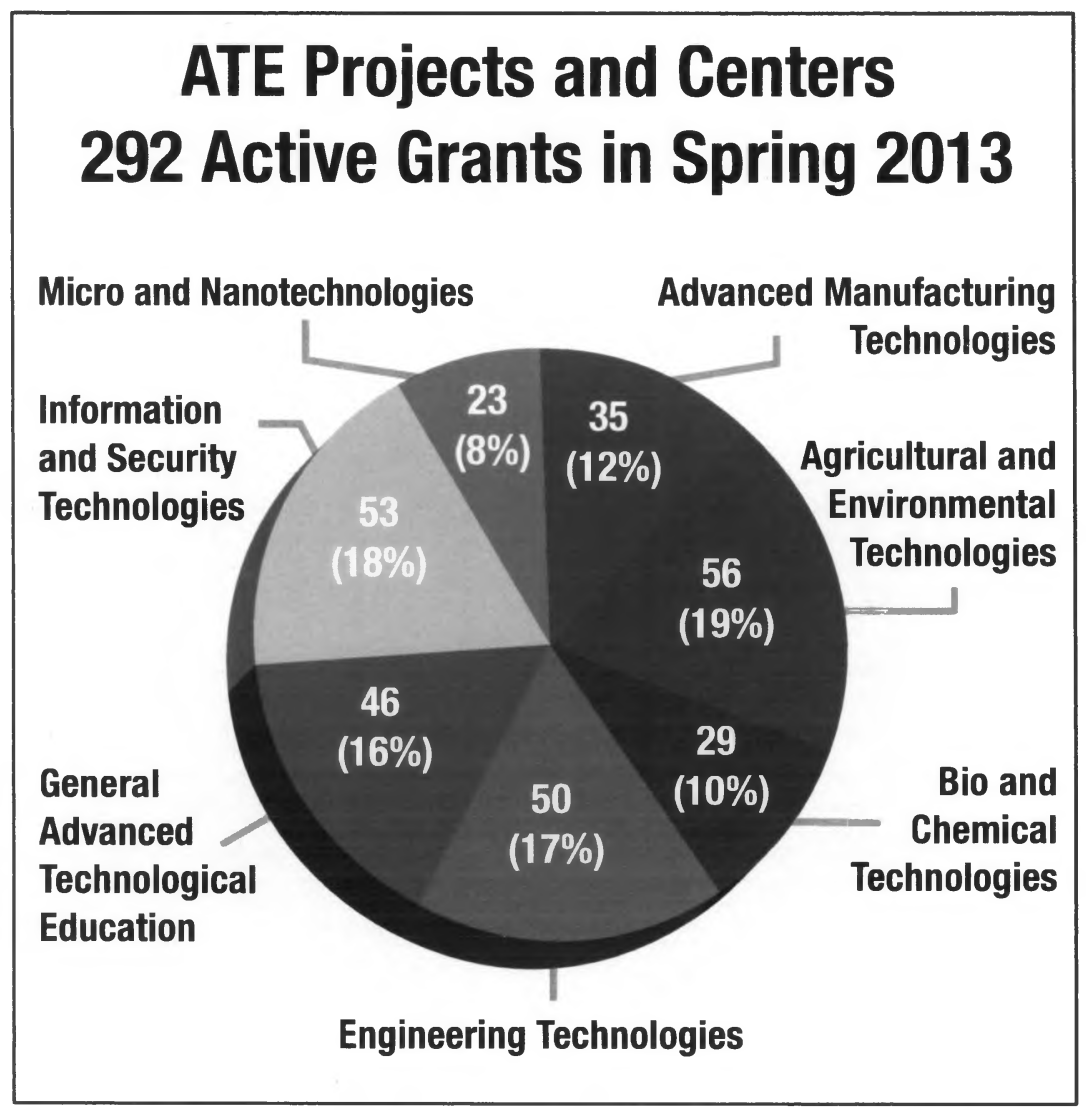

Figure 3. Advanced Technology Education grants as of 2013: ATE projects and centers. Figure is courtesy of Patton \& Internet Research Group (2013).

\section{Advanced Technology Education Centers}

Advanced Technological Education (ATE) centers have a greater capacity than ATE projects. The scope of ATE centers is typically regional and industry-specific, with the goal to create broad partnerships to drive "industry specific reforms" and test cutting edge advances (Badway et al., 2010; Maricopa Community College, 2014, p. ii; Patton \& Internet Scout Research Group, 2013). Through these cross-organizational collaborations, 
ATE centers offer effective, established program models, methods and instructional materials for advanced technological education and partnerships, effectively acting as “clearinghouses" (Bailey, Matsuzuka, Jacobs, Morest, \& Hughes, 2003, p. 2; Patton \& Internet Scout Research Group, 2013; Sarangee \& Echambadi, 2014).

The 42 ATE centers are across the nation fall into one of the following eight areas of study: 1) Advanced manufacturing technologies 2) Agricultural and biological technologies 3) Energy and environmental technologies 4) Engineering technologies 5) Information technologies 6) Learning, evaluation and research 7) Microtechnology and nanotechnologies 8) Security technologies (Patton \& Internet Scout Research Group, 2013) (see Figure 4).

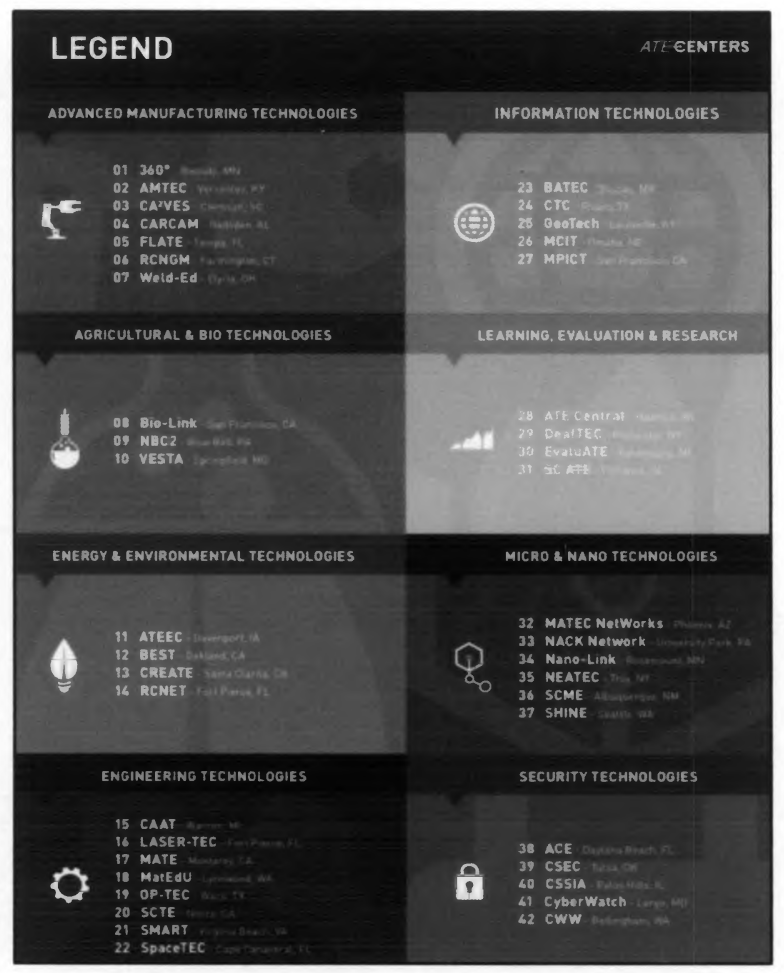




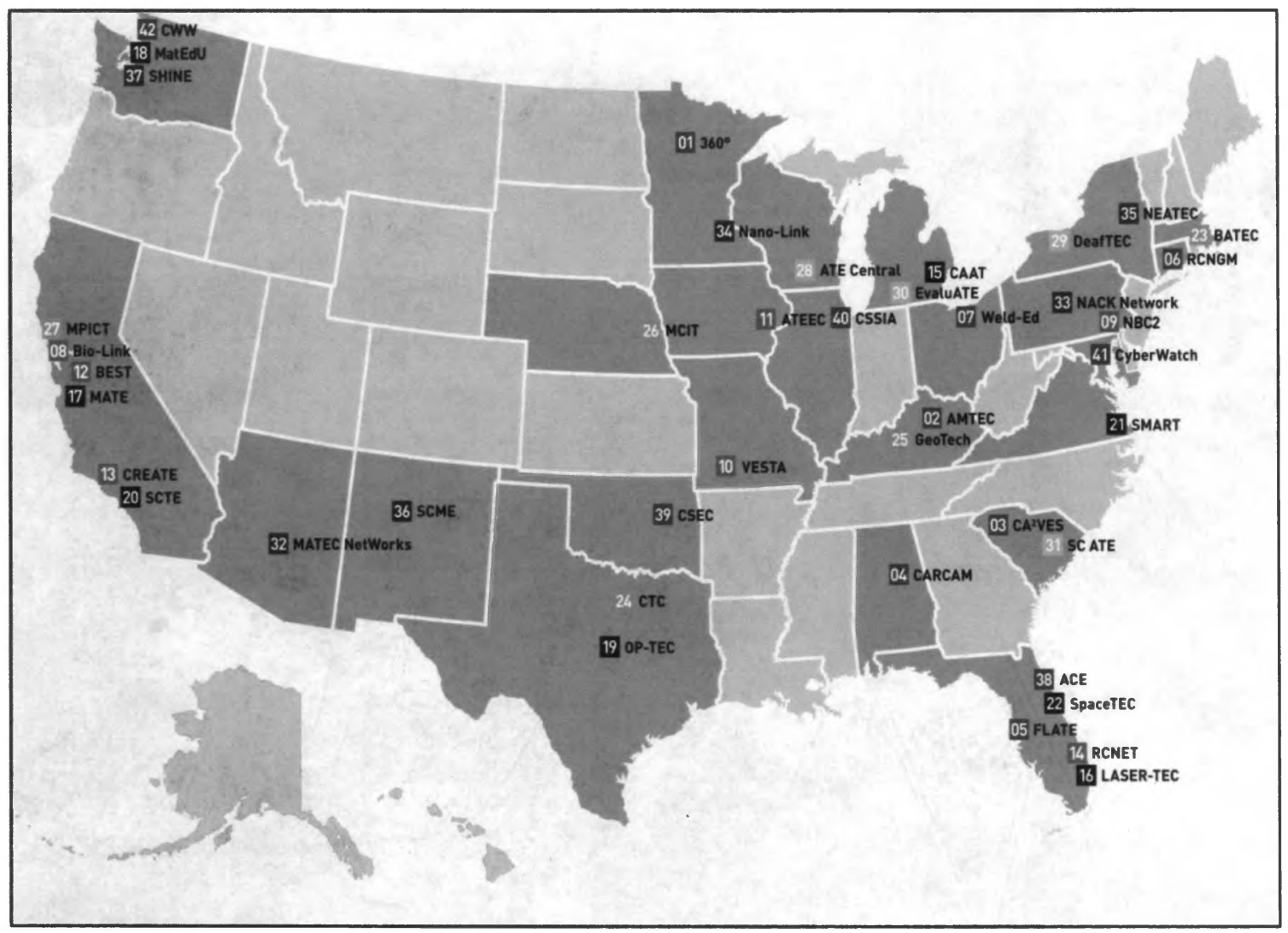

Figure 4. Current ATE centers across the United States. Figure is courtesy of Maricopa Community College (2014).

\section{Advanced Technology Education Projects}

Using hands-on, project-based learning strategies, ATE projects offer STEM sub-baccalaureate degrees that aim to train students in cutting edge advanced technology techniques (Maricopa Community College, 2014; Patton \& Internet Scout Research Group, 2013). ATE projects form key partnerships with local technology industries, high schools, four-year colleges and government groups to provide an interdisciplinary 
approach to technician education and meet the needs of local industry employment demands (Costello, 2012; Maricopa Community College, 2014; Patton \& Internet Scout Research Group, 2013). These partnerships provide the critical link between the community college offerings and the industry needs in order to employ graduates of the ATE programs in local industries. These collaborations are the core of ATE projects since these local partnerships lead to effective technician training and high employment rates of ATE technicians (Maricopa Community College, 2014; National Science Foundation, 2006; Smith et al., 2014). Furthermore, community colleges typically have students that desire to remain in the region and be employable with the skills they have gained in community college (Grubb, 2013; Levin \& Kater, 2012; Maricopa Community College, 2014; Patton \& Internet Scout Research Group, 2013).

\section{Advanced Technology Education: Gender Equity}

The National Science Foundation (NSF) is committed to increasing the number of women entering, persisting, and finishing ATE certificate programs and/or earning ATE sub-baccalaureate degrees (National Science Foundation, 2006). In 2006, the National Science Foundation included a commitment to gender equity in the ATE strategic plan (National Science Foundation, 2006). However, the number of women graduating from community colleges with an ATE sub-baccalaureate degree has declined from $31 \%$ in 2006 to $26 \%$ in 2014 (see Figure 5) (Costello, 2012; Maricopa Community College, 2014; Smith, Wingate, \& Gullickson, 2013). 


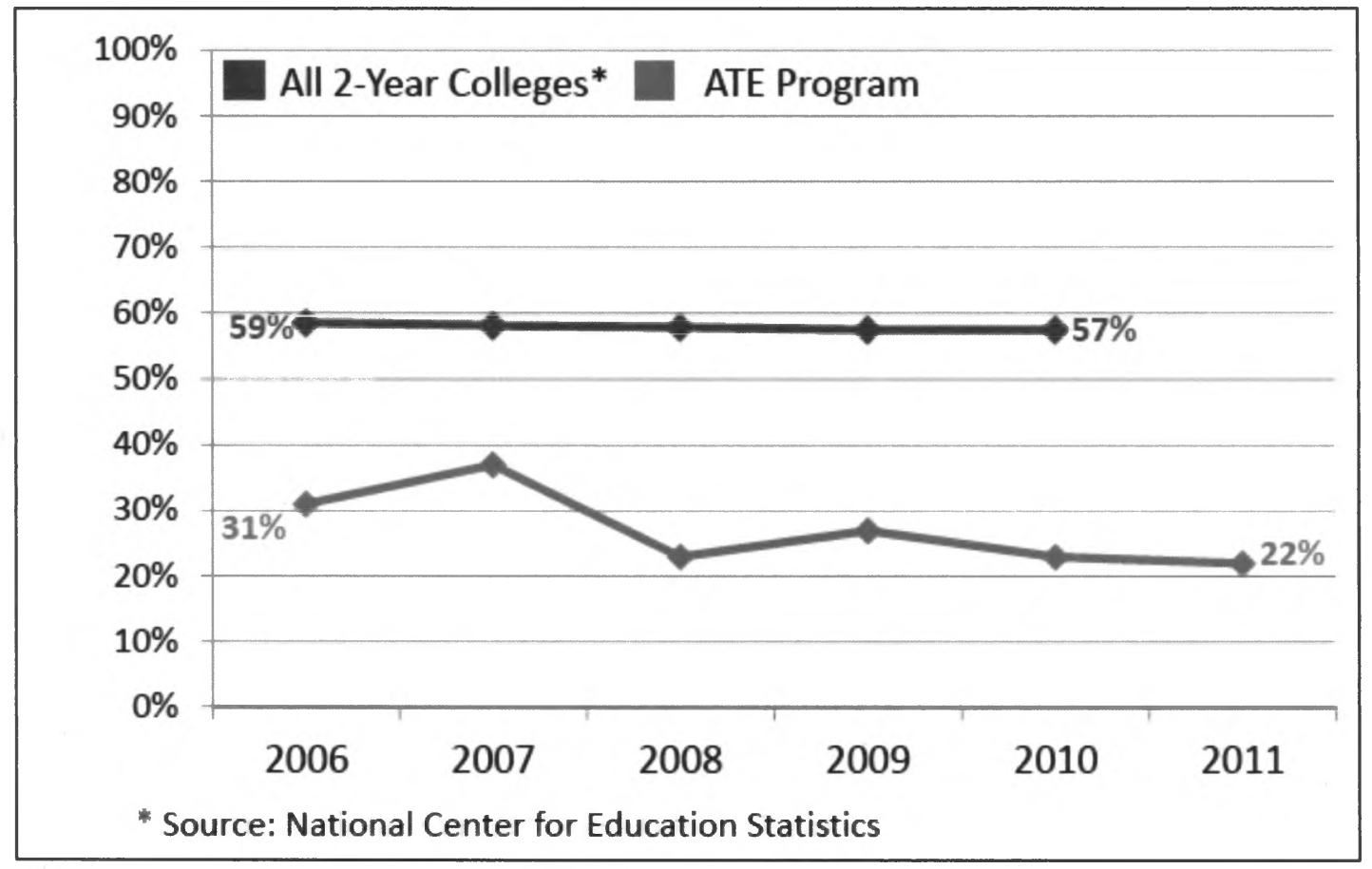

Figure 5. Participation rate of women in two-year colleges with ATE programs. Figure is courtesy of Wingate and colleagues (2010).

The five-percent decline in women's ATE degree attainment rates is a serious issue; fewer women are joining the ATE workforce and obtaining ATE-related jobs (see Figure 6) (Westine et al., 2010; Wingate et al., 2010). The dearth of women graduates is a serious issue since ATE programs are critical to this nation's prosperity and economic security, playing a key role in preparing students to obtain ATE technician jobs (Maricopa Community College, 2014; National Science Foundation, 2012; Patton \& Internet Scout Research Group, 2013). 


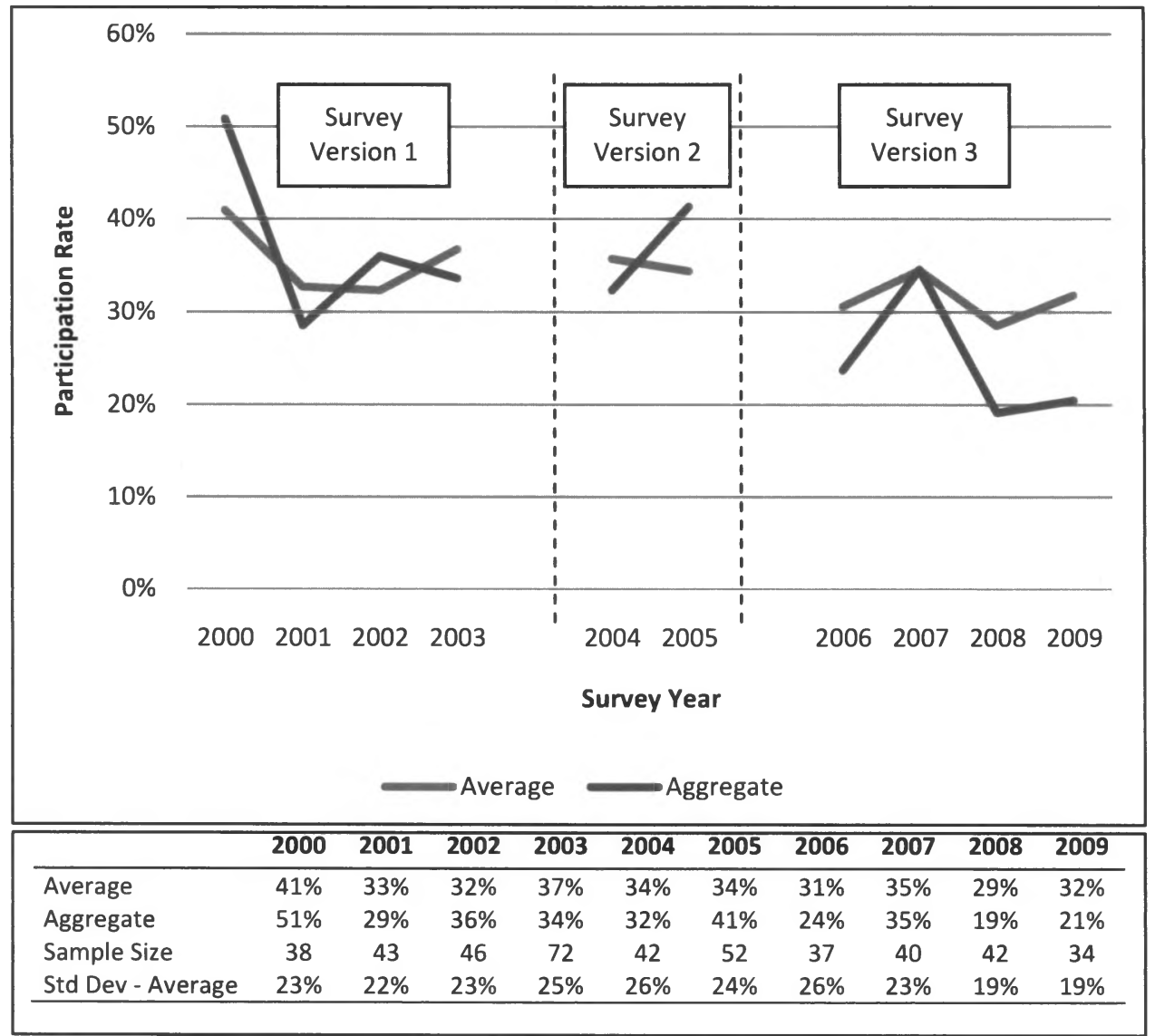

Figure 6. Participation rate of women in ATE programs. Annual aggregate percentage = the sum of the number of the women in all ATE programs that year, divided by the total number of students in all ATE programs that year, multiplied by 100 . Annual average percentage $=$ the sum of the self-reported percentages of women students reported by each ATE program, divided by the number of total ATE programs in existence that year. Three survey instruments were deployed throughout the nine-year study. Figure is courtesy of Westine et al. (2010).

As shown in Figures 5 and 6, the past rates of women ATE students reveal a downward trend in degree attainment. Not only are the number of women ATE graduates decreasing over time, but as of 2013, only one in five ATE graduates is a woman, only 26 percent of ATE graduates (see Table 1) (Patton \& Internet Scout Research Group, 2013; 
Smith et al., 2013). The reasons for the downward trend and current disparities are unclear and underexplored (Maricopa Community College, 2014; Patton \& Internet Scout Research Group, 2013; Smith et al., 2013; Westine et al., 2010; Wingate et al., 2010).

There is no evidence that this decline was spread unevenly across ATE programs and the nation. During this time frame since 2006, the funding for the ATE program has increased by 60 percent and the number of participants increased by 22 percent (National Science Foundation, 2001, 2012).

Table 1.

Race/ethnicity and gender demographics of ATE students. Low sample sizes or incomplete data may be due to the nature of demographic data reporting; table is courtesy of Smith and colleagues (2014).

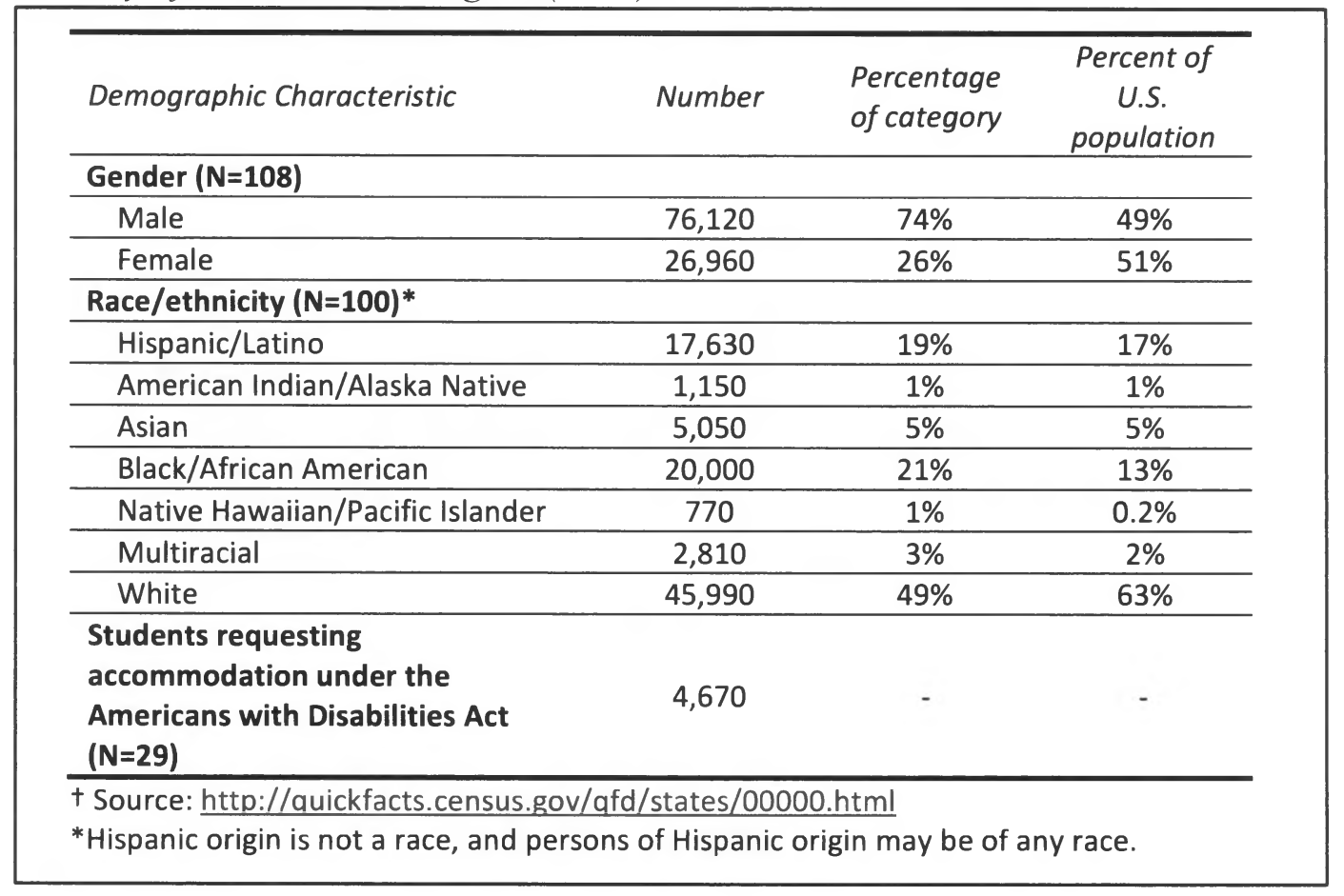

Table 1 reveals a downward trend in the number of women students in ATE 
programs; from 2000 to 2009, there was a five-percent decline in women ATE students (Westine et al., 2010; Wingate et al., 2010). Unfortunately, the decline in the number of women in STEM programs is a trend that extends beyond ATE programs, and is commonly referred to as the STEM gender achievement gap (Bayer Corporation, 2012; Robelen, 2012; US News Staff, 2012).

\section{The Gender Achievement Gap in STEM}

The discourse on the deficiency of women in STEM centers on women's underachievement and lack of academic ability (Blickenstaff, 2005; Riegle-Crumb et al., 2012). Training for STEM careers is academically rigorous and it necessitates advanced literary and mathematical proficiencies; areas of study in which women traditionally have been considered less successful than men (Benbow, Lubinski, Shea, \& Eftekhari-Sanjani, 2000; Fryer \& Levitt, 2009; Penner \& Paret, 2008). However, few studies test these assertions empirically, and recent data confirm that women are academically successful in STEM fields; women have eclipsed men in advanced STEM course-taking, math testtaking scores, and math and science postsecondary grade point averages (Barone, 2011; Dalton, Ingles, Downing, \& Bozick, 2007; Hyde, Lindberg, Linn, Ellis, \& Williams, 2008; Riegle-Crumb et al., 2012). Critics of the gender achievement gap explanation suggest that women students do tend to meet the qualifications to succeed in STEM education, but do not persist in STEM due to their reading/literature "comparative advantage" (defined as an association between a student's grades/test scores and her 
aptitude in two or more fields of study) (Barone, 2011, p. 161; Riegle-Crumb et al., 2012). While the achievement gap explanation has been rejected, the comparative advantage explanation presented by Riegle-Crumb et al. (2012), using a quantitative analysis still deserves follow-up studies. If achievement does not explain the underrepresentation of women in STEM, it is critical to examine other potential barriers to women's success in STEM education.

\section{External Barriers}

For the purposes of this study, external factors are defined as societal and structural constructs that may contribute to the internal psychosocial experiences of women ATE graduates (Griffith, 2010; Hunter, Laursen, \& Seymour, 2007; Solorzano, Ceja, \& Yosso, 2000). Limited research has been conducted on external factors of successful women in STEM at the community college level and in advanced technology education.

\section{Societal Barriers}

Societal barriers are defined as milieu as well as broader stereotypes and norms that are reflected in institutional and hegemonic structures (Griffith, 2010; Hunter, Laursen, \& Seymour, 2007). Research indicates that external barriers can significantly affect career and academic goals (Bielby et al., 2014; Cundiff, Vescio, Loken, \& Lo, 2013; Kanny et al., 2014; Packard et al., 2011; Spencer, Steele, \& Quinn, 1999; Steele, 2010). Further research shows a host of societal barriers that appear to contribute to low 
participation by women (Costello 2012; Hill, Corbett, and St. Rose 2010; Osborne, Miller, Farabee-Siers 2008). Ong and colleagues (2011) reported that aspects of social atmosphere negatively affect women in STEM through microaggressions (defined as short or indirect instances of non-physically violent hostility), lack of recognition, feelings of being an outsider, and patronizing behaviors (Solorzano, Ceja, \& Yosso, 2000).

Women students in STEM are operating in a "matrix of oppression," in which the hegemonic cultural structures such as gender, race/ethnicity, or class create difficulties for women while also offering skewed advantages for those at the top of these structural hierarchies (Calabrese Barton et al., 2013; Collins, 2000, p. 17). Furthermore, the dominant archetype in science is still masculine and Caucasian and this creates a challenge for women in choosing STEM goals or career paths (Carlone \& Johnson, 2007; Grossman \& Porche, 2013; Rosenthal et al., 2013). This proves increasingly difficult because women don't have sufficient role models in institutions and society to support their STEM education career path; this can have significant effects on women's ability to persist and graduate in STEM fields (Espinosa, 2011; Griffith, 2010; Rosenthal et al., 2013). Furthermore, research shows that women do best in STEM education and careers when they have role models that look like them (Rosenthal et al., 2013). Institutional and cultural environments influence how women perceive gender, race/ethnicity, the masculinity of STEM, and the "fundamental division of society" (West 
\& Zimmerman, 1987, p. 126). Specifically, "institutional narratives" and norms can impact women's persistence and interest in STEM education (Calabrese Barton et al., 2013, p. 73). Calabrese Barton and colleagues (2013) describe one student was deeply engaged with science courses, but was not recognized by her teacher or classmates as a competent, successful STEM student due to the "hidden institutional narrative" of a student that scores high on tests and completes homework on time (p. 73). Furthermore, being validated as a scientist is more likely if the appearance and identity of the student is comparable to the historic and institutional notions of scientists (Carlone \& Johnson, 2007). The results from Griffith (2010) indicate the school environment has significant impact on STEM student persistence, but programmatic aspects also influence the success of STEM students.

\section{Educational and Organizational Factors}

Educational and organizational factors are defined as aspects of educational organizations and other professional organizations including, but not limited to: factors at the elementary and secondary school levels, community college level, higher education, place of employment organizations, or professional memberships. Education and organizational barriers can emerge at the secondary and high school levels prior to the woman entering the ATE program. For example, research shows that middle school is a tipping point for girls' interest in science and their interest in STEM careers is most pronounced (Tai, Christine Qi Liu, Maltese, \& Fan, 2006). 
Educational and organizational barriers can also occur in ATE programs, and the STEM department generally, and include but are not limited to: curriculum, professors, program services and pedagogical approaches (Brandt, 2014; Guertin, 2015; Mansfield, Welton, \& Grogan, 2014; McClelland \& Holland, 2014; Tolley, 2014). The results from the study by Griffith (2010) revealed that student experiences within STEM programs and departments had a significant effect on their persistence and graduation in STEM fields. However, few researchers have studied the impact of gender equity issues in STEM curriculum, academic program services, or instruction at the community college level (Hill, Corbett, and St. Rose 2010; Osborne, Miller, Farabee-Siers 2008). Research studies reveal that qualities of STEM departments that resemble masculinity such as aloof professors, high levels of competition in grading, and courses that intend to filter out weak students can estrange women STEM students (Blickenstaff, 2005; Carlone \& Johnson, 2007; Espinosa, 2011; Malone \& Barabino, 2009; Seymour \& Hewitt, 1997). Research by Bettinger and Long (2005) demonstrated that women students were more likely to continue in the STEM course progression and enroll in STEM courses that were taught by women. Espinosa (2011) showed that certain programmatic aspects can encourage and support women in STEM education, such as opportunities to collaborate with peers, hands-on authentic research experiences, as well as extracurricular participation. Several research studies show that these barriers can affect students' career 
choices and educational aspirations (Bielby et al., 2014, 2014; Espinosa, 2011; Hill et al., 2010; Marra et al., 2009; Ong et al., 2011).

Aspects of STEM programming can also conflict with women's individual and social beliefs (Rosenthal et al., 2013). For instance, objectivity and authoritative notions of STEM can clash with women's altruistic, social or personal motivations in STEM (Carlone \& Johnson, 2007; Ceci \& Williams, 2011; Malone \& Barabino, 2009; Rosenthal et al., 2013). Many aspects of STEM education also occur in the laboratory, but laboratories can be places of great learning and socialization or great ostracism for women students (Malone \& Barabino, 2009; Ong et al., 2011). Furthermore, studies show not only do societal and programmatic barriers affect women's persistence, but personal and psychosocial barriers also impact women's success in STEM education.

\section{Internal Barriers}

Internal barriers are psychosocial or behavioral factors that contribute to one's ability to succeed or fail (Calabrese Barton et al., 2013; Carlone \& Johnson, 2007; Garza, Bain, \& Kupczynski, 2014; Johnson et al., 2011; Loo \& Choy, 2013; Marra et al., 2009; Ungar, 2012). Research studies indicate that internal factors may be critical to our understanding of the types of barriers exist for women's pursuit of STEM career pathways (Brandt, 2014; Costello, 2012; Guertin, 2015; McClelland \& Holland, 2014; Riegle-Crumb \& King, 2010). 


\section{Self-efficacy}

Self-efficacy is a construct that explains a person's self-perception of her aptitude to pursue and to accomplish a goal (Bandura, 1997). Since there is a greater underrepresentation of women in STEM than expected based on achievement, other researchers have investigated the psychosocial aspects of educational pathways to affirm the influence of self-efficacy (Blickenstaff, 2005; Johnson et al., 2011; Marra et al., 2009). Research emphasizes the role of self-efficacy in career decisions; other researchers have shown it to be a significant factor in women deciding against a STEM career path (Brown \& Burnham, 2012; Holland, 1997; Loo \& Choy, 2013; Marra et al., 2009; Starobin et al., 2014; Trujillo \& Tanner, 2014). Self-efficacy affects student decisions generally, including time management practices and goal development (Brown \& Burnham, 2012). Self-efficacy bolsters student persistence and women with high selfefficacy are more likely to achieve goals, even in the face of adversity (Marra et al., 2009). Loo and Choy (2013) demonstrated that self-efficacy is a critical component to student persistence in engineering programs at four-year colleges. Despite the abundance of research documenting the effects of self-efficacy, it is a complex concept to measure, document, and validate.

A strong sense of self-efficacy is typically developed through five foundations (Bandura, 1997). The first foundation is termed "mastery experiences," in which students complete objectives to gain basic skills and comprehension; for academics, this means a 
non-specific, positive experience in a STEM course (Brown \& Burnham, 2012, p. 114; Marra et al., 2009). Loo and Choy (2013) show that in ten of the fourteen student participants, mastery experiences were a key determinant in math and engineering academic achievement. Even though women achieve at comparable levels as men in STEM courses, they do not have commensurately high levels of self-efficacy (Ong et al., 2011; Riegle-Crumb et al., 2012).

The second foundation for developing self-efficacy is through "vicarious experiences," in which women see women succeed as mentors, or as role models, in STEM fields (Marra et al., 2009, p. 28). Women mentors and professors are uncommon within STEM disciplines in postsecondary institutions; Ceci and Williams (2011) show that women occupy less than fifteen percent of tenure-track STEM professor positions at the top one hundred universities in the United States. Additionally, research has revealed that male STEM professors are likely to offer informal mentor positions to white male students who are most similar to the professors themselves (Ceci \& Williams, 2011; Ceci et al., 2009). Research by Moss-Racusin et al. (2012) indicated that both men and women professors often chose male students for mentorships or lab technician positions, instead of women with identical résumés. Women in STEM education face both ostracism by professors and a lack of women role models, resulting in the loss of essential foundations for building self-efficacy.

The third source for self-efficacy is "social persuasions" (defined as the influence 
of others' viewpoints and opinions) (Loo \& Choy, 2013; Marra et al., 2009). Students may build self-efficacy through encouragement from professors, but studies show that STEM professors are more likely to ignore women students than male students (Espinosa, 2011; Tan \& Barton, 2008). Concurrently, microaggressions (defined as daily reoccurrences of actions, words, and/or environmental derogations, meant or accidental, targeted toward a specific group) from STEM peers and professors impede the development of women's self-efficacy (Riegle-Crumb et al., 2012; Steele, 2010). Due to the positionality of researchers, microaggressions are difficult to capture objectively in classroom observations and warrant further study.

The fourth source for building self-efficacy is peer support and communities of practice (defined as a group of individuals who share an interest, a career, or a field of study and work together or alongside one another to further their knowledge) (Marra et al., 2009; Tan \& Barton, 2008; Wenger, 1999). Without these affiliations, women are unlikely to support women through collaboration that promotes inspiration, innovation, and group cohesiveness (Ong et al., 2011; Watermeyer, 2012). For example, because of the dearth of women students studying STEM fields, current women STEM students are unlikely to find a study group or a lab team of women (Moss-Racusin et al., 2012; Riegle-Crumb et al., 2012). Stimulating women's group process is important in STEM because of the forces that lead to women's attrition.

The final foundation for building self-efficacy is a student's physical and 
emotional state, particularly anxiety, when completing tasks (Brown \& Burnham, 2012; Loo \& Choy, 2013). For women in STEM, factors such as microaggressions, low grades, and stereotype threat create internal states of high emotional arousal that may compromise performance significantly (Marra et al., 2009). For example, women STEM students are particularly vulnerable to stereotype threat; research demonstrated that women performed poorly on standardized tests when asked their gender as the initial test question (Picho \& Brown, 2011; Shapiro \& Williams, 2012; Steele, 1997, 2010). Such environmental factors strongly influence how women interpret their internal state, thus exerting profound effects on the motivation necessary for persistence.

While all five sources of self-efficacy have been studied at the four-year college level, research in the area is embryonic and oftentimes conflicting (Loo \& Choy, 2013). Furthermore, not one of these studies has examined the role of self-efficacy in women persisting in ATE education at the community college level. Numerous studies confirm that women's enthusiasm about and interest in science is undeniably strong, but women's core identity as scientists may lack depth, breadth, and cohesion (Calabrese Barton et al., 2013; Carlone \& Johnson, 2007; Johnson et al., 2011). This "science identity" can also be a pervasive barrier to women's success in STEM education (Calabrese Barton et al., 2013, p. 46). 


\section{Science Identity}

Science identity is a construct defined as the active, iterative development of being acknowledged, and of acknowledging oneself, as a competent and confident scientist (Calabrese Barton et al., 2013; Johnson et al., 2011). In alignment with identity theory, science identity is a manifestation of a person's interest and goals in STEM and can be a serious psychosocial barrier to success in STEM education (Carlone et al., 2014; Johnson et al., 2011; Williams \& George-Jackson, 2014). Identity formation results from a complex negotiation of social interactions, self-perceptions, norms, dominant discourses, and collective past experiences (Calabrese Barton et al., 2013; Malone \& Barabino, 2009; Tan \& Barton, 2008). Carlone and Johnson (2007) describe the dynamic process of authoring science identity as an "identity trajectory," based on cumulative dayto-day experiences (p. 1211). Johnson et al. (2011) show that disruption of the science identity trajectory can be a significant factor in underrepresented students persisting in STEM.

Carlone and Johnson (2007) offer a promising framework for science identity consisting of three key interconnected factors: "competence, performance and recognition" (p. 1119). Identity is developed by a combination of experiences such as roles in the community, social positioning, and use of resources (Calabrese Barton et al., 2013). There is a growing body of research suggesting that women's social identities are in conflict with identities promoted within STEM classes (Calabrese Barton et al., 2013; 
Grossman \& Porche, 2013; Johnson et al., 2011; Rosenthal et al., 2013). Specifically, women students do not find STEM courses or laboratories to be relevant or interesting, with respect to their personal and social identities (Espinosa, 2011). Furthermore, a failure to find relevance in STEM courses estranges women students generally, particularly because these students have dissimilar self and cultural identities than those typically associated with conventional STEM fields (Thompson \& Windschitl, 2005).

Social milieus surrounding STEM education forge women's science identity (Johnson et al., 2011). The development of positive science identity typically is accomplished in social settings in which a STEM student is recognized, both by peers and by professors (Bandura, 1997; Calabrese Barton et al., 2013; Hill et al., 2010; Johnson et al., 2011). Science identity can be defined within the realm of science achievement, and within the patterns and norms in classrooms, labs, and study groups (Rosenthal et al., 2011; Thompson \& Windschitl, 2005). For instance, Calabrese Barton et al. (2013) describe one student who was deeply engaged with science courses. However, she was not recognized by her teacher, or by her classmates, as a top science student because she took extra time to understand and to complete homework. She was compared negatively to students who fit the "traditional narrative" of a good science student who efficiently turned assignments in on time, but lacked deep understanding of the STEM homework topics (Calabrese Barton et al., 2013, p. 73). While studies confirm 
the importance of science identity for STEM students, further research is needed to explore the factors that contribute to the development of a positive science identity.

Science laboratories can be a critical and natural place for shaping a student's science identity (Hunter et al., 2007; Malone \& Barabino, 2009). Cohesive laboratory groups are incubators for the socialization that shapes scientists (Malone and Barabino, 2009). The research process taught and implemented in the laboratory setting is central to science identity development as it reinforces discipline and motivation necessary for persistence in STEM (Buday et al., 2012; Ramsey et al., 2013). Malone and Barabino (2009) show that students value the science laboratory as a place that shapes their educational pathway and that reinforces their science identity development. In contrast, other studies confirm that women students in research laboratories report feeling isolated and invisible around male colleagues, supervisors, and instructors (Marra et al., 2009; Ong et al., 2011). It is important to explore further why women feel marginalized in a laboratory setting that could promote positive science identity construction. The science laboratory offers a unique, critical learning setting, potent for science identity development, but the mechanisms are poorly understood (Hunter et al., 2007; Malone \& Barabino, 2009).

The "culture of science" is associated with valued masculine traits, such as objectivity, lacking global relevance, and a practice of impersonally filtering out unqualified students (Carlone \& Johnson, 2007, p. 1211; Espinosa, 2011). This culture 
promotes male students who succeed in congruence with these norms, while women students become alienated (Archer et al., 2012; Ong et al., 2011). Validation as a scientist is impeded if the student's physical appearance and identity differ from established stereotypes of scientists as white males (Carlone \& Johnson, 2007). In STEM fields, professors, courses, and milieu serve to discourage and eliminate the majority, with only an exclusive, elite set of students remaining (Calabrese Barton et al., 2013).

Without solid science identity development, women are unlikely to persist in STEM programs in higher education (Carlone \& Johnson, 2007; Espinosa, 2011). Few studies have examined the relevance of science identity to women's persistence in STEM programs at the community college level. High self-efficacy and strong science identity are necessary for longevity in STEM fields; understanding how identity and self-efficacy are grown is key to the future of women as scientists and to the advancement and diversification of STEM fields. The focus of this proposed research is an important contribution to the field, since few studies have examined the roles of self-efficacy and of science identity in the graduation of women students from STEM community college programs, particularly in Advanced Technological Education.

\section{Conclusions and Implications}

As described above, current research on women's participation in STEM focuses primarily on the deficits in STEM educational programs and society as well as the negative effects on women students. A gap remains in the understanding of successful 
women student experience in STEM programs, particularly in ATE programs.

Considering the declining numbers of women in community college STEM programs, and, specifically, ATE programs, research is needed to understand the supports and barriers for women ATE graduates. This study seeks to understand the experience of successful women graduates of ATE programs in order to recognize the potential impacts of curriculum, pedagogy, recruitment, support services, and laboratory experiences. The study offers promising practices to address the obstacles for women students to earn degrees and certificates in ATE fields while also offering data on successful completion of community colleges STEM pathways. 


\section{Chapter Three: Methodology}

This study sought to investigate the following central research question: How do successful women graduates from Advanced Technological Education (ATE) programs in community colleges describe barriers and supports to their success? This study was grounded in the conceptual framework shown in Figure 1 and followed a qualitative research design to reveal the meaning women ATE graduates ascribe to their success (Bogdan \& Biklen, 2006; Creswell, 2009; Silverman, 2009). These women have developed personal meanings of their life-experiences, and the social and historical contexts in which those experiences have occurred (Creswell, 2009; Seidman, 2006;

Silverman, 2009). In this study, I made sense of the meanings these women have about their world and their experiences in ATE. To do so, I studied a small number of successful women graduates through a semi-structured, multi-interview research design (Moustakas, 1994).

\section{Phenomenology Methodology}

The strategy of inquiry utilized for this study was phenomenological interviewing as described by Seidman (2006), in which researchers use both comprehensive interview life experience questions and open ended, meaning-making questions (Creswell, 2009). Phenomenologically-based interviews were the most appropriate mode of collecting data because I was particularly interested in the lived experiences of community college ATE women graduates (Bogdan \& Biklen, 2006; Creswell, 2009; Silverman, 2009). 
Phenomenology-based interviewing uses probing questions that build upon participants' responses in order to explore his or her actual, authentic experiences and the significance of those life experiences (Moustakas, 1994). The process of phenomenological based interviewing helps the participant "reconstruct his or her experience" and (Seidman, 2006, p. 14). In describing phenomenology, Seidman (2006) emphasizes the humanity and ephemeral aspect of the lived experience; the goal is to capture the "essence" of the human experience (p. 16).

Phenomenological-based interviewing typically takes the form of three standalone interviews with each research participant, and each interview is typically three to seven days apart, allowing both the participant and researcher time to reflect on previous interviews but remain connected to the process (Seidman, 2006). The first interview focuses on the participant's life history, where the researcher learns about the participant's life experiences in relation to the research focus (Moustakas, 1994). In the second interview, the emphasis is on the contemporary experience and the participant's current goals, successes, challenges, and interests (Seidman, 2006). In the final interview, the researcher asks questions to encourage the participant to reflect and make sense of his or her life in relation to the experiences discussed in the interviews (Moustakas, 1994). This phenomenological approach encourages the exploration of the interplay between perceptions of external (i.e. programs and culture) and internal experiences (i.e. feelings and recollections) (Moustakas, 1994; Seidman, 2006). 


\section{Participant Selection}

Study criteria for participants was two fold: 1) Be nominated as a successful ATE graduate 2) Graduated with a sub-baccalaureate degree (defined as an associate's degree or certificate) in an of ATE area of study from a community college on or after May 2005 and before June 2013. At the time of participant recruitment, the inclusion criteria were purposefully broad in order to solicit participation from as many potential participants as possible. The identification of participants occurred in one of two ways: 1) Women were nominated by an ATE project's Principal Investigator (PI) as an exceptional graduate and invited to participate in a presentation session at an annual conference (title withheld for anonymity) 2) An ATE Principal Investigator (PI) nominated the women graduate to participate in this study. Since participants were nominated as exceptional graduates in one of the above ways, participants were deemed as "successful" ATE graduates.

In order to seek nominations for these women by ATE Principal Investigators (PI), solicitations were made through email, phone, in addition to in-person meetings at conferences, site visits, and through email introductions by the Principal Investigator of the Pathways to ATE Careers Project (National Science Foundation Grant No. DUE 1003589). In total, 73 PIs were contacted by email to solicit nominations (see Appendix A). In most cases, I received no response to multiple e-mail communications. However, I received nine total responses from PIs; four responders expressed interest in nominating women graduates but despite follow up calls and emails, did not provide a nomination. 
One responder wrote back as a response to the recruiting email, "I actually don't have any women grads [graduates] yet" (Anonymous, personal communication, January 2014). The challenges in nominating research participants highlight the importance of this research. In total, four PIs did respond to the solicitation and each nominated one successful woman graduate for this study.

The second approach to soliciting participants was when the woman was nominated by an ATE Principal Investigator (PI) as an exceptional graduate and invited to participate in a presentation session (title withheld for anonymity) at an annual conference. In order to make contact with these women, I either attended the technician session, met the participant in person during the conference, looked up contact records of past conference sessions, or contacted the ATE PIs.

Once a woman was nominated, I would send out an email in which I asked the women if they would be willing to participate in one-on-one interviews about their experiences in ATE (see Appendix B) (Creswell, 2009). In total, I contacted 18 potential participants that had been nominated. Based on the original invitation to participate in the study, eight women responded. Two of the eight women respondents were ineligible for this study: 1) One respondent was a current ATE student (this study requires that participants have graduated from an ATE program between 2005 and 2013) and 2) One respondent was working as a lab manager at an ATE project but had not graduated from an ATE program. One of the eight respondents initially expressed interest in participating 
in the study but did not respond to follow-up emails or phone calls. Another of the eight respondents began participating in the study but did not complete the interviews for unknown reasons. Four of these eight women ATE graduates fully participated in this study.

Of the initial 18 potential participants, six women did not respond to multiple emails regarding the invitation to this study. The email addresses for two other women were undeliverable and the ATE PIs did not have additional contact information for the women. To increase my sample size, I continued to send follow up emails and made personal phone calls (only possible when I had access to the respondents' phone numbers). Two participants, which had not responded to emails, accepted my phone call and agreed to participate, increasing my sample size to a total of six women participants. Table 2 displays the list of participant pseudonyms, current employer pseudonyms, current job titles, community college pseudonym, sub-baccalaureate degree date and area of study (for more in-depth participant demographics, see Appendix C). Each participant, employer, and community college were assigned pseudonyms to safeguard confidentiality. 
Table 2.

Demographic data of study participants (each participant, the community college and employer have been appointed a pseudonym to safeguard confidentiality).

\begin{tabular}{|c|c|c|c|c|c|}
\hline Pseudonyn & $\begin{array}{l}\text { Current } \\
\text { Employer } \\
\text { Pseudonym }\end{array}$ & Current job title & \begin{tabular}{|l|} 
Community \\
College \\
Pseudonym
\end{tabular} & \begin{tabular}{|l|} 
Sub- \\
bacculaureate \\
Degree - Area of \\
Study
\end{tabular} & $\begin{array}{l}\text { Date of Sub- } \\
\text { bacculaureate } \\
\text { Degree }\end{array}$ \\
\hline Roxanne & $\begin{array}{l}\text { Llorando } \\
\text { Manufacturing }\end{array}$ & Skilled Technician & $\begin{array}{l}\text { Green } \\
\text { Mountain } \\
\text { CC }\end{array}$ & $\begin{array}{l}\text { Industrial } \\
\text { Maintenance }\end{array}$ & 2012 \\
\hline Nena & $\begin{array}{l}\text { Worldwide } \\
\text { Energy } \\
\text { Management }\end{array}$ & Program Manager & $\begin{array}{l}\text { Genesee } \\
\text { County CC }\end{array}$ & $\begin{array}{l}\text { Energy } \\
\text { Management }\end{array}$ & 2013 \\
\hline Betty & $\begin{array}{l}\text { Windy Forest } \\
\text { Energy }\end{array}$ & $\begin{array}{l}\text { Compliance } \\
\text { Specialist }\end{array}$ & $\begin{array}{l}\text { Mountain } \\
\text { Range CC }\end{array}$ & $\begin{array}{l}\text { Power Plant } \\
\text { Technology }\end{array}$ & 2005 \\
\hline Audra & $\begin{array}{l}\text { STEM Pipeline } \\
\text { Company }\end{array}$ & $\begin{array}{l}\text { Masters Biology } \\
\text { Student }\end{array}$ & Oceana CC & Biotechnology & 2011 \\
\hline Kyla & $\begin{array}{l}\text { DNA } \\
\text { Technicians, } \\
\text { Inc. }\end{array}$ & $\begin{array}{l}\text { Research } \\
\text { Associate }\end{array}$ & $\begin{array}{l}\text { CC of San } \\
\text { Marcos }\end{array}$ & Biotechnology & 2005 \\
\hline Sula & $\begin{array}{l}\text { Atlantic Electric } \\
\text { Co }\end{array}$ & $\begin{array}{l}\text { Machine } \\
\text { Maintenance } \\
\text { Supervisor }\end{array}$ & $\begin{array}{l}\text { Abraham } \\
\text { Lincoln CC }\end{array}$ & $\begin{array}{l}\text { Architectural } \\
\text { Technology }\end{array}$ & 2011 \\
\hline
\end{tabular}

\section{Statement of Ethical Considerations}

The research participants in this study may have been at risk for a potential loss of privacy. In order to minimize this risk, I stored all research data in secure file cabinet in a locked office. To further lessen the risk, I stored all electronic files of research data in a password-protected cloud storage application. In publishing the research findings, I used pseudonyms to safeguard the identity of research participants. Women were advised that they were able stop at any point in the process if they become uncomfortable without consequences. Original audio recordings were destroyed immediately after transcripts 
had been made. All data will be kept for three years, at which point original audio recordings and transcripts will be destroyed (three-year minimum as per IRB website). Transcripts were member-checked, defined as the gaining feedback and validation from participants, and member-checking was used to validate the content of each transcript (Silverman, 2009).

\section{Research Procedures and Data Collection}

To depict narratives that may contradict common biases about women's experiences and success in STEM education, I conducted one-on-one interviews with six women graduates from ATE programs across the nation (Bold, 2012). Using semistructured, phenomenological interviews, I completed a series of three consecutive interviews with each of the participants, focusing on her past experiences and interest in STEM, her experiences in the ATE community college program, her hopes for the future, and her reflections and meaning-making of her experience (Seidman, 2006).

All interviews (with the exception of one, phone-based interview) took place via videoconferencing technology, defined as a live, real time connection of simultaneous two-way audio and video data that is transmitted between two or more computer devices in different geographic locations using satellite or an internet network (Deakin \& Wakefield, 2014; Janghorban, Roudsari, \& Taghipour, 2014; Redlich-Amirav \& Higginbottom, 2014). This study utilized one of two programs for videoconferencing, FaceTime ${ }^{\circledR}$ and Skype ${ }^{\circledR}$, depending on the participants' comfort level and access to 
technology. FaceTime ${ }^{\circledR}$ and Skype ${ }^{\circledR}$ have been used by researchers to collect qualitative research data (Janghorban et al., 2014; Sullivan, 2013). These teleconferencing options are preferred over other technological qualitative data gathering approaches (i.e. telephone or email) since videoconferencing allows researchers and participants to exchange non-verbal communication and increases participant comfort level by conducting interviews in known locations absent of personal space invasion (Boydell, Volpe, \& Pignatiello, 2010; Hanna, 2012; King \& Horrocks, 2010; RedlichAmirav \& Higginbottom, 2014).

While videoconferencing is still an emerging data collection method among qualitative researchers, numerous studies attest to the value in this type of interviewing, particularly when snowball sampling or in geographically diverse participant samples (Deakin \& Wakefield, 2014; Glassmeyer \& Dibbs, 2012; Janghorban et al., 2014;

Redlich-Amirav \& Higginbottom, 2014; Sullivan, 2013). For this study, videoconferencing was a necessary data collection strategy in order to have an inclusive sample of ATE women graduates in diverse locations across the United States, follow the three-interview data collection protocol with three to seven days between interviews, and to offer accessible options for participants to engage in this research study.

There are potential drawbacks in using videoconferencing technology, such as technological glitches or a danger of unnatural conversations, but the benefits offset the disadvantages (Deakin \& Wakefield, 2014; Hanna, 2012; Sullivan, 2013). Seidman 
(2013) describes the value of a phenomenological approach to videoconferencing as long as care, caution, and a sense of value for the participant are enacted when setting up the videoconferencing-based qualitative interviews. In order to circumvent drawbacks to the use of videoconferencing technology, I provided each participant with informed consent, I discussed the potential drawbacks of technological glitches prior to the start of the interview series, and I was conscious to establish natural rapport.

In order to begin the study with the six research participants, I emailed with the participant to ask about convenient times to conduct one-hour interviews via videoconferencing (or via phone if the participants didn't have access to videoconferencing technology). Four of the six participants preferred to participate in the study using Skype, one participant preferred FaceTime, and one participant preferred to use her mobile phone. Issues that may have influenced data collection or analysis were noted during the interview and analysis processes. Every interview was recorded using a digital audio recorder and were transcribed verbatim.

For each participant, I scheduled each of the three in-depth interviews three to seven days apart, making every effort to schedule interviews at the participant's convenience. Data from interviews was collected via three focused interviews using an interview protocol (Creswell, 2009). The interview protocol was designed to directly address the research questions and is grounded in this study's conceptual framework. The focus of the interviews was on exploring the participant's life history and contemporary 
experiences while also encouraging the participant to reconstruct and reflect on her experiences. The participants in the study were all over 18 and are a representative sample of women ATE graduates.

\section{Data Analysis}

All data collected for this study - interviews and member-checking feedback from participants - were transcribed verbatim. These qualitative interview data were analyzed to ascertain emerging themes using this study's conceptual framework (Silverman, 2009). Based on the description of phenomenological interviewing and data analysis by Seidman (2006), my goal was to highlight key phenomena in interviews, and the phenomena that occur with a regularity and pattern ultimately became codes and categories (Bogdan \& Biklen, 2007; Moustakas, 1994). I analyzed these in-depth interviews in order to hone in on the critical components of the participant's experiences and detect key themes, barriers, and supports to the participants' success.

In the first analysis of my data corpus, I did "first-cycle" or "open coding" and created a data index with 12 main codes and 27 other codes (Bogdan \& Biklen, 2007; Creswell, 1998, p. 59; Saldaña, 2013, p. 58; Silverman, 2009). To do this within the context of phenomenological interviewing, I used this study's conceptual framework to interpret, decontextualize, and recontextualize the data during several reviews of the entire data corpus (Seidman, 2006; Starks \& Trinidad, 2007). This allowed me to examine the data across participants, interviews, and themes but also recontextualize the 
themes that emerge within and across participant narratives, central patterns, and in interview sequences (Starks \& Trinidad, 2007). In order to examine the phenomena and the essence of the participants' experiences, I used the following two subcategories simultaneously within first cycle coding: en vivo coding and process coding (Saldaña, 2013). Upon finishing the simultaneous first cycle coding, I then listened to the full audio recording of each transcript, to emphasize the participant's voice and experience. Then, I wrote a data memo for each of the 21 interviews. Upon finishing the first cycle coding, I then underwent "themeing the data" and a thematic analysis of the entire data corpus. (Saldaña, 2013, p. 129).

In conducting the second round of coding, I did "second cycle" coding to restructure and reexamine the data with the goal being to create a "coherent metasynthesis" of the data (Saldaña, 2013, p. 207). Through this process, I condensed and solidified comprehensive categories and themes using the following subcategory strategies within second cycle coding: focused coding, axial coding, and longitudinal coding (Creswell, 1998; Saldaña, 2013).

In addition, I employed other qualitative data analysis approaches to complement the second cycle coding: listening again to the audio interview files, reviewing the interview transcripts, and writing data memos. These strategies were instrumental in this iterative process of condensing and solidifying the themes and patterns within the data. Grounded in this study's conceptual framework, and as suggested by Seidman (2006) and 
Starks and Trinidad (2007), I paid particular attention to the descriptions and experiential aspects of the central phenomenon of this research study: supports and barriers to success as experienced by women ATE graduates.

\section{Internal Validity}

In order to have strong internal validity, I incorporated five assurances and strategies. First, I made sure all transcripts were member-checked by participants and I used "respondent validation" by having participants review the verbatim transcripts from the interviews (Clandinin \& Connelly, 2000; Silverman, 2009, p. 278). Next, I verified that my coded themes were repeated in interviews (Bogdan \& Biklen, 2007; Saldaña, 2013). If themes were not repeated throughout the data, I discussed any misalignment with my chair and my dissertation committee to determine to what extent any revisions of themes and codes are appropriate. For the third assurance of internal validity, I employed "critical rationalism" and attempted to disprove presumed connections between codes, themes, categories, phenomena, and experiences (Popper, 1959, p. 67; Silverman, 2009). In order to provide a fourth assurance of validity, I compared my findings, codes, themes, and categories to related research in the field of STEM education, community colleges, ATE, and equity. Finally, I used an interview protocol from the National Institute for Women in Trades, Technology \& Science (2010) and adapted it to align with this study's conceptual framework and to align with the three-interview phenomenological protocol (Moustakas, 1994; Seidman, 2006). 


\section{Limitations}

A limitation of this study was that the six women participants do not serve as a representation of all successful ATE women graduates and my ability to generalize their experiences is limited (Bogdan \& Biklen, 2007). Maxwell (2005) describes

generalizability to be both internal, such as within a subgroup or particular environment, and external, extending beyond the subgroup or environment. This research was particularly focused on the specific experiences of women graduates of ATE programs and has limited external generalizability. Specifically, this research examined ATE programs and was set within the context of areas of study within ATE. Within the continuum of ATE disciplines, the participants were from a range of ATE fields, but I was not able to represent all eight areas of study within the ATE program portfolio (see Figure 4 for the list of eight areas of study). Furthermore, since ATE is a targeted STEM program, the results of this research may not be generalizable across STEM education disciplines in community colleges.

In addition, the phenomenological-based interviewing presented other limitations. In qualitative research, it is possible that participants may feel uncomfortable being honest, afraid of sharing personal information, or may feel influenced by other conflicting factors (Creswell, 1998; Maxwell, 2005; Silverman, 2009). I attempted to circumvent these limitations by scheduling interviews at convenient times for participants, 
establishing rapport and reciprocity with participants, and underscoring the confidentiality of this research study (Seidman, 2006). 


\section{Chapter Four: Report of Findings}

Recent studies have focused on women graduates in science, technology, engineering, and math (STEM) fields and have sought to understand degree and job attainment and other quantitative factors (Archer et al., 2012; Brandt, 2014; Kanny et al., 2014; McClelland \& Holland, 2014). However, many of these studies were conducted in four-year colleges in order to understand the mainstream narrative that few women are graduating with STEM degrees and even fewer are succeeding in obtaining STEM careers. We know very little about successes and challenges for women participants at two year colleges in ATE preparation programs, a growing pathway for STEM careers (Cannady, Greenwald, \& Harris, 2014; Hagedorn \& Purnamasari, 2012; Robelen, 2012). To better understand the experiences of women graduates, I used a qualitative approach to discover the supports and barriers faced by ATE women graduates.

In order to elucidate the true experiences of the women ATE graduates, I employed emergent coding to create a coding scheme (Berg, 2007; Haney, Russell, Gulek, \& Fierros, 1998; Saldaña, 2013; Stemler \& Bebell, 1999). Although I began with a set of tentative coding categories based on prior research in the field, the use of emergent coding resulted in iterative refinement of the coding categories based on the responses of participants. With emergent coding, I allowed the codes to transpire from the data corpus. Therefore, the findings in this chapter may not exactly match the 
literature review provided in Chapter Two. For more information on this process of coding, refer to methodologies in Chapter Three.

This emergent coding process and coding scheme were rigorous in nature. Table 3 shows the coding results in the form of coding tallies to demonstrate the emergent codes and themes and the precision that I undertook in the coding process. As shown in Table 3, self-efficacy emerged as a theme that contained both a positive value, when self-efficacy was acting as a support; and a negative value, when self-efficacy was acting as a barrier. Accordingly, I originally coded every theme with both a positive and a negative value, but it became clear through multiple passes of coding that value-based coding was only relevant for the self-efficacy theme. The thorough coding process reveals the manner in which main themes emerged across all participants.

Table 3.

Coding tally chart for all participants. Each value represents the number of times the theme emerged per three interviews for each participant.

\begin{tabular}{c|c|c|c|c|c|c|c}
\hline Pseudonyn & $\begin{array}{c}\text { Self Efficacy: } \\
\text { As a Support }\end{array}$ & $\begin{array}{c}\text { Self Efficacy: } \\
\text { As a Barrier }\end{array}$ & STEM Identity & Resilience & $\begin{array}{c}\text { Race/ } \\
\text { Ethnicity: The } \\
\text { Double Bind }\end{array}$ & $\begin{array}{c}\text { Gender: } \\
\text { (Un)becoming } \\
\text { a Woman }\end{array}$ & $\begin{array}{c}\text { Patchowork } \\
\text { of Support }\end{array}$ \\
\hline Roxanne & 9 & 8 & 21 & 11 & 0 & 28 & 13 \\
Nena & 8 & 3 & 18 & 15 & 6 & 20 & 5 \\
Betty & 12 & 3 & 25 & 3 & 0 & 19 & 9 \\
Audra & 11 & 2 & 27 & 7 & 9 & 7 & 12 \\
Kyla & 7 & 6 & 15 & 10 & 17 & 16 & 11 \\
Sula & 8 & 3 & 10 & 12 & 8 & 12 & 2 \\
\hline
\end{tabular}

This study identified the following six themes that addressed the study's research question and emerged as supports and barriers experienced by the women ATE 
graduates. Figure 7 shows the percentage occurrence and visual representation of the six main themes (and other minor themes), as demonstrated in pie charts. The research findings are organized into two categories: supports or barriers to success for women ATE graduates

Supports:

1. STEM identity

2. Patchwork of support

3. Resilience

4. Self-efficacy

Barriers:

1. Race/ethnicity and gender: The double bind

2. (Un)becoming a woman

I ground this study's findings around the conceptual framework (see Figure 1). Figure 1 shows the way a factor can be perceived a support or a barrier to success for women ATE graduates. For each woman, it was the balanced interplay of these themes that contributed to their success; this success was not realized in isolation (see Figure 7). Additionally, seven other minor factors emerged for one or more participants: spirituality, helping, friends and family as supports, friends and family as barriers, social capital, independence, and age. 

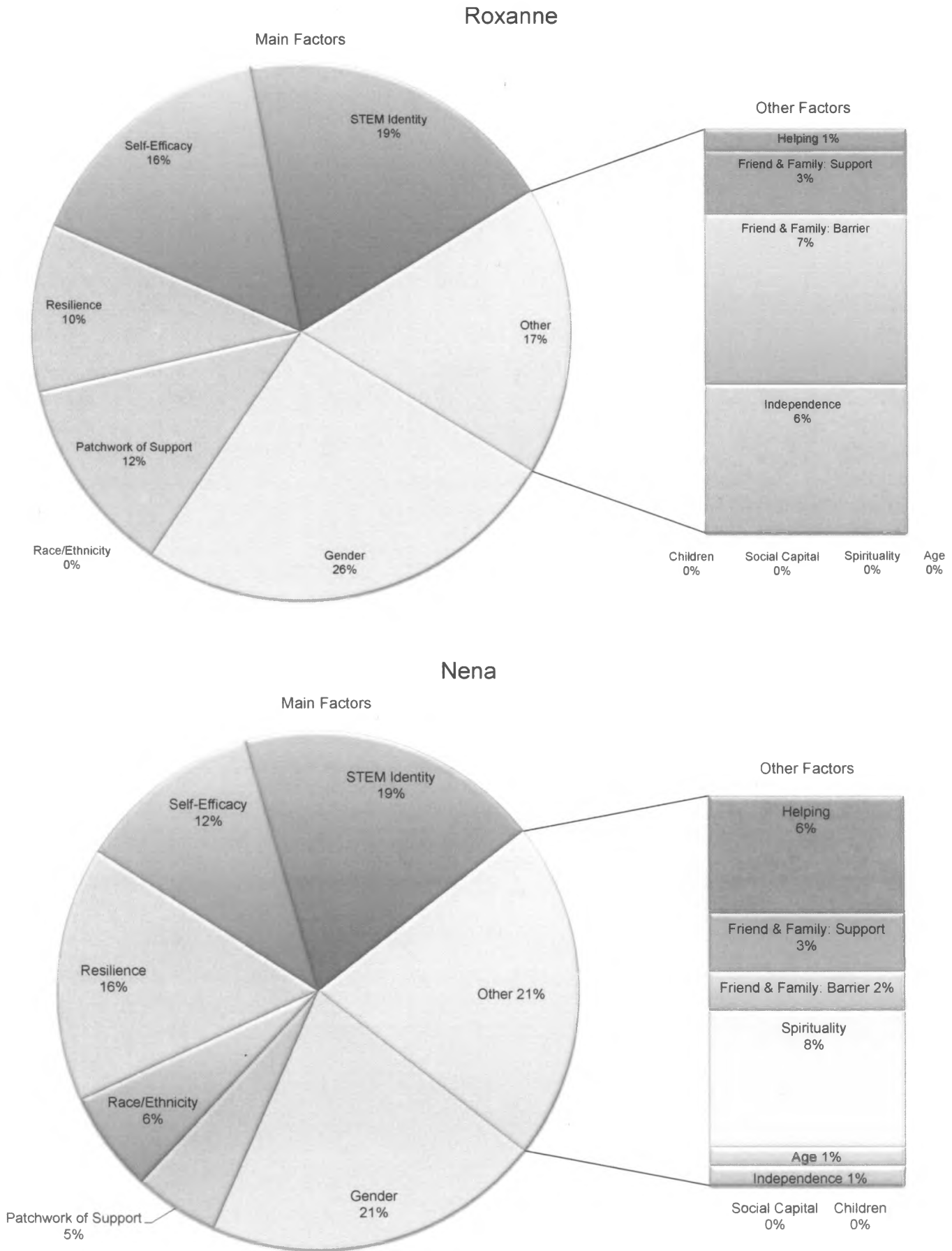


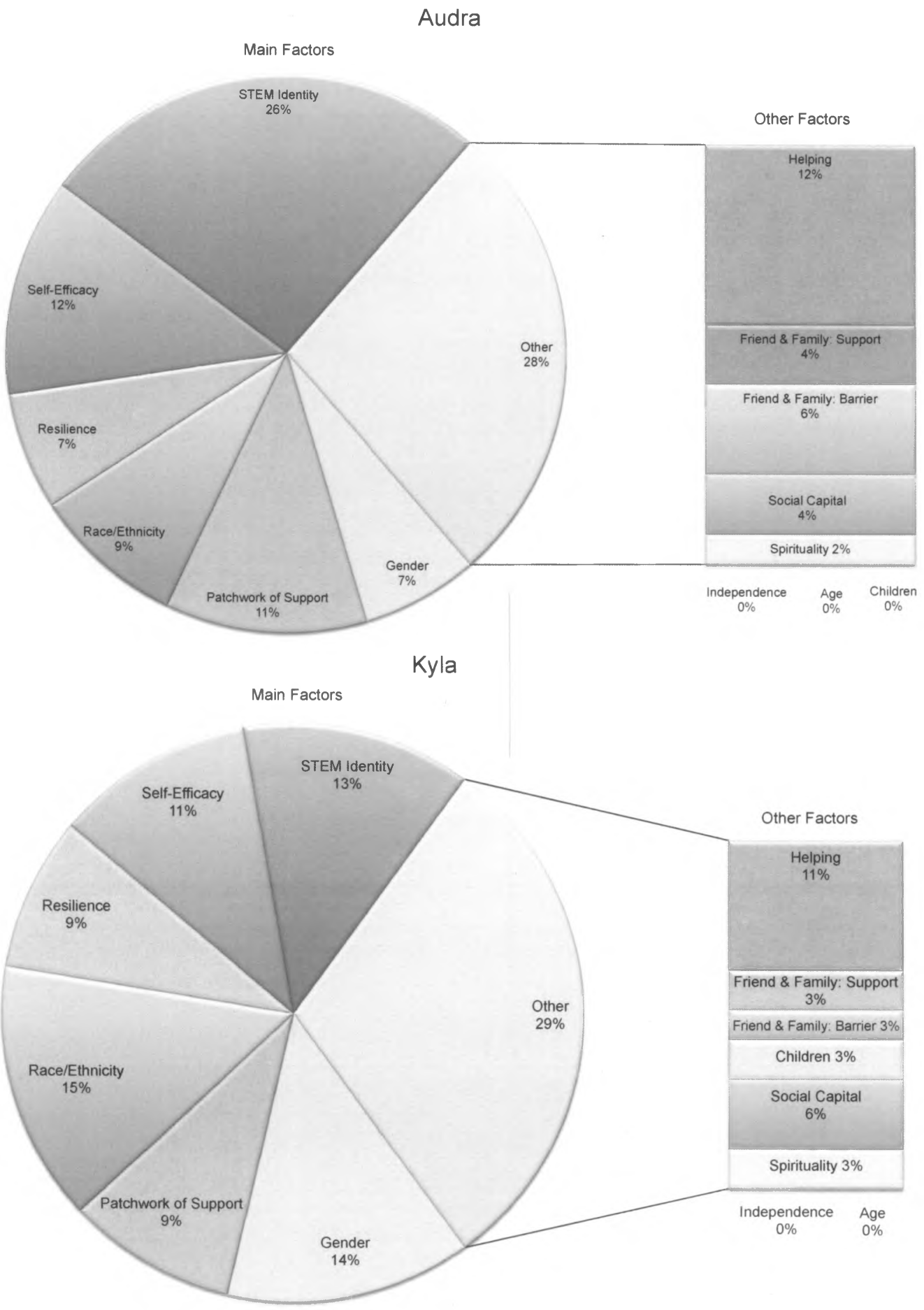



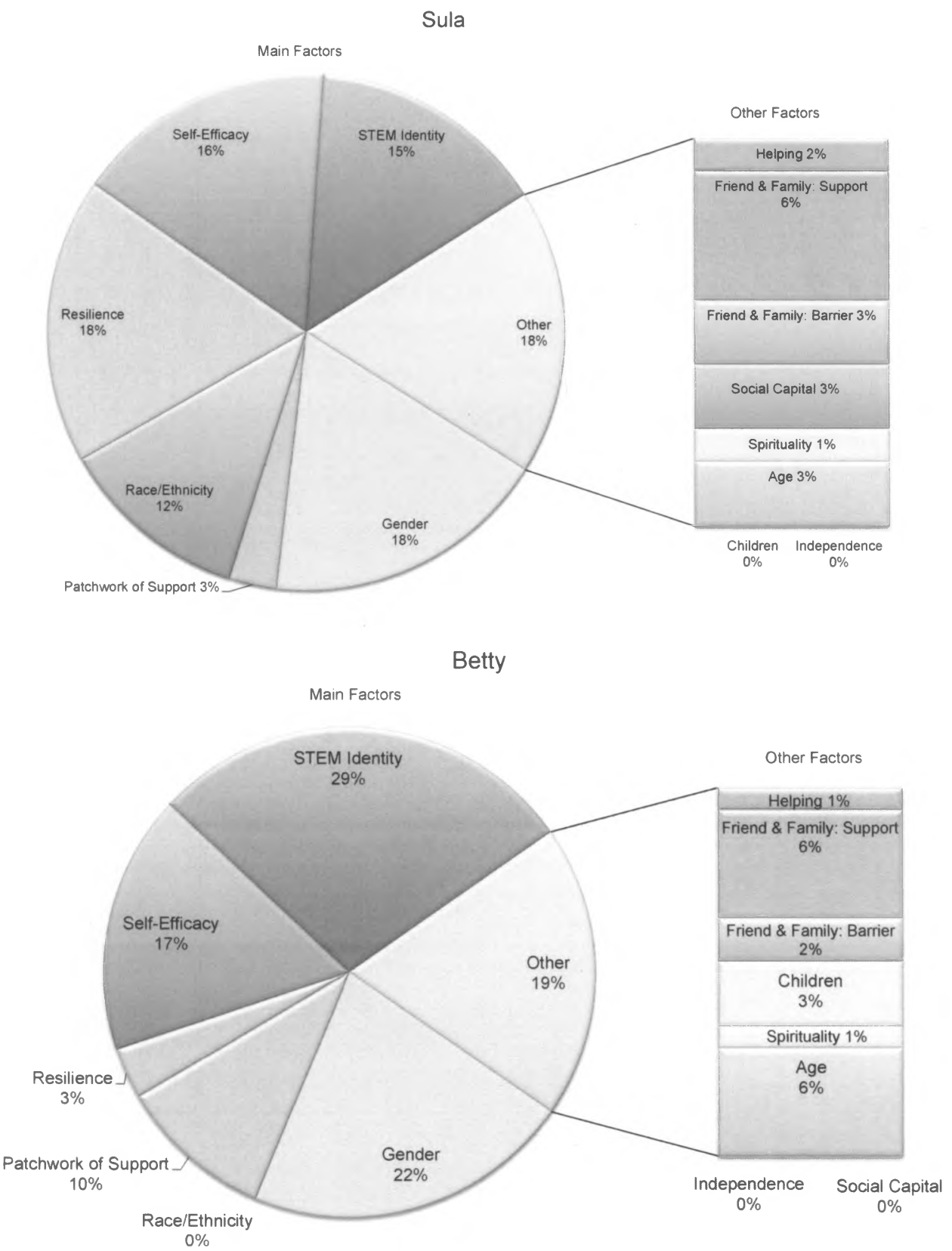

Figure 7. Pie charts representing frequency of the six main themes across participants. For each of the six participants, one pie chart is shown. In the pie chart, each main theme is represented by one pie segment (and accompanying percentage value); this pie segment 
and percentage represent the frequency of occurrence per theme, as a function of total coded responses for each participant. For each participant, the main pie chart shows the six main themes and the "Other" pie segment represents the occurrence (or absence) of themes that emerged less often (discussed in the Other Factors section). Themes that did not emerge for participants are displayed underneath the pie chart or other factors section and are labeled as zero percent.

In each section of this chapter, I explain each theme, offer key data excerpts, and provide context and discuss similarities across participants. I also discuss dissonances and incongruities across all participants and how these themes relate to the research question. Throughout this chapter, Figure 7 can serve as a reference to demonstrate the frequency of occurrence of each theme for the participants. This chapter concludes with a summary of the study findings.

\section{STEM Identity: "Science Is Really Cool”}

The "STEM identity" main theme emerged across all participants and is a term I created in order to expand the notion of a science identity, a phrase well established by recent literature (see Figure 7) (Calabrese Barton et al., 2013; Carlone \& Johnson, 2007; Johnson et al., 2011). STEM identity extends beyond just a science identity, to an allinclusive identity that embraces science, technology, engineering, and math (STEM) topics. Furthermore, this theme is important because science is inherently interdependent on technology, engineering and math. For instance, math is essential to understanding the sciences; thus, a science identity cannot exist without a co-existing math identity. Similar to literature on identity as a construct, a STEM identity is iterative and adapts over time and space (Johnson et al., 2011; Rosenthal et al., 2013; Watermeyer, 2012; Wenger, 
1999).

Each of the women participants articulated the iterations of their STEM identity as being developed by "microaffirmations." I define the microaffirmations as micro, informal, subtle affirmations of the women's STEM identities. Microaffirmations emerged from the data as micro-actions that validated the women's STEM identities; for example, working with a tool successfully to hang a picture frame. It was in these types of short-lived moments that women built robust STEM identities

STEM identity includes an affinity for the sciences or scientific thinking. As the women explained their intrinsic interests in science, they exclaimed, "The science museum was just the best thing since ice cream!" or shared, "I love math, I love the sciences, even as a kid, I loved science!" and that STEM is cool, "It [STEM] is just really fun and interesting." STEM identity also means thinking science is "fun and I can do it," "I love algebra." Participants expressed this aspect of STEM identity when they described their excitement and engagement in science courses. Audra described a "cool project" in the laboratory to make biodiesel from e-coli, and explained "I just found it really fascinating." Other evidence of STEM identity was when participants explained the simultaneous interests in one or more of the four STEM topics. At the same time as expressing her interest in engineering, Sula also describes her interest in biological sciences, "I'm a huge animal fan, I love every type of animal, I love the sea like I'm just I love nature." Betty had a strong interest in agricultural/biological sciences but also 
explained that when she was younger, she "became really interested in technology science." Beyond her interest in engineering, Nena describes, "I definitely was naturally good at math, I was just always excited about numbers."

Another way that STEM identity manifested was an aptitude in STEM courses. For some of the women, this was an act of the iterative nature of STEM identity, evolving into high engagement in science courses and extracurricular activities. I noticed this emerged as Audra made a comment, "I was always more inclined to the science courses and math courses. This includes doing well on the math proficiency tests, high grades in STEM courses or saying, "I always liked science, science experiments" or getting "second place in science fair." Other evidence of STEM identity emerging in STEM courses was fostering mentorships with science teachers.

A strong STEM identity was connected to good relationships with STEM teachers. Nena described, "My biology teacher was one of my favorite teachers in high school" and Audra explained, "My favorite teacher in grade school was Ms. Jeremiah, she was my math teacher." Betty described her favorite teacher in high school, "He actually did teach science and maybe that contributed somewhat to why I enjoyed science."

Other evidence for a STEM identity was a desire as a young child to attain a STEM-related career, as shown by other studies to be important (Carlone \& Johnson, 2007). Interestingly, four of the six participants expressed early desires to be a STEM 
related professionals. Kyla hoped to be a dentist, Nena wanted to be a doctor, and Audra strived to be a scientist. Roxanne shared with me that she wanted to pursue veterinary school, "because I liked animals and I wanted to help them."

Many of the ATE programs have co-ops or internships and the women explained that these were invaluable experiences, often leading to job offers and/or clarity of their STEM interest. Audra recognized how her ATE internship was "how it all started" with her passion for STEM. She explained how doing the lab work was "really cool" and "top-notch" and she reflected, "I want keep doing this [STEM lab research], and this is so cool." This demonstrated a shared pattern among all six women that their STEM identity evolved in a positive way as a result of the ATE programs (see Figure 7). Also, for all six women, a strong STEM identity transitioned from the classroom into a STEM-related workplace. In addition, STEM identity reflected in the women's desire to stay within the science career field. Audra explained to me that her "entire career is based off science for sure." After she moved to the east coast last year, Audra took her STEM interest one step further by applying and gaining acceptance into a master's program in molecular biology.

Despite STEM identity being all inclusive of the four STEM fields, all six participants did tend to display a tendency toward one of the four topics within STEM. Certain participants showed a stronger sense of engineering-specific STEM identity. Sula showed early STEM identity with a focus on engineering. Sula told me that she has "always loved construction" and used to play with Tonka $₫$ and construction toys during 
her childhood. She explained her interest in engineering, building and construction, she says, "I just like dirt - and construction management or something like that was what I wanted to do."

Oftentimes, STEM identity was linked to a special person or mentor in their lives. This is not surprising since it has been thoroughly demonstrated in the literature (Brandt, 2014; Cullingford, 2012; Guertin, 2015). This was most poignant for Sula who lost her father in a car accident when she was 19 years old. She shared, "My dad always influenced me with mathematics." She explained that he had an uncanny ability to do complex math problems "In his head" and was Sula's "Greatest influence mathematically."

Like Sula, Roxanne shared an affinity for building and construction aspects of engineering, "I enjoyed putting stuff together, like my brother's toys." Her father was a mechanic and often worked fixing on farm tools on the weekends and she said, "I had always wanted to be around him." Roxanne's STEM identity continued to build as she pursued ATE courses and jobs. A strong STEM identity also refers to having an understanding and excitement of the science behind their career, describing the technicalities of his or her career. Roxanne explained her "STEM fluency" (defined as having an intimate relationship to STEM that is akin to language fluency) and first time she visited her current workplace, Llorando Manufacturing, I wanted to watch everything they have - assembly lines where they assemble the 
cars from like a hunk of metal - to actually what you see going on the road where they put the seats in, the dashboards, and everything. It goes from scratch to what it is and it's pretty cool watching it go through and all of that. You can watch it go from like a piece of plastic bead all the way up to a bumper or something... I thought that was pretty cool.

Another sign of a strong STEM identity was engaging in STEM beyond work and schooling. Research shows that identity formation is an iterative process (Carlone \& Johnson, 2007; Johnson et al., 2011; Rosenthal et al., 2011) and as the women grew, so did their STEM identity. Roxanne extended her STEM identity beyond her professional experiences by returning to her mentor teacher's high school agriculture technology class to show students how to make a robot frog, "When we would clap or make a noise, it would turn. That was pretty exciting."

Just as I identify that STEM identity was iterative within the context of education, all six women described their STEM identities morphing as they graduated from the ATE programs and began ATE-related careers. I noticed how excited Kyla became when talking about her work and when she moved a fully functioning laboratory across departments. She explained that she was "very proud of that moment" and the switchover was so seamless that the company "didn't even notice that this transition was happening!"

Kyla extended her STEM identity and "STEM fluency" by "starting my own 
organization to targeted to at-risk girls" and created this organization to offer an "afterschool science program" for young women who are traditionally underrepresented in the sciences. STEM fluency is a phrase I created in order to describe that as STEM identity grows, so does STEM fluency (defined as having an intimate relationship to STEM that is akin to language fluency). This key aspect of STEM identity was being able to converse on STEM technicalities with STEM fluency. For example, when asked about one of her most exciting days at work, Nena described a time when she was completing an energy home audit and crawled though the attic and exclaimed with excitement, "We found bat droppings and found three dead bats and a dead shrew!" She also mentioned another time when she was impressed to see "the coolest house" that overall had excellent use of energy. She exclaimed, "It was exciting to see how energy efficient it was and it's also exciting to crawl around on his floor and get grimy too."

Nena also explained that she was extending her STEM fluency beyond her ATE profession. She explained that she is volunteering her time to teach a "Lego ${ }^{\circledR}$ robotics class" for an afterschool program. She enjoyed sharing her passion for science and described, "It was cool! Yeah, they [the children] get pretty intricate. But this was ten year olds, so it was pretty basic and fun!"

When asked about one of the most exciting days at work, Betty (who works in power plant technology) shared what could be considered one of her most difficult days, "When the lights went out!" She had to take emergency action and explained, "So you 
don't know, did something blow up? You just have no idea what happened."

Betty described how her upbringing on a farm contributed to her affinity for the four disciplines within STEM,

We had a [working farm and machine] shop and was always out there figuring out how to make things more efficient and you know from the coal standpoint and how we were going to be efficient with the energy and then, from the science part of it - from farming - deciding what we needed to put in the field, as far as anhydrous, fertilizers, what's going to make the crop grow. And then, too, from the animal side of it, we raised chickens, and what we had to do to make them survive, we also milked at one time and had cattle, so we had also that aspect -can you mix these animals, is it going to cause an issue, same with our milking, what do you have to do to with the milk, you know to keep it processed so it doesn't go bad, that kind of thing. It came from all different directions.

During the ATE program, the contextualized nature of math and other STEM topics in the ATE programs helped Betty build a robust STEM identity. Betty told me about how the ATE program courses helped bring life to certain STEM topics, "That's when I really started thinking about science being related to something other than a schoolbook."

Similar to Sula, Betty admired her own father's STEM aptitude; for Betty's father it was specific to engineering. She described that they never took any farm equipment to 
get fixed, instead they tried "experimenting, and fixing our own things." She was impressed by her father's accomplishments and boasted, "My dad had a couple of patents." None of the other four women spoke of family members in their life who encouraged their STEM interest but they did share positive relationships with science teachers and extracurricular coaches.

\section{Self-efficacy: "There is Pretty Much Nothing That I Can't Do"}

The concept of self-efficacy is the belief that one's own capacity to take the necessary outlined steps in order to attain one's goals for the future (Bandura, 1997; Brown \& Burnham, 2012; Loo \& Choy, 2013). The core of the self-efficacy construct is that one has agency to influence their behaviors and choices in order to achieve future goals. Self-efficacy was not coded as participants saying "I excel at school" or "I got awards" or "I want the job badly." These phrases would have had to include that they had the goals to attain the accomplishments and that they believe they had the wherewithal to realize their goals. For instance, Audra shared with me,

I'm excited because I can go nowhere else but forward or up, you know... but I mean there's different ways I could go, but I feel like I want to pursue my Ph.D. and keep my academic career going for sure.

The self-efficacy theme may be under-coded; in order to meet the coding criteria for selfefficacy, participants had to articulate the fact that they knew they would succeed at attaining their future goals. However, self-efficacy emerged consistently as participants 
described barriers or supports in their pursuit of a STEM career path (see Figure 7). The women appeared confident and competent as they navigated their career paths. The feeling of self-assurance in her ability to attain her goals was apparent in Kyla's conversations. She reflects on her potential career opportunities, There is pretty much nothing that I can't do. It's one of those things where if you don't know that you can learn it. A lot of things that I have done I had not done before and maybe some of us have done it in the classroom setting however a lot of the skill set that I have now really truly comes from the job. So I have confidence that I can take it on.

Kyla was confident but unsure in describing what her future may hold, explaining, "I'm not done yet." Kyla went on to describe her educational goals for the future, "I want to further my education. I know that that is critical for me at this point of my life." When I asked her about her life five years from now, Kyla said she would hoped to have earned a doctorate in educational leadership and be "running my nonprofit fully and be able to leave my job [at DNA Technicians, Inc.]."

Kyla's high self-efficacy was apparent in her starting a non-profit for young girls interested in STEM. Kyla shared, "I need to start a program that is going to touch the lives of young women that look like me. Ah-hah! Yes, okay, I got this." She knew what she had to do and that she was going to succeed. 
Just as Kyla's future goals included furthering her education, Sula also discussed wanting to continue her education. Sula shared, "I definitely want to get my master's very soon. So I'm starting to get situated for that journey." Sula described her focus on her goals and her ability to self-author her life, "I think I've always been that type of person to just be able to just say, 'This is what I'm going to do and I do it, and you're not going to stop me,' so I did."

When asked about how they feel about their future, most participants were positive and hopeful in their abilities to accomplish their goals. For example, Sula responded with saying: 'I'm pretty solid about it [my future]. I don't have any doubts about it anymore." What's interesting about Sula's statement is that she doesn't have doubts "anymore," suggesting that at one time she did have doubts in her abilities and potentially low self-efficacy.

Audra described a strong sense of self-efficacy and its accompanying selfconfidence. Audra shared her determination to succeed especially when she shared a story, "Doctor Brown was like, 'You won't be able to get in [to the internship program].' and I was like, ‘Ah, you can't tell me what I can’t do!' so like I tried to get in.” When asked about her future, she explains,

I feel like I have a lot of different avenues that can open up for me, it just depends on what opportunity presents itself. I definitely have a bright future and I know I will be successful wherever I end up. I'm excited because I can go nowhere else 
but forward or up.

Betty explained that her self-efficacy has grown as a result of the ATE program and career. She shared how she was iteratively building her self-efficacy, "Each step just gave me a little more confidence in myself, that I can do these things." Her ultimate success and degree attainment from the ATE program boosted her self-assurance, "It [the ATE program] gave me confidence and it gave me pride in myself for accomplishing it." She even credits the experience with increasing her goals, "It [her ATE degree attainment] has given me more drive that I probably have ever had." When asked, how she feels about her future now, she shares how her self-efficacy has grown over time, I feel good, I feel confident, I feel like even if this [her job in advanced technology] was gone tomorrow I'm not so scared that I wouldn't find something else, you know, umm. I had those [scared] feelings before. And I didn't like them [Laughter]. So, yeah, [I am] just a lot more confident in my future and knowing that it will be okay.

Like Betty, Nena discussed actively building her self-efficacy, "I'm still building confidence but the more I do, the more confident I feel. It helps to work with a [colleague] that is approachable and willing to discuss things with me." She also shared her strong belief in her ability to succeed, "Just know that I live life without those things [drinking and drugs] and I've been really successful, so once I choose a direction, I can be successful at it." 
Roxanne was specific about her future and expressed high expectations. When asked about her life in five years, Roxanne explained that she would like to be promoted to a management position, earn a bachelor's, and also shared, "I see myself at least married, maybe a kid. I expect to have a house by that time." In the six months since talking with Roxanne she has already purchased her first house.

\section{Self-efficacy as a Barrier: "I Never Saw Myself Where I Am"}

The role of self-efficacy in career decisions is broadly acknowledged and has been shown to be a key factor in women choosing against a STEM career path (Holland, 1997). This duality of self-efficacy that emerged was that women's low self-efficacy hindered their success in their ATE education pathways. The dichotomy participants described was that they must overcome their own perceptions of their inabilities in science, almost describing their personal self-efficacy barrier (see Figure 1 for this study's conceptual framework). The idea of self efficacy as a barrier, was demonstrated when Roxanne shared,

I never saw myself where I am. I make almost 30 dollars an hour and I couldn't have ever seen that. I couldn't see myself being in the position that I am in... being able to do the stuff that I have done, like going to the conferences in Nevada and New York. It's nothing like I would have imagined it at all. I imagined just like, I guess like all the rest of my family...I never imagined that I'd not be living paycheck to paycheck because that's how I grew up. 
Both Betty and Roxanne expressed astonishment at their accomplishments and were clear at explaining how they had believed less of themselves. Betty also didn't think she would succeed in reaching her goals, "I remember winning the P.L. Scholarship and I'm like, wow! I would have never thought in the million years, that I would win that." Towards the end of our final interview, Betty further explained her disbelief in her accomplishments,

Never once did I see myself moving from [where she grew up], I mean all these things snowballed. I had my focus on power plant technology and I thought I was going to work an in a town that was 30 miles away. I never looked beyond that, never looked at the big picture and all of a sudden it started falling into place and I was like, "Wow! I never dreamt that this is where I would be..." It was just like a leap of faith, "Okay, I can do that." I guess it was meant to be. This key category across participants came up repeatedly that they didn't believe that they could reach where they did. The deficiency of self-efficacy also afflicted Audra as she navigated the next steps in her professional life, "I actually didn't think that I could get into a master's program this fall and with the possibility of getting funded." In the nine months since the interview with Audra, she was accepted to the master's program and received a full scholarship. In a similar vein, Roxanne thought she would never stop being shy,

When I was a kid, I would watch TV and stuff or something like that and I would 
see people standing up on stage and stuff and I would think about, how cool it would be to be one of those people and be able to talk in front of everybody and not have a stutter or stammers or something, and just feel confident like they do. I never thought I'd do it, but I did several times.

When asked about their accomplishments in science, participants described being surprised by their success. Nena described being, "discouraged by my grades" and that she lacked the incentive to continue, "I'm not motivated to keep going, basically." The women participants faced this diminished self-confidence, particularly when referring to their ATE studies and the idea that "I didn't think I would ever be able to do it [work in the machine shop as a technician]." Kyla shared her low expectations of herself, I've met CEOs of companies that I would have never saw myself in conversations with. I've met professors and other industry people who are executive directors that I would have never saw myself meeting or having conversations with or being friends with. I've met vice presidents of organizations that I would have never saw myself having friendships with.

In Roxanne's case, she particularly called out the professors in the ATE program as having the belief in her that she didn't have at the time, "The people at school [the community college and ATE program] were really helpful and encouraging...And I guess seeing the potential in me that I didn't see... The potential that I could make come out." On the other hand, Sula explains that she is particularly hard on herself,, 
I've worked really hard and I'm my worst critic. So if you ask me any day, I don't do enough, I haven't accomplished enough. But doing this [interview], in reflecting back, is like, "No, I've done a lot [Laughter]."And I should be proud. [Laughter].

Like Sula, Kyla shares that in during her first attempt at college education in STEM, "I lacked the confidence [I] needed to allow myself to pursue it [course load for dental school]. I definitely did not have the confidence that I needed. I had zero.” Audra was also self critical, saying, "I don't feel like the stuff I've done is like that impressive" despite her remarkable accomplishments in the sciences and her education. Roxanne also didn't believe she had the aptitude to enter the ATE program, she remarked, "I didn't think I was smart enough to be there [in the ATE program], and I didn't think that I could do any of those things [in machine shop]."

A common pattern through all of these statements is that the women did not see themselves achieving what they had accomplished. Research shows that on the surface this may be a learned way of downplaying success and implicitly expressing positive self-regard (Deutsch, 2007; Ervin, 2014; Mahone, Bruch, \& Heimberg, 1993; Risman, 2009). This is particularly demonstrated by Roxanne's comment, "I've come a long way from just four short years ago, a lot further than I could've ever imagined." Research has demonstrated women's learned behaviors based on subliminal messages from the dominant culture and that they should not express outward overconfidence (Deutsch, 
2007; Domosh \& Bondi, 2014; Mahone et al., 1993; Risman, 2009) While the women ATE graduates navigated their own self-efficacy gains and deficits, they were also facing external challenges and building resilience (see Figure 7).

\section{Resilience: "I Wouldn't Be Where I Am."}

Often described as ineffable, resilience is defined as enduring a setback or difficult situation and rebounding from the challenge with a positive outlook on the experience and lesson learned (Fletcher \& Sarkar, 2013; Goldstein \& Brooks, 2012; Masten, 2014). In the process of coding, it was essential to recognize resilience as more than just saying something was "really hard;" I did not code for resilience when participants mentioned hardships, such as: "I've worked every day for the last two months," or "We lived in a shack." Although it could be possible to infer resilience from these statements given the participants' ultimate success, I did not infer resilience. A section of data was coded for resilience only when the participant shared a challenge and how they persevered to become better from the experience. For instance, Audra's comment reflected resilience, "It was definitely a really long, hard learning process but in the end it worked out really well because I've learned a lot." These strict coding criteria may have resulted in the coding of resilience being under-representative.

The theme of resilience extensively emerged for four of the women (Nena,

Roxanne, Kyla, and Sula) to a lesser extent for Audra and Betty (see Figure 7). Betty did describe facing difficult situations, but did not articulate her growth or lessons learned 
from the experiences. The other five women demonstrated resiliency, yet the contextual experiences of their challenges varied widely. Nena revealed that over a 13-month period, she "was married, had a miscarriage, divorced" but she explained the meaning she gained these traumas, "It was rough. But I made it through and I felt like if I'm still here and if there's something else I'm supposed to do and here I am [in the ATE program]." Nena, a self-identified African-American woman, also demonstrated resilience when she faced racially charged interactions and microaggressions, such as a white colleague telling her to, "Just add black." Nena explained that she strives to garner something positive from racial and gender-based microaggressions. She describes, It's also empowering that I am a female technician, that I'm representing the female of, you know... and actually I'm the only black female too - only, black person, period. So I actually get to be someone that they know, that they can learn to relate to. Maybe it'll help them relate to other people, like me, moving forward, you know. So that part is hopeful.

Like Nena, Audra also faced adversity in her life and gained resilience. She reflected, "It [her challenging experience] was definitely a really long, hard learning process but in the end it worked out really well because I've learned a lot." Audra shared that her father was jailed for statutory rape, issuing death threats, kidnapping Audra and her sister, and for stalking Audra's mother. Because of this, her mother became "very protective of us [Audra and her sister]" and Audra explained, "We weren't 
allowed to go anywhere or doing anything." Instead of capitulating to the difficulties and trauma of the situation, Audra became determined to be independent and strong. She explained, "I feel like I'm pretty strong with just accepting things for the way they are and just moving forward." Audra turned her mother's overprotectiveness into a something constructive for herself and explained, "That [overprotectiveness] just kind of drove me more to finish [high school] faster." Audra went on to graduate high school one year early and moved out of her mother's apartment. She explained that, "I learned a lot of responsibilities really quickly that way" and strived to juggle college courses, a job, and a growing desire for playing poker. She reflected back on failing a college STEM course and trying to balance her new life as a 17-year old,

It was just like too much and so that whole process was definitely a learning process for me. It [the F in a STEM course] definitely affects my undergraduate GPA because I had to learn - I learned stuff on my own."

Throughout this research study, five of the six participants articulated their resilience by describing condition(s) where they confronted traumas but found a way to work through these challenges and come out better for the experience. Sula had the highest level of resilience among the six women (see Figure 7). She revealed the difficult trauma of her father dying suddenly when she was 19 years old. In reflecting back, Sula shared what she gained from the impulsive life decisions she made after his death, "even being an exotic dancer was a very positive experience for me" and she was grateful that 
these experiences led to "how much more of a better person it's made me." In reflecting on her accomplishments, Sula demonstrated her perseverance and resilience despite a scarcity of support along her career journey. Using the "you" pronoun as a way to distance herself and avoid using the "I" pronoun (Evans \& Demuth, 2012; Kern, Lee, Aytug, \& Brett, 2012), she explained,

If you don't have the resources, like the family backing or networking already, to kind of push you... because it definitely- a lot of it is what you know and who you know. And if you are an individual who doesn't have family or friends or people to push you along, then you have to do it on your own. And I think the best way to do that is to educate yourself.

Kyla described her own life-challenges and her resilience was evident when she described the way she was hoping to "make it better generationally" and created \#ScienceGirls (pseudonym used to protect anonymity), a non-profit afterschool STEM program for young girls typically underrepresented in STEM fields. She reflects, Having the career at DNA Technicians, Inc. also enabled me to be inspired, to start my program \#ScienceGirls to give back to my community. So, this was all for-so, this was not done in vain. This was the purpose, right? For me, where I am, and where I am is where I was supposed to be because I probably would have never been that inspired to actually start the program because I saw that there was a need, right. I looked around me and saw that there was a need. 
When Kyla reflects, "this was not done in vain," she is implicitly referring to the hardships she faced and the support she wished she had (for more on this, see support section). In Kyla's her activities with \#ScienceGirls, she is turning her challenges into positive opportunities to help others, the very essence of resilience. In her reflections, she shares her hopes that young girls in the \#ScienceGirls program will be able to avoid the barriers that she faced in STEM as a young woman of color. Kyla shared, Maybe this is how things are supposed to be and so, now I know that I can [have an impact. I have total control over trying to make people's lives better in communities like the one I grew up in, so that they don't go through the challenges that will block [them] and barriers that exist. So that they can do this, right? And that this [\#ScienceGirls program] can change your life and I know that it can. So, I think that is what makes things okay. It makes me okay. Because I'm going to be okay, right? And this makes things okay.

Five of the six participants (with the exception of Betty) repeatedly explained how they faced traumas and challenging experiences but that these moments helped them become who they are today (see Figure 7). For Roxanne, she faced numerous challenges in her childhood. When she was in elementary school she explained that, "Instead of spending her [Roxanne's mother] money on us or bills and stuff," her mother purchased various illegal drugs. Roxanne reflected,

It was hard at the time, but my mom and I are not very close now, but it helped 
me not do those things [drugs and irresponsibility with money]; also it helped me steer away from the peer pressure in school and it made me grow a lot faster than I wanted to, but if I didn't, then I wouldn't be where I am now.

Another example of Roxanne's hardships and resilience emerged in elementary school. She explained,

When I got to fourth grade, my dad held me back, something about, I didn't do very good in math and he didn't want me to go on until I've done better or something. I passed, but he didn't like the grade, I guess.

The point of resilience in Roxanne's story is that she developed a meaningful relationship with her fourth grade teacher whom she was with for two consecutive years, "And then I got to be with Ms. Cisneros again and we became close while I was there and we're actually friends on Facebook now." Roxanne went on to grow an affinity for math and as she continued in school, "I learned to like math, it was one of my favorite subjects. I got into algebra stuff, I really enjoyed it." Roxanne is an exemplar of resiliency; she transformed challenges into opportunities to build self-sufficiency and independence as well as deepening her relationship with Ms. Cisneros (Goldstein \& Brooks, 2012) (see support section; for more on Roxanne's independence, see the other themes section).

\section{Gender: (Un)becoming a Woman}

I define the main theme of gender: (un)becoming a woman as when cultural stereotypes and norms were inflicted onto the women that led to a de-emphasis of 
femininity and an assimilation into gender norms and other genderized interactions. This strongly emerged for all five participants and to a lesser extent for Audra (see Figure 7). Just as with self-efficacy and resilience, coding for this theme may be underrepresentative. I did not apply the gender code when the participant only mentions their gender or other objective statements; instead, I coded this theme when the women explained how gender affected her success. For example, the bullying Roxanne faced from peers in her workplace made it difficult for her to work as a team with her colleagues.

The women's stories revealed that they were struggling to navigate STEM careers in "male dominated industries." The fact that the women would be in a male dominated career path was well known and accepted by the participants. In ATE laboratory sessions, Betty explained that, "It was mostly men; it was very male dominated without a doubt." Nena echoed Betty's experiences in the classroom and lab, saying, "I was the only woman." Sula shared with me her resignation of the fact, "Being in a male dominated field has been a huge hindrance...the industry I am in is male dominated and that is what it is." Like Sula, Roxanne was the first and only woman in the ATE program at her college and at her job at the Llorando Manufacturing site; she called the situation "rough" and said that, "It's not easy being a girl in a men's world."

In pursuing career paths in male dominated industries, the women made the decision to navigate the gender-based challenges in many ways. The gender theme 
emerged across time and space for the women, including the community college setting and the ATE programs where participants experienced charged genderized iterations with colleagues. Some experiences linked to this theme occurred in their places of employment, where the women would face covert and overt sexism.

Betty was the only woman among her male colleagues working the systems operations desk at Windy Forest Energy. She described her approach was to understand that men are a "different species" that are "dominant" with varied and strong personalities, revealing that she was "accommodating [to the men], to the point you can still respect yourself." She also addressed the tension and "reassured" her male colleagues that if any issue comes up, she would discuss it directly with them and explained, "I would never just go over your head and just go to HR [human resources]." In one experience when Betty was "Working the desk," there was "A big event on the system" and she asked her male colleague a question and her "snapped" at her. Betty explained, "I could see it in his eyes right after he did it [snapped at her], was like, 'Oh God, I'm in trouble." Betty reacted by telling him, "Although I won't allow you to disrespect me, I don't expect you to walk on eggshells around me, I want this to be like another guy is in the room with you." Betty felt she had to (un)become a woman and deemphasize her gender identity in order to succeed in her job.

Nena revealed a comparable situation. She shared with me that when Worldwide Energy Management, the energy management company, hired her she didn't have her 
energy audit certification and couldn't be hired as a technician yet. Instead, they hired her on as a secretary and allowed her the time off to take the certification test. She continued to work as a secretary for seven months after receiving her certification, despite several male colleagues being hired as technicians instead of promoting Nena into the role. She reflected on her workplace and that "there is kind of a boys' club" at Worldwide Energy Management and she felt that she had been seen as one of the "pretty girls that sit in the office and answer the phones and whatever." In telling this story, Nena noted the feeling of (un)becoming a woman and the gender differences, explaining that as a woman, she felt the pressure to "be helpful and pleasant." Nena distinguished between her feminine attributes and as the only woman technician in the company, she feels pressure to act in less "dainty" ways,

I think, naturally guys assert themselves more authoritatively at times, especially in a male dominated field and I think, as a woman, you just have to be able to say, "This is what I need" and make sure you get it - part of it is embracing that authority as a scientist, as a person, as a woman, and feeling empowered.

Sula shared a similar story in which she explains being the only woman supervisor of 30 men in an already male dominated field.

They [her direct reports] call me their baby, they're like, and "You're a child." Which is fine, because most of them treat me like their own daughter, they're pretty respectful but I have few that are just nasty, just nasty. Every day is 
different but every day is full of the same bullshit. And, you know, a person can only take so much. I am at the end of my rope. I'm mentally exhausted.

She is the first and "only woman ever" to supervise a maintenance team at her site. Sula's perspective is inherently different than Nena and Betty since she supervises a team of men between the ages of 30 and 60 years old. She shared that some of her direct reports told her to be more direct and "bossy," and that the previous manager in her role used to tell them, "Shut the fuck up and get back to work." Sula explained that it is important to her to avoid speaking to her staff that way, as she fears it "opens the door for them to talk to me that way." She explained to me that some of her staff, "are just straight assholes who don't give a shit, and they're going to treat you any way they're going to treat you." Sula echoes Nena's challenge in being caught between genderized constructs; she oscillates between being a "nice" person and having "literally been stepped all over for and they take advantage of me because I am really nice." She shares with me that she doesn't want have to be a "bitch to get [her] point across," but she "wrote up [disciplined]" her staff for their disobedience and remarked, "These guys have literally pushed me to my breaking point. I almost quit this week."

Roxanne explains that being in a "male dominated field" presents significant challenges. Roxanne's awareness of stereotypical genderized roles began at a young age; she shared, 
I was really young, I was about three or four, I suppose. My dad is a mechanic and he would work on the tractors and stuff down at the barn, and I had always wanted to be around him. So I would go down there with him and he [Dad] would always tell me to go back to the house with my mom because that was a man's job and that was big boy toys and I didn't need to be around him or anything. In addition, Roxanne grew up in environment where she felt pressure to (un)become a woman and to not depend on a man because she observed that her mother "depended on guys a whole lot to do a lot of stuff." Roxanne shared with me, "I decided when I was in high school that I didn't have to depend on a guy for anything like that." As a result, Roxanne explained that she became very self-reliant and confident (for more on Roxanne's independence, see other factors section).

Unfortunately, as the first and only woman in her ATE program in her workplace, Roxanne continues to face genderized tension and manages it by saying, "I don't need anything negative in my life, so I just try not to be around them." Roxanne shared that her male colleagues ignore her, are "Treating me like I don't know anything" and are often "rude, and nasty." On her shift at the manufacturing plant, the main function of her position as a technician is to fix machine breakdowns. At these breakdowns, Christina used to ask her colleagues questions and they would ignore her or make rude comments and microaggressions. Instead of asking her colleagues questions, she now will, "either 
go to the manuals or to the production people that actually do the processing of the machines." When Roxanne tells me about her colleagues, she describes them as, Very competitive, and arrogant, and cocky, and jerks. So there's a few coming in that I guess are jealous or don't like that I'm a girl, think that I'm incapable, or stupid, or just don't have anything nice to say, so that's been pretty difficult. Meanwhile, both Audra and Kyla de-emphasized the importance of gender in STEM academic and professional settings. Interestingly, both Kyla and Audra are in biotechnology industries, commonly known to have a comparable numbers of women and men (Bayer Corporation, 2012; Bybee, 2013). Audra explained what she experienced at school and the workplace were a "good mix of both" women and men, "not exactly 5050, but close." Unlike Audra, Kyla noticed a lack of women at her workplace, but, as a self-identified African-American woman, she stressed that race/ethnicity was more of an issue than gender (this will be discussed further in the following section on the race/ethnicity theme). Kyla shared that there is a dearth of women in leadership roles at her workplace and she remarked, "It is still very heavily male dominated." Overall, Kyla attributed race/ethnicity as the source of her social estrangement that she experienced at DNA Technicians, Inc. but also acknowledged that gender also is a factor, "I would say like I think in my life, a black male may have an easier time, you know, getting into a [social] circle than black female." 


\section{Race/Ethnicity \& Gender: The Double Bind}

I define the race/ethnicity theme as when the participants explained that race/ethnicity contributed as a barrier to their success. As women of color, Nena, Kyla, Audra and Sula, described a profound sense of racialized and genderized challenges as women of color (see Figure 7). This theme was absent for two participants: Roxanne and Betty, who are self-identified as Caucasian. For the remainder of this section, I will be referring to only Nena, Kyla, Audra and Sula since these four women explain to be most affected by this theme.

At this intersection of race/ethnicity and gender, the four women of color felt pressure that Nena described as, "I have to do more to be seen as equal." Malcolm and colleagues (1976, p. 1) described what these four women of color face as a "double bind;" defined as a construct that illustrates the amplified result of women of color undergoing sexism and racism concurrently. These four participants explained experiences of racism, such as, "obviously, there is racism," while also described covert racism and labeled it "bias." The four women simultaneously emphasized the importance of diversity, "There was a lot of diversity there [at the community college and ATE program], which I really, really appreciated and I felt like I did better because I'm different," or the challenges of being an "outsider" (Lorde, 2007) in explaining, "I'm the only black female too. So, [the only] black person, period." 
The four women shared a sentiment of "overbearing" pressure as a result of race/ethnicity in the workplace. Kyla described that she felt this pressure from her manager in how she was treated in contrast to her colleagues, "They hold me to a totally different standard." Nena mirrored Kyla's feelings as she shared with me about the challenges of navigating race/ethnicity in her workplace and having to be an "exemplary" person for her race/ethnicity, "I do feel like there's this message that I have to do things better than everybody else to be considered equal to them. Like I have to go above and beyond to prove that I am good enough." Sula spoke directly to the fact that she works harder than other employees, "You just have to maintain, you have to be consistent, and you have to know that you are there for a reason and over-deliver." Nena suggested that some of this pressure is because there are so few people of color in their workplaces or classrooms, and she explained, "I do feel like I'm going to create their mold of what they think black people or black woman are like." Although she was comfortable being a role model, it only served to magnify the burden of "over-delivering."

The disparity of women of color in STEM-related academic and professional settings left a forceful impression that the women participants did not "belong." Kyla explained that in high school, "I was the only black kid in all of my classes in high school." And freshman year of college, Kyla struggled to find acceptance and a sense of belonging in STEM courses; she shared, "At the university, I really think I was the only black kid in my all my science classes." In contrast, Audra talked about pursuing 
graduate school, "It's a historically black school and I'm obviously not black, but I am Hispanic. I will definitely get to know what it feels like to truly be a minority." Sula struggled with a sense of outsiderness in her high school that was full of "all rich white kids" and explained, "It's definitely different when you're literally one of four black girls in the whole school and there's literally one Asian girl, one Spanish girl, and one black guy in each class." Sula went on to describe,

I was bullied really badly when I was younger. My mom's white and my dad's black, so I guess back in that day there weren't a lot of mixed kids around and I have like darker skin, but I have freckles, and my mom could straighten my hair, but then it could be like super curly. So I don't think people really knew what to make of me because I wasn't quite white like the white kids and I wasn't black like the black kids.

Kyla experienced outsiderness in her workplace and revealed, "I am the only black person in that whole department" and she felt socially ostracized. Kyla couldn't make sense of the "outsider" feeling and she reflected, "I don't know if they [her colleagues] had ever seen a black person. I would go through the hallway, everybody would just drop their head, and I was like, is it me?" Nena also described the way she faced felt being an outsider in the ATE program, You're kind of an example of what a person like a woman of color can be. If they have no experience with them [women of color], then you are their experience. 
And I think because of where I live, and the community I live in, and the people that are in this [ATE] program, they don't have a lot of experience with a woman of color, so I get to be the person and then influence some change, maybe, in that little classroom, or building or whatever and [I try] not to forget that. But not to look at it as a burden, but just think it's an opportunity - it's a gift to be able to be something new for somebody and expose them to someone real and authentic.

Sula also explained the forthright nature in which her mentors and colleagues told her that she would stand out, but to her advantage; they predicted that she would succeed because of the double bind and she should think of her race/ethnicity and gender as an "asset" and she shared, "I've been told a lot of times that, 'You will make it because you're black and you're a woman.'”

When I asked the four women about challenging moments in the workplace or academic settings, they shared stories of overt and covert racism. Kyla hesitates to call what she is experiencing anything other "bias,"

I don't know if it's bias, I think it's bias. It's bias, that's all. You are favoring other people or another person over another. So I can't say that is racism, but it's very - it's very biased there. I know for a fact it's extremely biased because if I look at the hiring, if the person that runs the department is Indian and the majority of the people that are in his department are Indians what does that say, they favor - he's not racist, he just favors one group over the other...there is clearly a bias 
there but I'm the only one that probably sees this craziness because I'm the only one that doesn't look like them.

Sula describes her experiences of overt racism,

Obviously there [at her workplace], is racism and yeah, there are skinheads there absolutely. I guess I say obviously because it's just something I've always dealt with my whole life. I think it's hard for some guys [of her 30 male direct reports] to accept the fact that there's this young, black woman telling them what to do. Unlike Sula and Kyla, Audra faces challenges with her mother and previous boyfriend. Audra revealed to me that she's unable to talk with her mother about her pursuits in graduate school and her ultimate goals of earning a Ph.D. Accordingly, Audra wonders about why her mother has difficulty hearing about Audra's professional successes and if it's similar to her previous boyfriend's unhappiness with her career pursuits,

I think it is part of the Mexican culture. I think it's something that has to do with like me exceeding what she [Audra's mom] has accomplished. And I told you about how I had that one boyfriend; he's like, "Why don't you want just to have a normal job [when she was pursuing a career pathway in advanced technology]?" He was Mexican too and so I don't know if it's something with the culture. It's like [her mother and boyfriend are thinking], "You think you're all that now because you're becoming scientist." 


\section{Patchwork of Support: "Someone Cared About Me."}

Support from professors and managers emerged as a key factor in influencing the women's success in ATE courses and careers. Particularly, all of the women acknowledged that their achievements were partially due to the caring, advice, and help from key mentors or supports, especially in navigating their career path and any genderized issues. Each of the six women explained that they did not have the advantage of formal mentorship, nor did they come from families with social capital, but they had "fragments" of support that contributed to their success (see Figure 7).

Many of the women revealed that it was informal mentorships that helped them in their STEM career and the encouragement to persevere in the face of challenges within STEM. For all six women, the support and guidance was displayed as belief in the women and their potential, despite the women's own negative self-efficacy (see Figure 7). Support and guidance was also displayed by preparing the women for the aspects of the male-dominated career in STEM fields. Without familial ties and the advantages that come with social networks, it can be critical for women to create these advantages by gaining support in formal and informal relationship and mentorships. Accordingly, these six women synthesized these advantages by a "patchwork" of fostering support-based relationships. This "patchwork of support," is a construct I crafted to describe isolated, transient "pieces" or "patches" of support that helped the women to be successful. This construct was particularly important for the six participants since each of the women 
faced a shortage of support from their families, friends, programs, and/or educational institutions.

A key pattern among all of the participants was that of being opportunistic and seizing microaffirmations and support in any way it was offered - from a mentorship to a colleague, to a manager, the women weaved together their patchwork of support. Kyla clearly articulated this, "That's the only way I got here. Because someone cared about me." The microaffirmations and help from her advisors and professors were clearly illustrated in the story of how she obtained the job she has today. For ten years, Kyla says, "I tried over and over again” to apply for job positions at DNA Technicians, Inc., without getting a response. It wasn't until she received a flyer on her doorstep about an ATE biotechnology program that she enrolled in the ATE program. In the ATE courses, Kyla's professors "didn't just teach the science" they went a step farther and "also taught you the life skills that you needed." It was then that she realized her resume was formatted incorrectly and her lack of internship experience were directly linked to the fact that DNA Technicians, Inc. had not responded to her applications. She then was awarded an internship through her connection with the ATE program and but it was the manager at her full-time, school bus-driving job that helped her at this critical juncture. Kyla described how her manager at her school bus driving job helped her attend an internship, 
My manager at the school bus job gave me permission to actually do that [drive the bus to her internship on her off hours] because that was definitely not allowed. That was like a "no, no." But he [her boss] said, "I tell you what I am going to do - just be very careful - I am going to give you permission to take your school bus from [the school bus headquarters to her internship 30 miles away], do what you need to do."

After this internship, one of her professors urged Kyla to apply to DNA Technicians, Inc. again, "She was hardcore about how she pestered you, and at the same time, she gave you the life skills that you needed," and Kyla received a job offer from DNA Technicians, Inc. Kyla explained that,

Someone cared enough and put a little bit of energy into me because I didn't have answers and that changed the trajectory of my life, which -- here I am now, right. I have been at DNA Technicians, Inc. since 2006.

In reflecting back on her past and current attainments, Kyla explains that in lieu of support from her friends, family, and early education, it was her microaffirmations and supporters from the ATE program and her school bus driving job that allowed her to fill the void of support she needed, "I think it's the mentors that I have in my life that really allow me to get support." She discusses the lack of support in the social capital theme explained in the other themes section below. Kyla's story shows that the support she received from various sources along the way enabled her to achieve success. She 
explains, "Someone takes an interest in you, that makes all the difference and changes the trajectory of your life and that's exactly what happened to me."

Like Kyla, Audra described her best efforts to succeed in her first attempt at a four-year college and wished that she had had "more guidance" and someone to "tell you 'Hey, you should probably do this." She described that, "It may sound stupid but I didn't know that you could drop a class" and instead, she stayed enrolled in a course and "ended up with F from my transcript." In a similar way to Kyla, Audra explained that the professors helped fill her void of support,

It's always been like a really big deal for me to get advice from mentors as far as like my career goes because, you know, I don't have anyone else to ask.

At the four-year university level, Audra describes one of her professors, "You could tell he really cares about the students" and that Audra choose to go to him, "for help because I really felt like he actually cared." Beyond her mentors, she also had other folks help her out, including a post-doc at her summer internship, her manager at [her old employer] who enabled her to leave for the summer and return to work during the school year, and the staff at nearby public agencies when she worked at a private company as a lab manager.

Audra explains that she "still retains relationships with them [ATE and four-year university professor/mentors]." And that they help to "guide me through my career and figure out exactly like what I want to do and where I'm going." Just as Kyla did, 
Audra directly links this to the lack of support she has from family and friends and how she filled this void with supporters and microaffirmations,

I have an aunt that I ask for advice sometimes, because she helps my cousin get into med school but definitely the majority of the advice I get, as far as career and education, it's all been through my mentors. Yeah, I did because I feel like that I couldn't have accomplished what I have without them.

All participants described key figures in their lives that helped them succeed, and often the women emphasized that they are still in touch with these supporters. For Roxanne, after her parents divorced, she moved in with her father but "barely saw him." Instead her high school automotive technology teacher, Mr. Pollan, "wound up being my favorite teacher, he's almost a second dad." He offered microaffirmations and encouraged her to explore her skills and talents instead of pursuing her plan to join the National Guard, "he said that I looked like I felt comfortable in the shop with the tractors and stuff." Roxanne's other favorite high school teacher, Mr. Spelling, was "impressed" with Roxanne's work in the agriculture class and he invited the ATE coordinator to the school to speak with Roxanne and recruit her into the ATE program. Roxanne reflected, And through their encouragement, I wound up going into the manufacturing field. Mr. [Spelling] had my brother too, so he knew how much we were going through in the family, as far as custody and just the divorce and everything. So he knew the background of where I came from. 
In addition to having support figures in high school, Roxanne went on to also have advisors and supporters in the ATE program. She explained that the ATE professors and staff were instrumental in her recognizing her potential, The people over at the [ATE] program, they were really helpful and encouraging and I guess seeing the potential in me that I didn't see that I could make come out. I guess all the positive encouragement and reinforcement and I guess -- the push that they gave me to not be so shy. The faith that they had in me to be able to do it when I didn't think I could do it myself, kind of gave me all the things that I needed to have the confidence to be able to do it.

The results from the study by Griffith (2010) revealed that student experiences within STEM programs and departments had a significant effect on their persistence and graduation in STEM fields. Roxanne explains how professors in the ATE program encouraged her to persevere despite her own doubts of her abilities, I didn't think I was smart enough to be there, for one, and I didn't think that I could do any of those things and the fact that they tried so hard to get me there and kept pushing me and encouraging me to do all these things that I didn't think I could do, kind of showed that they'd seen the potential in me that I know I didn't had.

Presently, in Roxanne's manufacturing job she has several people she goes to for "support" including Pablo, who work as managers. Roxanne describes that she also 
forged a mentor-type relationship with him, explaining that "He's [Pablo] about my dad's age and he's kind of like my dad, I call him my work dad. [Laughter]." She goes on explain the challenges she faces being the only woman in an all-male workplace, There is a team member on day shift named Omar, I was closer to him than I was to Pablo, so he was like my work dad also. He helped me through a lot of the issues that I was having with the guys at work and he took a lot of time out of his day to show me stuff and I think... I was able to learn a lot in the areas that I was in because he would strive to make sure that I got into stuff, was able to work on it...And he saw how the guys on my shift, on their shift treated me and how wrong it was, so I guess that gave him the extra... that made him support me even more because he'd seen how I got treated with them, so. And a lot of support, especially at work and at school, along the way.

For Kyla, the feeling opposite of support, that "no one cared about me" was so paralyzing and overwhelming that she didn't complete her first attempt at a four-year degree. Prior to joining the ATE program, Kyla had gone to a four-year college, "I felt like at the university, no one cared about me. And I was trying to figure it all out, so I was like a fish out of water trying to basically trying to keep myself from drowning." This contrasted with the mentorship and support that she received in the ATE program, where she describes the each professor, "cares about their students" and directly attributed the support network for her degree and job attainment in ATE, "I think it [the 
support] helped me to be successful." She also explains that these advisors continue to support her in her professional pursuits, "I am close to almost every single professor that I met going through the ATE Program."

Key supporters were also a critical aspect for Betty's success in her ATE academic and professional pursuits. In the ATE program she attended, one professor, Reginald, "was always cheering me on." He helped her to contextualize the STEM topics, particularly math, which she had previously seen as "impossible" (see STEM identity section for more). She explained to me that he gave "different real life stories" and that each concept had "a story that goes with it." Betty went on to identify this as a "mentor-type relationship," and explained that despite having two other jobs, a husband, and two children, she still found the time and "I would go to lab early, so I could sit and pick his brain or we could sit in talk about things."

Reginald was not only a mentor to Betty in the classroom, but he also went as far as helping prepare her for the male dominated workplace of advanced technology and power plants,

I do remember in my little talks like before class with Reginald, him saying to me, you realize that you're not going to be employed with a lot of women - and he was very clear, he goes that "I don't want to deter you from wanting to do it and you certainly can excel in it" but he said, "You know, just know that you're going to face some different obstacles than if you were a male because it's so dominated 
by males."

For both Sula and Nena, support was less of a theme (see Figure 7). Both of these women did acknowledge the support from their mentors and professors, but only a few times. For example, Sula explains,

I thank the professors that I've had throughout the years that have been extremely supportive. And they've also been probably monumental in my success because they've gone above and beyond for me because they seen how I work and that I am doing it on my own. Their networking prospects and the ability to hand an assignment in late without penalty. Or you know, the quality of your work may not be up to the quality of what you normally do, and you're not really judged too harshly on that, I think it's really important.

Interestingly, both Nena and Sula had ATE programs that helped them get jobs. Sula tells me that her internship "co-op was phenomenal" and after she finished almost all her ATE courses, and her former co-op manager offered her a job.

Like Betty, Sula explained that one of her supporters went as far as helping prepare the women for the male dominated workplaces, "He [the ATE professor] did a really good job for preparing me for the type of environment that these guys [her staff of 30 men] operate in." But beyond these two instances, Sula attributed most of her encouragement to her family and friends support network (see other themes section on family and friends as a support for Sula). 
Just as Sula didn’t emphasize this support as integral to her success, neither did Nena. She gained a fair amount of support from her spiritual guides, particularly when she was a minister but also after (see other themes section on spirituality for Nena). However, Nena had a unique situation since while she was in the ATE program, her job was at the community college, "I had a lot of support just from my co-workers [at the community college] because half of them were students, a lot of them were students. " Nena also went onto explain that she gained a lot out of a study and support group with her fellow students in the ATE program, "I had a good, really good support group, support network. Lots of study buddies."

Similar to Kyla, Nena's ATE professor helped her with applying for a job after the ATE program, "My [ATE] adviser was so very hands-on and he did a really good job of advertising for jobs, up-coming positions and he has a really good relationship with the General Manager at Worldwide Energy Management."

\section{Other Themes}

There are seven other themes that applied to only one or two women, but were significant to each woman and reflected their individuality. Ultimately, these idiosyncrasies play a lesser role for the women than the six overarching main themes. This section describes the other themes that emerged only for one or two participants but formed core parts of their narrative. A theme was considered an "other factor" if the theme occurred in five percent or more of the coded data (see Figure 7). 


\section{Roxanne}

Beyond the six main themes that emerged in this study, two other themes surfaced for Roxanne that shaped a critical aspect of her story: 1) Independence and 2) Friends/ family support as a barrier (see Figure 7).

Independence: "I hate having to depend on somebody like that." Roxanne's preference for independence and self-sufficiency was her coping mechanism and how she dealt with the lack of support in her family and school and work life. As mentioned in the gender section, when Roxanne observed that her mother "depended on guys a whole lot to do a lot of stuff, fix the cars, provide money, and stuff like that," Roxanne decided as a high school student that she was going to be independent and get to a place where she, "didn't have to depend on a guy for anything like that." Roxanne really took the idea of independence far as she aimed to become as self-sufficient as possible. At twenty-four years of age, she just fulfilled one of her goals and bought her first home. Her thirst for independence was threatened when she faced the reality of her lack of physical strength in comparison to her male colleagues at work. She shared being frustrated about, "just the fact of being a girl you're not as strong. That's difficult to handle because you always have to ask for somebody's help when it comes to a bigger job." When I asked her for an example of a time when she had to ask for help, she shared,

One PM [preventative maintenance task] is to tighten bolts and you have to put like a thousand torque pounds or something on them and that's a lot and I can't do 
that, even with the big tools that they have I still can't physically do it like one time we were joking around and I was helping someone do it and he's like, "Here try it." so I'm literally hanging on the end of like a five foot torque wrench [and I] couldn't touch the ground or nothing. I'm like literally hanging off of it and I still could barely get it. I was jumping and I could barely get it.

When a man took over her spot, she said, "he was able to do it pretty easy, you could tell he had to work for it, he didn't have to hang also or jump up and down or nothing." When reflecting on when she has to ask a male colleague for help, Roxanne explained that "it really sucks" and when I asked her why, she said, "Because you have to have somebody there to do it for you and I hate having to depend on somebody like that." This attitude of independence continued as she got a job in the manufacturing industry where she was the only woman working at her site. She describes one of the "best days at work" as a day when "I would do things on my own without having to ask for help."

Friends and family as a barrier. This barrier was described by Roxanne as the way in which her lack of support from family and friends impacted her success. The story that best illustrates this lack of support, and Roxanne's accompanying resilience, is about Roxanne's father. When I asked Roxanne when she first became interested in STEM topics, she shared with me that she always was fascinated by her father's mechanical projects but instead he told her to "go back to the house with my mom" and that he was using "big boy toys" (for more on the genderized aspect of this, see the gender section). 
Unfortunately, her father's lack of support in Roxanne's STEM interests and STEM identity continued. When she was in fourth grade Roxanne passed her math class but her father was disappointed in her grade and held Roxanne back a year. She says, "I passed, but he [her father] didn't like the grade, I guess" (for more on Roxanne's resilience in this experience, see resilience section). As Roxanne pursued advanced technology education, she excelled and her teachers became sources of support, she called them her "work dad" or her "second dad" (for more on this experience, see support section). When reflecting on how she received support from her family, Roxanne shared,

My Dad wasn't very thrilled about it [Roxanne pursuing an ATE degree and job] for a long time because he said that it was a guy's field and he knew how guys were, he didn't want them to mistreat me and stuff like that.

Now that she is an accomplished STEM technician, I asked her to reflect on her childhood experiences related to STEM and her father. She presented at an annual national conference and her father watched the video of her conference presentation. She reflected,

I understand why he said it [that she should go in the house and not play with big boy toys] because he was trying to keep me from getting hurt and stuff and he didn't want to mess any of his stuff up and he actually watched the video from the [national conference]. Afterwards, he said that he felt bad for saying that...that he was young and stupid and didn't really, he wasn't thinking and didn't realize 
what kind of effect it would have. He was like -- he just said that he felt bad, that he didn't mean it that way but that he felt bad because of it.

\section{Nena}

Beyond the six main themes that were relevant for all participants, there were two other themes that emerged for Nena that illustrate her individuality and important aspects of her story: 1) Spirituality and 2) Helping (see Figure 7).

Spirituality. Nena's parents changed their religions several times growing up and it led to the family living a transient lifestyle, switching friends and neighborhoods when switching religions. Nena explained that this instability and shifting of spiritual directions was difficult for her; she couldn't identify with any of her parent's religions. She attributes her self-described "wild child" behavior while in college on a full scholarship to pursue engineering to these challenges in her childhood. Her own grappling with spirituality and faith continued to be a theme throughout her life; she went on to become a Christian minister that led her to move across the country and helping her to refocus her interests on STEM and attending community college. Her shifts with identity and religion were even relevant in her name changes; as her parents shifted religions, her name shifted and when she was " ordained a deacon," she was baptized with a new first name. One of the main challenges that Nena described was trying to fit the mold of a spiritual identity, rather than maintaining a strong sense of her own identity. At work, school, and in personal contexts, she explains that she was "just trying to fit into 
what they want me to be or what someone wants me to be" Nena goes on to describe, Growing up, I tried to fit the Muslim thing and trying to fit in these boxes, like in these boxes and roles, I don't ever want to do that...I don't want to ever sell myself short or try to fit into some picture, I want to always to be able to be my true self in whatever I'm doing.

Despite ending her work as a deacon with the ministry a few years ago, she still maintains a spirituality identity. She also still finished pursuing STEM in the community college by earning her sub-baccalaureate degree from the ATE program. Her spiritual identity has helped her to understand her goals in STEM and also find meaning in her life's hurdles. When facing challenges, she reflects,

Okay, what am I really supposed to really take on? And not be afraid of....and even the spiritual path, knowing that if I take time to meditate and spend time focusing on certain things that I'll keep reenergizing.

Helping: "Being of service." Throughout Nena's interviews, it was very apparent that she wants to "be of service" and sees this as her purpose in life. When asked about her future goals, she shares, "I want to inspire change, I want to be a part of something that solves a problem." Nena felt very strongly about this motivation, "I am not just passively going through life, but I'm actually participating in... and using the things I've learned to apply them and help people." Prior to beginning the ATE program, Nena "did come from a very service oriented background," working as a teacher and preschool site 
manager.

Nena put her beliefs in helping people into practice in the way she approaches her current work in energy management. She explains, "I want to see things grow and thrive, and I want to keep seeing the earth be abundant and everybody be healthy and happy." With the employer she currently works for, she strives to be serving low income populations with weatherization, since currently her company's only clients are those that can afford to make non-essential energy efficient home improvements. She explains that, "It would be great to get into multi-family and low income [homes]. I feel we're just barely scratching the surface of who we [her and her employer] can help."

\section{Audra}

In addition to the six main themes that were relevant for all participants, one other theme arose for Audra and played a dominant role in her story: Helping (see Figure 7).

Helping: "Being of service." During her college tenure, Audra moved back in with her mother and she helped take care of her stepfather, her mom's third husband who had "multiple myeloma" and ultimately "passed away." She explained to me that this informs her interest in doing biotechnology research on cancer and said, "That's [cancer research] kind of like something I've always wanted to do." When I ask her about why she is excited by this research, she explained,

I guess the cause behind it, I think it's pretty noble and then also too, it's just really fun and interesting to kind of work with like mammalian cells and see what 
happens when you, introduce like chemotherapeutic drugs and just incubate them and then check them out afterwards, see what happens and I think that's pretty fun. I have never done research with the mammalian cells, so this is something that would be exciting for me.

Also, since she experienced critical forms of support in her "patchwork of support" (for more on this, see support section), Audra is inspired to support others. She shared, "I definitely love helping my friends out and seeing everybody succeed and get accepted into the programs then accomplishing their goals." When I asked her what she would ultimately like to do, Audra shared that she would like to earn a doctorate degree in the sciences and would like to "Go the academic route and mentor students." She shared with me that she had originally "wanted to do pharmaceutical sales and real estate on the side" and that she was "all about income level." After doing the ATE program, she explained that her goals shifted to be more focused on helping others than her annual salary, You may not make as much money teaching than you would like in the industry with a big company, but I feel like your job would be more stable and probably more rewarding because you're helping so many other students and that's your future.

\section{Betty}

For Betty, two other minor themes developed as core parts of her narrative: 1) Friends and family as a support and 2) Age: "Not a spring chicken" (see Figure 7). 
Friends and family as a support. In contrast to Roxanne, Betty was encouraged by her father to explore her interests in STEM fields, particularly in agriculture technology. She was encouraged to defy gender norms and work with the men on the farm while "the inside [house] component [cooking, cleaning, etc.] was my sister." She goes on to describe how she was treated as "one of the men,"

I can tell you straight up, I grew up outside, I did the lawn, did the farming, did the truck driving, did all that. My sister did [the inside component], I can tell you straight up I can't cook. I never spent time cooking with my mom and all of that... She's [her sister] the one that learned to sew, she's the one to do that stuff not me, and I was working outside and so were my brothers-- they were outside all the time.

When I asked Betty what she did for fun as a child and she explained, "We'd find stuff to tinker with. He [Dad] would give us wood, nuts and bolts." In Betty's situation, she was unique among the participants in saying that one of her family members was a support to her and a mentor. Like other the support other participants received to prepare them for being the only women in the workplaces, Betty's brother also helped prepare her for the male dominated at power plant industry (for more on this, see gender and support sections). She describes, He's [her brother] seven years older than I am so he was this success figure for me. He was instrumental and getting me into the program, steering me where I 
had to go, what I had to do, how to get started.

Age: "I'm not a spring chicken anymore." Betty went back to school as an "older student" and felt that her relationship with Reginald was only possible because she and Reginald were close in age. Also, compared to her fellow classmates she felt like a "fuddy duddy" because she couldn't go out for a drink with her classmates after class due to her family responsibilities. She revealed, "Sometimes I have this little ping of jealousy [that her other classmates had less responsibilities]." It was clear that throughout her experience as a woman in ATE programs and workplaces, Betty viewed age as a obstacle to her success. Her age was also a hurdle for Betty when she reflected on her current career goals. She explains,

I keep telling the guy that sits next to me and I said, you know, "I should probably have had these goals [to move up in advanced technology positions] years and years ago because I'm not a spring chicken anymore" [Laughter].

\section{Kyla}

The six main themes emerged as key components of Kyla's narrative, but two other themes arose to complete her story: 1) Helping and 2) Social capital (see Figure 7).

Helping: "Being of service." Like Audra, Kyla also had a close family member with cancer and that is what drove her to apply to DNA Technicians, Inc. multiple times over a ten-year period with no success. In explaining her perseverance to keep submitting job applications over the decade, she told me that, "I knew that they [DNA Technicians, 
Inc.] made medicine that could potentially make people well." She also continued to support her family and worked as a school bus driver for the public school system. As she applied for jobs at DNA Technicians, Inc., she reflected on her motivations,

I felt like I can somehow contribute to the science and that was probably the passion and the desire to wanting to be there...I felt like I had more to contribute to my community and to society than driving the school bus, not that there is anything wrong with that.

After completing the ATE program, Kyla has worked at DNA Technicians, Inc. for nine years with several promotions. However, she has been facing "bias" and isolation at work and is managing her frustrations around some challenges at work (see race/ethnicity section). She has also began a side project \#ScienceGirls that reveals her sense of purpose, to "make the community better, you make the society better." She described that \#ScienceGirls has been her inspiration since she feels drained at work,

I think what keeps me going is that there is another project that I am super excited about. To address that issue of lack of diversity, in not only STEM, but particularly in the sciences, I decided that I would start my own organization that was really to targeted to at-risk girls and communities that traditionally no one would really care about. I started an after school science program in my community. I can give back to my community to learn how to help empower young girls. 
Social capital. Kyla was explicit in explaining that she lacked the "social capital" in her upbringing. In her current non-profit, \#ScienceGirls, she feels a lack of support, explaining,

Even if me starting \#ScienceGirls, I still have to figure out how to make \#ScienceGirls a sustainable program, and I can't like talk to my parents and say, "Mom, you know, I want to start this company, I want to make it a non-profit, what am I supposed to do?"

When Kyla discussed her childhood, she described the supportive community that looked out for one another, but also shared that the community lacked social capital needed for her to succeed. She reflected that, " There were no mentors" and "there was no people that were needed to really guide someone throughout a career."

Kyla had wanted to be a dentist and went to a four-year college to pursue her goal. She was struggling in her classes and explained that "I couldn't talk to my parents about it because what were they going to do for me? They didn't understand what I was going through, they couldn't really be of support, they didn't have any friends that were dentists." One of her most difficult realizations in college was that most of her classmates wanted to pursue dentistry "because they have a parent or an uncle that was already a dentist." I asked Kyla how she felt that the support she did or didn't receive throughout her life affected her career path and she replied, 
It slowed me down, I'm behind. I'm behind, so I'm playing catch-up right now, really fast. But my life would have been different if I had the support or what I needed, something -- had I had that like when I was in early to mid twenties. I would have made a huge difference, huge.

\section{Sula}

The six main themes of this study emerged for Sula, in addition to one other theme: Friends and family as a support (see Figure 7).

Friends and family as a support. Like Betty, Sula was fortunate to have a strong support network from both family and friends as she pursued her advanced technology education and career. Sula was aware of her good fortune and explained to me that her "family is extremely supportive" and that she is "really lucky to have them." Her father, who passed away suddenly when she was 19 years old, left a lasting impression on Sula's STEM identity. She still remembers that as a schoolgirl,

I remember doing sitting and doing my homework with him at the kitchen table and we'd be doing multiplication and I'd be like, "Multiply 58 times 72," and he'd answer it, I was blown away by that because it's like, "Whoa."

Sula's mother still serves a strong emotional anchor and support for her. Sula told me that no matter how hard it is at work, "I can always call my mother. If I'm really upset, I call my mom right away." When Sula returned to school in the ATE program, she shared that "My family was just overall genuinely happy." Sula also explained her strong core group 
of friends that may have shifted in the exact makeup of the people, but have always been there for her, "I think I have good friends that I can always lean on, that will listen to me if I'm having a hard day."

\section{Summary}

In doing this study, I wanted to better understand the supports and barriers to success for women ATE graduates. I began this research by considering the current explanations for the disparity of women ATE graduates. The mainstream narrative in the literature offered indications of the range of external and internal factors that may impact the woman ATE graduate.

In conducting the in-depth multi-interview process with each of these six participants, I gained insight into the experiences of success for women ATE graduates. The notion of STEM identity captures the ways in which the women harnessed a strong sense of identity with respect to science, technology, engineering, and math. The selfefficacy concept emerged as a barrier and a support for the women's path to success. In the face of a variety of adversities, the six women revealed a tremendous level of resilience that may have enabled them to endure the genderized and racially charged field of STEM careers.

The experiences of Nena, Roxanne, Kyla, Sula, Audra, and Betty bring life and voice to the many women ATE graduates. They also elucidate the factors that enabled and blocked their success. In the stories were their own individual selves as wives, 
mothers, daughters, managers, students and employees that are managing (un)becoming a woman, the double bind, self efficacy, STEM identity, patchwork of support and resilience. It was in these stories that hegemonic genderization and racialization of STEM fields emerged as significant challenges for women ATE graduates. Accordingly, it is in the complexities of these stories that understanding emerges to address which structural challenges contribute to the barriers for women in ATE and which supports for these women ATE graduates merit attention and implementation. 


\section{Chapter Five: Discussion and Recommendations}

This study examined the experiences of six women and was grounded in the research question, how do successful women graduates from Advanced Technological Education (ATE) Programs in community colleges describe barriers and supports to their success? The six women graduated from ATE programs within the last ten years and their discipline of advanced technology were varied: two of the women graduated from biotechnology-based ATE programs, one from an architectural technology, one from power plant technology, one from energy management, and one from industrial maintenance (see Table 2).

Overall findings revealed six coherent themes; three of which were internal factors: self-efficacy, STEM identity, and resilience and three of which were external factors: gender: (un)becoming a woman, race/ethnicity and gender: double bind, patchwork of support (see Figure 7). Each factor exists in a tension between being a support or barrier to the success of women ATE graduates; this tension is visually represented in the conceptual framework of this study (see Figure 1). Figure 8 demonstrates the main themes described as supports by the six women participants: selfefficacy, STEM identity, resilience, and patchwork of support (see Figure 8). In contrast, Figure 9 displays the two barriers to success described by the six women participants: (Un)becoming a woman and race/ethnicity and gender: the double bind (see Figure 9). 

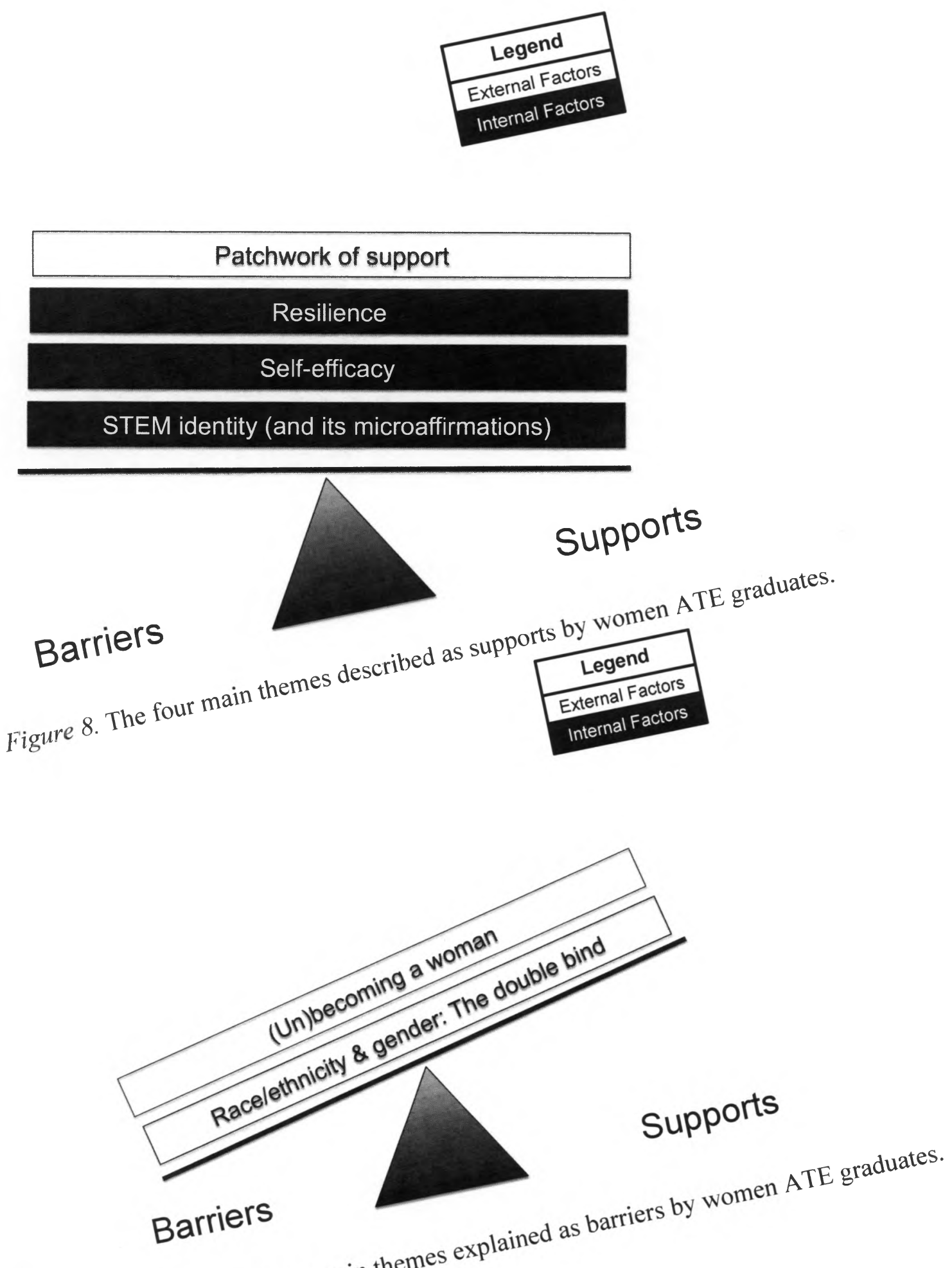

Figure 9. The two main themes explained as barriors by wo 
The women's characteristics revealed their individual complexities: four women were over the age of 30 , two of the women had children, and two self-identified as white, two as African-American, one as half-white, half African-American, and one as Mexican, (see Table 2 and Appendix $\mathrm{C}$ for more participant demographic information). The consistency of these findings across participants, as displayed in Figure 7, was notable particularly because of the participant differences in age, geographic location, ATE disciplines, and many more characteristics (see Table 2 and Appendix $\mathrm{C}$ for more participant demographic information).

In this final chapter, I consider the key findings within the context of this study's research question, the participants' stories, and current literature. In the first section, I evaluate how the results of this study confirm or extend current literature. In the second section, I offer key policy and practice recommendations based on the outcomes from this study. In the final section, I propose future directions for research to build on this current study and I conclude by providing an overall summary of the research study.

\section{Confirming and Extending Prior Research}

Three of this study's six main themes emerged and confirmed findings from prior research studies: 1) Self-efficacy, 2) Resilience, and 3) Race/ethnicity and gender: The double bind. The remaining three themes emerged to contribute new ways of thinking to the field, expanding upon current research: 1) STEM identity (and its accompanying 
STEM fluency and microaffirmations), 2) (Un)becoming a woman, and 3) Patchwork of support (and its accompanying resilience).

\section{(Un)becoming a Woman}

An individual's gender can be a barrier in male-dominated STEM fields (Grossman \& Porche, 2013; Moss-Racusin et al., 2012; Riegle-Crumb \& King, 2010) and four of the six women named genderized interactions and microaggressions (Solorzano et al., 2000; Steele, 2010) as barriers to their success. These four women's gender identities were in conflict with the male-dominated culture in the ATE programs and careers. To compensate, the participants had to (un)become women to blend in with their male counterparts by acting masculine. In explaining the tenuous relationship between her gender and her ATE career, Betty shared that in order to succeed in her advanced technology workplace, she needed to "have them [her male colleagues] understand that you're not that this delicate little piece of china."

The four women persevered by de-emphasizing their gender identity. For instance, as the first and only woman supervisor at her site, Sula described feeling the tension between (un)becoming a woman and becoming more masculine, "They've [her 30 male direct reports] told me that, some foreman in the past have told them, 'Shut the fuck up and get back to work.' I can't say that to someone!" The women strived to resist but ultimately felt they had to conform by (un)becoming women in order to work in their advanced technology discipline. 
Both of the women who de-emphasized the importance of gender as a barrier to their success work in biotechnology, a field well penetrated by women as compared to other ATE disciplines (Bayer Corporation, 2012; Bybee, 2013). However, these two participants also explained that race and ethnicity were a greater challenge than gender, which may mean that difficulties in these areas masked the challenges posed by issues of gender.

\section{Race/Ethnicity \& Gender: The Double Bind}

This study confirmed what previous research studies describe as the "double bind" for the four women of color in this study who faced the magnified combination of racism and sexism (Malcom et al., 1976, p. 1). In this study, the women were clear that their race/ethnicity caused a profound sense of "outsiderness" and lack of belonging in their STEM departments, confirming literature (Lorde, 2007). Being woman of color left an impression on the women that they did not belong and Sula explained, "I wasn't white like the white kids and I wasn't black like the black kids." Audra, who self-identifies as Mexican, explained that peers at her new college's orientation told her, "'Let me just tell you, you're going to stand out."'

This double bind was also described by the women as extra pressure that they, "Have to do more to be seen as equal." This invisible stress to over-perform was also manifested as pressure to be a positive model of their race/ethnicity; Nena shared, "You're kind of an example of what a person like a woman of color can be." 
The women shared that race and ethnicity amplified the discrimination and stereotypes they faced as a woman, citing that a man of color, "may have an easier time." All four women also had a strong sense of (un)belonging and shared that in their academic classes or workplaces, they had the experience of being the "only black person" and that "obviously there is racism [in her workplace]." Colleagues said to Nena who self-identifies as African-American, "Just add black...you know what I mean." Meanwhile, Sula explained her double bind in the context of her workplace: "it's hard for some guys [her 30 direct reports] to accept the fact that there's this young, black woman telling them what to do."

These feelings of "outsiderness" were coupled with what the women described as subtleties, "bias," and microaggressions (Bielby et al., 2014; Griffith, 2010; Lorde, 2007; Schuck, 2009). Kyla explains, "I'm the only one that probably sees this craziness because I'm the only one that doesn't look like them [her colleagues]." For the two self-identified white women participants in this study, they did not mention race/ethnicity in any context despite its emphasis for the other four study participants; this serves as evidence of their "white privilege" (Delpit, 2012, p. 7; Green \& Dantley, 2013; Riegle-Crumb \& King, 2010). For the four women of color, being at the intersection of race/ethnicity as well as gender was a core barrier to their success. While this study focused on gender, the intersectionality of multiple identities within ATE programs deserves further study. 


\section{STEM Identity (and its Accompanying STEM Fluency and Microaffirmations)}

All six women in this study maintained a strong "STEM identity," a construct I introduce as an extension of science identity (a concept defined by research studies as an iterative identity related to science in which there are high levels of science "competence; performance; and recognition”) (see Figure 7) (Carlone \& Johnson, 2007, p. 1190). STEM identity extends the concept of science identity from a singular identity to an allinclusive identity that encompasses the multiple disciplines of science, technology, engineering, and mathematics. The notion of STEM "fluency," clarifies that as STEM identity grows, the participants display a fluency in STEM, as if it were a language. I define the term "STEM fluency" as having an intimate relationship to STEM that is akin to language fluency. This "native" fluency in STEM extends the concept "digital natives" (Prensky, 2001, p. 1) and fluency is evidenced by a clear understanding of the vernacular and jargon within STEM disciplines, easily conversing on topics and ideas in a scientific manner, and effortlessly engaging in scientific thinking.

All six participants demonstrated this type of STEM fluency, particularly when describing their current job positions and responsibilities. For example, when Nena showed me (using the video conferencing camera) her technician equipment and explained to me her step by stop process of doing a home energy audit. She explained, "It was exciting to see how energy efficient it was and it's also exciting to crawl around on his floor and get grimy too." Audra's passion and fluency in STEM was evident when she 
described, "It's just really fun and interesting to kind of work with like mammalian cells and introduce chemotherapeutic drugs and incubate them and then check them out afterwards."

There was a generalized benefit that occurred when the women increased their fluency in STEM; the women participants explained that when they excelled in their advanced technology field, the success reverberated out to other STEM disciplines. For instance, Roxanne described that being in the ATE program made her have a strong identity in all fields of STEM, including math, which was a subject that had been a challenge for her in elementary school. Four of the women described shifting from a negative to a positive STEM identity, as Betty did when exposed to the contextualized nature of math in the ATE program. This study reveals the role of retrospection on how the women identify and describe their STEM identity shifting over time. These STEM identities also proved robust and flexible enough to withstand societal and structural barriers.

Women also described STEM identity when they had a strong identification with the principles of STEM and the scientific method. Five of the women described that there was no difference between themselves and a scientist; Roxanne shared, "It's [science is] more along the lines of like figuring things out, more mechanical I guess. Now that's kind of what I do [in her job]." These five participants described their jobs as "doing real STEM" that is relevant and connected to their every day lives. Nena explained, "I don't 
think it's [STEM] separate, I think it's a part of our lives all the time, it's just a matter of how much we chose to know about it or embrace it, or apply it." The only participant that didn't describe her current work as "doing science" was Audra, who is in a master's program in molecular biology and believes, "Technically, a scientist, you have to have your Ph.D."

Microaffirmations: Building blocks of STEM identity. Each of the women participants explained that microaffirmations helped to iteratively build their STEM identity. I explain "microaffirmations" as an extension of the concept of "microaggressions" (Solorzano et al., 2000, p. 61) (four of the six women participants explained experiencing gender and/or racial-based microaggressions) as a positive, "micro" expression of affirmations. I define the microaffirmations phenomenon as informal, casual, subtle encouragements, accomplishments, mini validations, barely visible, and at times, unintended that helped the women iteratively build a robust STEM identity. The microaffirmations can manifest in many direct, indirect, interpersonal or impersonal ways, such as accomplishing a small STEM-based task, homework assignment, work with a tool successfully to hang a picture frame. For instance, Roxanne explained a brief moment when she triumphed in her chemistry class experiment building a tower from PVC tubes. It was in these seemingly insignificant moments that helped the women gain the building blocks of their STEM identity, even in the face of adversity in a male dominated STEM culture. 
Instead of the women participants sharing how formal efforts by programs or organizations (as referenced in Chapter Two) helped support their success, the women shared that they gained support from the informal moments in the microaffirmations. These microaffirmations loomed larger for these women than did the formal efforts of college. It was the microaffirmations of STEM identity that helped the women to successfully transition their STEM identity from the classroom into a STEM-related workplace. The microaffirmations were a direct result from their patchwork of support (see next section) helped them manifest a strong STEM identity.

\section{Patchwork of Support (and its Accompanying Resilience)}

All six women in this study described the support they received as from an array of sources well beyond formal support structures such as academic counselors and professors. The resilience the six participants gained from their personal experiences such as traumatic childhoods, deaths of loved ones, and also prepared women to persevere despite a dearth of support in their personal lives for the STEM academic pursuits. It was in this resiliency that the women's deficit in support from friends and/or family was seen as an opportunity to gain support from nontraditional and informal sources. The resilience also ultimately led to the women having the positivity to grasp the positive microaffirmations and "micro" support out of experiences that otherwise might have been seen as challenging. The resilient women "patched" together an array of support in order to achieve success. 
This phenomenon is what I describe as the women creating a "patchwork of support," a concept that extends the notion of a "support network," defined by research studies as a network of as consistent, interconnected and overlapping supporters (Bligh, 1999; Schuck, 2009; Skahill, 2002). I define the patchwork of support as "fragments" or "patches" of support that are isolated but do support the women momentarily, (or occasionally, for a longer period of time) to move forward towards success. I also define support patchwork by the multitude of sources of support these women had to gain, perhaps because they didn't have support in their family or because there is a dearth of women (and women of color) mentors and role models in STEM.

These fragments of support were pivotal to the women's success and the women directly articulated this; from Kyla's supervisor allowing her to use the company vehicle to commute to her ATE internship, to Roxanne's high school teacher believing in her and "showing me the potential I didn't know I had," to Betty's ATE teacher meeting with her before class for conversations that ultimately prepared Betty "for the aspects of the maledominated career."

There were several crosscutting themes within the patchwork of support concept. First, the supporters often exceeded the expectations of traditional advising roles. Second, the supporters demonstrated a high level of caring. Finally, these supporters filled the women's voids in areas of growth and learning. Kyla described that her ATE professors "didn't just teach the science" they "also taught you the life skills that you needed." 
Audra remarked that instead of getting support from her family members, "I think it's the mentors that I have in my life that really allow me to get support."

\section{Recommendations for Policy and Practice}

In this section, I offer potential policy and practice implications based on the experiences of supports and barriers described by the women ATE graduates. The advantage of a phenomenological study such as this one is the concentration on the central phenomenon: the woman's experiences of supports and barriers to her success (Seidman, 2013). The following key recommendations focus on how we can progress forward to ultimately increase the number of successful women ATE graduates.

Since this study primarily focused on women in ATE programs and careers, the following recommendations are directed towards ATE programs. While these recommendations target ATE programs, they may have applications across other ATE partnerships such as secondary schools, four-year universities, local industries, and nonprofits. Also, whereas this study centered on gender, the women's other identities, such as sexuality or race/ethnicity, may contribute to their success and it could be important to consider how the following recommendations may extend to all of the women's

identities. Research on ATE programs in general is limited but burgeoning; this research study contributes research and helps close the gap in understanding.

\section{Recommendation \#1: Gender Sensitivity Training For ATE Students and Staff}

I recommend expanding gender sensitivity training modules for two target 
audiences within the ATE community: 1) ATE community college students and 2) ATE staff/professors. This two-prong approach to gender sensitive training is key to addressing this issue and increasing the success of women ATE graduates since four of this study's six women participants indicated that gender insensitive interactions affected their success.

There could be value for all members of the ATE community to engage in a dialogue around genderized constructs and interactions, since these microaggressions were so pervasive for the participants in this study. Both the staff and student training modules could foster a setting for discourse around gender microaggressions, labels and stereotypes. The goal of these trainings would be to diminish these gender-based interactions, which is especially important since four of the women participants felt they had to (un)become women in order to incorporate themselves into the ATE programs and/or ATE workplaces.

For ATE community college students, I recommend establishing a required gender sensitivity and equity module for all ATE students (men and women). It is important that the learning module is contextualized into ATE education and integrated as part of an introductory ATE course because this signifies the importance of gender equity to the program. In the gender sensitivity training approach for ATE staff, I recommend expanding the offerings of professional development on gender sensitivity and equity. This is already occurring in many ATE programs, such as professional 
development and proven practices by the Institute for Women in Trades, Technology \& Sciences (Maricopa Community College, 2014; Milgram, 2013). It is important that these gender sensitivity trainings are acknowledged by the community college institution as a critical aspect of professional development. As this study shows, microaffirmations from ATE faculty and staff support women's' STEM Identity. This professional development module for ATE staff must explain that women can be supported by microaffirmations that boost and build their STEM identity. Also, as the findings from this study suggest, it could be highly useful to also include culturally sensitive training modules simultaneously.

\section{Recommendation 2: Implement Strategies to Increase Women's Success in ATE}

In order to increase women's success in ATE programs and beyond, I recommend streamlining programmatic and organizational efforts towards factors identified by this study. First, I suggest setting up a structure to scaffold a strong, support network with continuity, a contrast to the patchwork of supported that women in this study had to piece together to garner support.

Specifically, ATE programs could pair each student in ATE with a "success coach" to support them throughout the stages of the ATE program. This study confirms the efficacy of even micro-supports have tangible positive effects on women's STEM identity (Holmegaard et al., 2014; Malone \& Barabino, 2009). In an effort to provide an array of support sources, I suggest that ATE programs implement structured opportunities 
to affirm and build their STEM identity. The scope and processes of these opportunities can be shaped around the idea of developing their fluency in STEM terminology and the scientific process, and "micro" and "macro" opportunities do hands-on, authentic STEM projects and presentations and assert their STEM capacity.

This research has several potential implications for practitioners including opportunities to create programmatic and institutional environments to support women in ATE programs and careers. Both of the above recommendations could also incorporate a cultural focus to include strategies to support women of color, of different socioeconomic status, ages, and more. The above recommendations also have relevance for ATE partners and it could be important to invite ATE partners to trainings, discussions, and events. In order for all ATE partners and students to increase the number and success of women ATE graduates, it is important for future research to continue research on this topic.

\section{Recommendations for Future Research}

The results of this study offer a greater understanding of how women ATE graduates experience supports and barriers to their success. However, due to the complexities of the reasons for women's success in ATE, it is important to conduct further research until we have a solid foundational understanding of women's success dynamics. To date, there have been limited studies on ATE in community colleges (Badway et al., 2010; Smith et al., 2013, 2014). Efforts must continue to close 
knowledge gaps in ATE and the disparity of women ATE graduates. In this section, I consider the questions raised by this study and suggest directions for future study.

\section{Future Research Direction \#1: More Research on Women in ATE Overall}

The disparity of women ATE graduates is a central equity issue and it is important to increase understanding of women ATE students and graduates in general. While the present study examined self-reported supports and barriers of six women graduates from six different ATE programs across the United States, follow-up studies could consider both increase the breadth and depth of the participant sample. For instance, future research could complement this study by applying qualitative methodologies to understand the experiences of women across all eight ATE disciplines. In that way, future research could examine differences in women's experiences that might exist amongst and between technological fields. This is important to understand because there may be discipline-specific considerations needed to support women. Alternatively, there may be ATE-wide programmatic aspects that could be implemented to support women across all ATE fields. Also, based on the experiences of the two women in this study stating that gender was less of a barrier to their success, future studies should compare experiences of women ATE biotechnology graduates with a group of women in a male dominated ATE field, such as car manufacturing. Ultimately, by increasing the sample size to include more women in all ATE disciplines, there will be greater understanding of the factors 
affecting women ATE graduates. Closing this knowledge gap will inform policies and practices in ATE programs, a vital STEM initiative in community colleges.

Since this study was retrospective in its approach, it would also be important to do research studies on women students in ATE programs, women ATE professors/staff, and women graduates who are working in ATE fields. This would be important to understand if and how the support and barriers to women's success in ATE programs differs from success in ATE careers, and could elucidate promising practices for how to support women in different settings. Future studies could also broaden the sample size to include men in ATE. This could provide key insights into how men view gender as a construct, women peers, the ATE culture, and how men describe supports and barriers to success.

It is critical that we learn more about women (and men) in ATE programs, since these programs are in STEM fields critical to national and economic security (Brandt, 2014; Henderson et al., 2011; Levin \& Kater, 2012; Maricopa Community College, 2014; Patton \& Internet Scout Research Group, 2013). Furthermore, ATE programs offer women (and all students) a pathway toward upward mobility, job stability, and civic engagement (Donovan, Mateos, Osborne, \& Bisaccio, 2014; Maricopa Community College, 2014; Smith et al., 2014)

\section{Future Research Direction \#2: Longitudinal Research on Women ATE Graduates}

The current study's phenomenological approach was both an asset and an opportunity for delving deeper into this research. For example, the life history approach 
in this study offers data about ATE programs and careers and thus informs numerous avenues for further research. A follow up to this study might be to interview successful women graduates at various time points in their career, such as five, ten and 15 years after ATE graduation. These interviews could be focused around how and if their success in ATE led to career success and if any factors were similar or dissimilar to the barriers or supports they faced in ATE programs. Long-term studies such as this could increase understanding between the intersection of gender, ATE programs and ATE career experiences. The present research study offers a jumping off point for the focus of longer-term studies.

\section{Future Research Direction \#3: Employ a Mixed-Methods Approach}

Setting up a mixed-methods could help increase the understanding of the ATE program gender gap and inform action steps to increasing gender equity. The current study utilized an in-depth multi-interview methodology in order to discover key phenomena identified by participants and a mixed-methods study could complement these findings and offer a range of quantitative data to offer voices and narratives to pair with the statistics.

A key area of follow up research would be to investigate the role of personal identities such as race/ethnicity, sexuality, age, or socio-economic status, in women's success in ATE; in the present study, one or more of these factors beyond gender appeared to intensify the women's experience in ATE. Specifically, as raised by four of 
the six women participants in this study, women of color faced extra pressure to perform, a consequence of the "double bind." Researching all of women's identities, not just gender, will contribute to our understanding of women's experiences in ATE. Ultimately, these follow-up studies would enable investigation of the intersectionality of gender and women's identities such as religious, racial/ethnicity, and how these impact women's success in ATE.

ATE programs across the United States already collect data on the number of women and men entering and graduating from ATE programs (see Table 1). One key way to expand these data collection practices could be to collect data on all identifying characteristics of women (and men) in ATE. Based on the findings of this study, these characteristics could include how many are women of color, their ages, how many women have kids, spirituality, other academic degrees, etcetera. The equity of ATE programs rests on the ability to collect accurate data to understand past, current, and future progress towards gender (and cultural and sexuality) equity and increasing the success and numbers of women ATE graduates. It is important to increase the breadth and depth of ATE data to increase the number of women entering, persisting, and graduating from ATE programs and to inform policy and practice.

\section{Conclusion}

The results from this study are significant because of the dearth of research on women graduates from community college programs funded by the National science 
Foundation in Advanced Technological Education division(ATE Centers, 2013; Maltese, Potvin, \& Florin, 2014; National Science Foundation, 2006; Patton, 2011; Westine et al., 2010). ATE is a STEM program that serves to train technicians in cutting edge advanced technology disciplines such as power plant technology and nanotechnology (ATE Centers, 2013; Patton, 2011). Since only 26 percent of Ate graduates are women (Westine et al., 2010), this study focused on women's responses and reactions to the ATE programs. As described in limitations section in Chapter Three, this study does not conflate ATE programs with all STEM programs in community colleges, although overlap may exist. This research study broadens understanding of women's ATE experience and informs the development of supports for women in ATE community college programs.

The six women participants were resilient in piecing together microaffirmations to build a patchwork of support and a strong STEM identity. However, microaffirmations are difficult to institutionalize. The fact that these self-created systems of support were "good enough" to support the participants' success in ATE is also an indictment of a system in which women participants are still not fully supported at institutional, programmatic, and societal levels.

These suggestions for future research directions offer initial directions for followup studies to closely investigate ATE community college programs and workplaces. Collectively, these future research areas and policy and practical recommendations offer 
insight and increased understanding of the supports and barriers of women in ATE. The disparity of women in ATE, and STEM generally, is a key equity issue and it is important to develop understanding in order to move the needle forward and increase the rates of successful women ATE graduates. As we compile more research on the supports and barriers for women in ATE, we can better understand how to support women in being successful in ATE programs and careers. Studies such as this one contribute more data towards understanding the complexities of this issue.

Since this research focused on experiences of successful women in STEM education, this study provides key implications the field. Since few studies have examined the ATE, or even the STEM-based, gender achievement gap through a successbased approach, rather than a deficit-based approach, further studies in postsecondary settings will be important to supplement the results of this study. In examining the experiences of successful women in ATE education and the meaning of these experiences, I illuminated ways in which internal and external factors serve as supports or barriers to women's success. Based on these implications, a key contribution of this work is that if some women succeed in ATE education, how can we better support all women through ATE education (as well as men)? This research informs the work of scholars and practitioners with meaningful practical, policy, and research-based ways to support the success of women in ATE. 


\section{References}

Allison, C. J., \& Cossette, I. (2007). Theory and practice in recruiting women for STEM careers. Women in Engineering ProActive Network.

Archer, L., DeWitt, J., Osborne, J., Dillon, J., Willis, B., \& Wong, B. (2012). “Balancing acts:" Elementary school girls' negotiations of femininity, achievement, and science. Science Education, 96(6), 967-989.

ATE Centers. (2013). About ATE. Retrieved July 31, 2012, from http://atecenters.org/about/

Badway, N. N., Bell, D., \& Grubb, W. N. (2003). Community colleges and the equity agenda: The potential of noncredit education. Annals of the American Academy of Political and Social Science, 586, 218-240.

Badway, N. N., Somerville, J. A., \& Anderegg, B. (2010). The most important information needs for advanced technological education: A delphi study of the opinions of project directors, center directors, and others. Manuscript in Preparation for the National Science Foundation.

Bailey, T. R., Matsuzuka, Y., Jacobs, J., Morest, V. S., \& Hughes, K. L. (2003). Institutionalization and sustainability of the national science foundation's advanced technological education program.

Bandura, A. (1997). Self-efficacy: The exercise of control. New York: Freeman. 
Barone, C. (2011). Some things never change: Gender segregation in higher education across eight nations and three decades. Sociology of Education, 84(2), 157-176.

Bayer Corporation. (2012). STEM education, science literacy and the innovation workforce in America: Analysis and insights from the Bayer facts of science education surveys 1995-2011.

Bekelman, J. E., \& Hahn, S. M. (2013). The body of evidence for advanced technology in radiation oncology. Journal of the National Cancer Institute, 105(1), 6-7.

Beltman, S., \& Schaeben, M. (2012). Institution-wide peer mentoring: Benefits for mentors. The International Journal of the First Year in Higher Education, 3(2), $33-44$.

Benbow, C. P., Lubinski, D., Shea, D. L., \& Eftekhari-Sanjani, H. (2000). Sex differences in mathematical reasoning ability at age 13: Their status 20 years later. Psychological Science, 11(6), 474-480.

Berg, B. L. (2007). Qualitative research methods for the social sciences. Boston, MA: Pearson/Allyn \& Bacon.

Bettinger, E. P., \& Long, B. T. (2005). Do faculty serve as role models? The impact of instructor gender on female students. American Economic Review, 95(2), 152 157. 
Betz, D. E., \& Sekaquaptewa, D. (2012). My fair physicist? Feminine math and science role models demotivate young girls. Social Psychological and Personality Science, 3(6), 738-746.

Bielby, R., Posselt, J. R., Jaquette, O., \& Bastedo, M. N. (2014). Why are women underrepresented in elite colleges and universities? A non-linear decomposition analysis. Research in Higher Education, 55(8), 735-760.

Blickenstaff, J. C. (2005). Women and science careers: Leaky pipeline or gender filter? Gender and Education, 17(4), 369-386.

Bligh, J. (1999). Mentoring: an invisible support network. Medical Education, 33(1), 2.

Bogdan, R., \& Biklen, S. K. (2006). Qualitative research for education: An introduction to theories and methods (5th ed.). Boston, MA: Allyn \& Bacon.

Bogdan, R., \& Biklen, S. K. (2007). Data analysis and interpretation. In Qualitative research for education: An introduction to theories and methods (5th ed., pp. 159-197). New York, NY: Pearson.

Bold, C. (2012). Using narrative in research. London, UK: Sage.

Boydell, K. M., Volpe, T., \& Pignatiello, A. (2010). A qualitative study of young people's perspectives on receiving psychiatric services via televideo. Journal of the Canadian Academy of Child and Adolescent Psychiatry, 19(1), 5.

Brandt, R. (2014). Why do undergraduate women persist as STEM majors? A study at two technological universities. 
Brown, S., \& Burnham, J. (2012). Engineering student's mathematics self-efficacy development in a freshmen engineering mathematics course. International Journal of Engineering Education, 28(1).

Buday, S. K., Stake, J. E., \& Peterson, Z. D. (2012). Gender and the choice of a science career: The impact of social support and possible selves. Sex Roles, 66(3-4), 197209.

Bybee, R. W. (2013). The case for STEM education: Challenges and opportunities. National Science Teachers Association.

Calabrese Barton, A., Kang, H., Tan, E., O’Neill, T. B., Bautista-Guerra, J., \& Brecklin, C. (2013). Crafting a future in science: Tracing middle school girls' identity work over time and space. American Educational Research Journal, 50(1), 37-75.

Cannady, M. A., Greenwald, E., \& Harris, K. N. (2014). Problematizing the STEM pipeline metaphor: Is the STEM pipeline metaphor serving our students and the STEM workforce? Science Education, 98(3), 443-460.

Carlone, H. B., \& Johnson, A. (2007). Understanding the science experiences of successful women of color: Science identity as an analytic lens. Journal of Research in Science Teaching, 44(8), 1187-1218.

Carlone, H. B., Scott, C. M., \& Lowder, C. (2014). Becoming (less) scientific: A longitudinal study of students' identity work from elementary to middle school science. Journal of Research in Science Teaching, 51(7), 836-869. 
Carnevale, A. P. (2000). Community colleges and career qualifications (p. 18). W.K. Kellogg Foundation.

Ceci, S. J., \& Williams, W. M. (2011). Understanding current causes of women's underrepresentation in science. Proceedings of the National Academy of Sciences.

Ceci, S. J., Williams, W. M., \& Barnett, S. M. (2009). Women's underrepresentation in science: Sociocultural and biological considerations. Psychological Bulletin, $135(2), 218$.

Clandinin, D. J., \& Connelly, F. M. (2000). Narrative inquiry. New York, N.Y.: JosseyBass.

Coda Zabetta, E., Barisic, V., Peltola, K., Sarkki, J., \& Jantti, T. (2013). Advanced technology to co-fire large shares of agricultural residues with biomass in utility CFBs. Fuel Processing Technology, 105, 2-10.

Collins, P. H. (2000). Black feminist thought (2nd ed.). New York, N.Y.: Routeledge.

Costello, C. B. (2012). Increasing opportunities for low-income women and student parents in science, technology, engineering and math. Washington, DC: Institute for Women's Policy Research.

Creswell, J. W. (1998). Qualitative inquiry and research design: Choosing among five traditions. Thousand Oaks, CA: Sage Publications Inc.

Creswell, J. W. (2009). Research design. Los Angeles, CA: Sage Publications, Inc. 
Cullingford, C. (2012). Mentoring in education: An international perspective. Ashgate Publishing, Ltd.

Cundiff, J. L., Vescio, T. K., Loken, E., \& Lo, L. (2013). Do gender-science stereotypes predict science identification and science career aspirations among undergraduate science majors? Social Psychology of Education, 16(4), 541-554.

Dalton, B., Ingles, S. J., Downing, J., \& Bozick, R. (2007). Advanced mathematics and science coursetaking in the spring high school senior classes of 1982, 1992, and 2004. Washington, D.C.: U.S. Department of Education, National Center for Education Statistics.

Darling-Hammond, L. (2010). The flat world and education: How America's commitment to equity will determine our future. New York, NY: Teachers College Press.

Deakin, H., \& Wakefield, K. (2014). Skype interviewing: Reflections of two PhD researchers. Qualitative Research, 14(5), 603-616.

Delpit, L. D. (2012). “Multiplication is for white people:" Raising expectations for other people's children. New York, NY: New Press.

Deutsch, F. M. (2007). Undoing gender. Gender \& Society, 21(1), 106-127.

De Weck, O., Reed, D., Sarma, S., \& Schmidt, M. (2014). Nine trends in advanced manufacturing technology innovation. Production in the Innovation Economy, 235. 
Domosh, M., \& Bondi, L. (2014). Remembering the making of gender, place and culture. Gender, Place \& Culture, 21(9), 1063-1070.

Donovan, B. M., Mateos, D. M., Osborne, J. F., \& Bisaccio, D. J. (2014). Revising the economic imperative for U.S. STEM education. PLoS Biology, 12(1), e1001760.

Duckworth, A., \& Gross, J. J. (2014). Self-control and grit: Related but separable determinants of success. Current Directions in Psychological Science (Sage Publications Inc.), 23(5), 319-325.

Duckworth, A., Peterson, C., Matthews, M. D., \& Kelly, D. R. (2007). Grit: Perseverance and passion for long-term goals. Journal of Personality and Social Psychology, 92(6), 1087.

Ervin, S. M. (2014). Lean in: Women, work, and the will to lead. Gender in Management: An International Journal, 29(3), 190-192.

Espinosa, L. L. (2011). Pipelines and pathways: Women of color in undergraduate STEM majors and the college experiences that contribute to persistence. Harvard Educational Review, 81(2), 209-240.

Evans, K. E., \& Demuth, K. (2012). Individual differences in pronoun reversal: Evidence from two longitudinal case studies. Journal of Child Language, 39(01), 162-191.

Fletcher, D., \& Sarkar, M. (2013). Psychological resilience: A review and critique of definitions, concepts, and theory. European Psychologist, 18(1), 12. 
Fryer, R. G., Jr., \& Levitt, S. D. (2009). An empirical analysis of the gender gap in mathematics. National Bureau of Economic Research Working Paper Series, 15430.

Garibay, J. (2012). Achieving equity within and beyond STEM: Toward a new generation of scholarship in STEM education. In R. T. Palmer, D. C. Maramba, \& M. Gasman (Eds.), Fostering success of ethnic and racial minorities in STEM: The role of minority serving institutions (pp. 209-220). New York: Routeledge.

Garza, K. K., Bain, S. F., \& Kupczynski, L. (2014). Resiliency, self-efficacy, and persistence of college seniors in higher education. Research in Higher Education.

Giroux, H. A. (1996). Counternarratives: Cultural studies and critical pedagogies in postmodern spaces. Psychology Press.

Glassmeyer, D. M., \& Dibbs, R.-A. (2012). Researching from a distance: Using live web conferencing to mediate data collection. International Journal of Qualitative Methods, 11(3), 292-302.

Goldstein, S., \& Brooks, R. B. (2012). Handbook of resilience in children. Springer Science \& Business Media.

Grandgenett, N., Ostler, E., Jeanetta, J., \& Surface, J. (2010). Evaluating a four state workforce education project: Questions of investigative interest and impact. Online Journal for Workforce Education and Development, 2(4). 
Green, T. L., \& Dantley, M. E. (2013). The great white hope? Examining the white privilege and epistemology of an urban high school principal. Journal of Cases in Educational Leadership, 16(2), 82-92. http://doi.org/10.1177/1555458913487038

Griffith, A. L. (2010). Persistence of women and minorities in STEM field majors: Is it the school that matters? Economics of Education Review, 29(6), 911-922.

Grossman, J. M., \& Porche, M. V. (2013). Perceived gender and racial/ethnic barriers to STEM success. Urban Education, 47(2), 123-8.

Grubb, N. (2013). Basic skills education in community colleges: Inside and outside of classrooms. New York, NY: Routledge.

Guertin, L. (2015). Sharing my experience as a woman in STEM: Pass it on. Women in Higher Education, 24(2), 5-19.

Hagedorn, L. S., \& Purnamasari, A. V. (2012). A realistic look at STEM and the role of community colleges. Community College Review, 40(2), 145-164.

Haney, W., Russell, M., Gulek, C., \& Fierros, E. (1998). Drawing on education: Using student drawings to promote middle school improvement. Schools in the Middle, $7(3), 38-43$.

Hanna, P. (2012). Using internet technologies (such as Skype) as a research medium: A research note. Qualitative Research, 12(2), 239-242.

Henderson, C., Fynewever, H., Petcovic, H., \& Bierema, A. (2011). Identifying the impact of ATE centers on their home institutions: An exploratory study. 
Hill, C., Corbett, C., \& St. Rose, A. (2010). Why so few? Women in science, technology, engineering, and mathematics. American Association of University Women.

Hoffman, E., Starobin, S. S., Laanan, F. S., \& Rivera, M. (2010). Role of community colleges in STEM education: Thoughts on implications for policy, practice, and future research. Journal of Women and Minorities in Science and Engineering, $16(1)$

Holland, J. L. (1997). Making vocational choices: a theory of vocational personalities and work environments. New York: Prentice-Hall.

Holmegaard, H. T., Madsen, L. M., \& Ulriksen, L. (2014). To choose or not to choose science: Constructions of desirable identities among young people considering a STEM higher education programme. International Journal of Science Education, $36(2), 186-215$.

Hunter, A.-B., Laursen, S. L., \& Seymour, E. (2007). Becoming a scientist: The role of undergraduate research in students' cognitive, personal, and professional development. Science Education, 91(1), 36-74.

Hyde, J. S., Lindberg, S. M., Linn, M. C., Ellis, A. B., \& Williams, C. C. (2008). Gender similarities characterize math performance. Science, 321(5888), 494-495.

Jackson, K. M., \& Suizzo, M.-A. (2015). Sparking an interest: A qualitative study of Latina science identity development. 
Janghorban, R., Roudsari, R. L., \& Taghipour, A. (2014). Skype interviewing: The new generation of online synchronous interview in qualitative research. International Journal of Qualitative Studies on Health and Well-Being, 9.

Johnson, A., Brown, J., Carlone, H., \& Cuevas, A. K. (2011). Authoring identity amidst the treacherous terrain of science: A multiracial feminist examination of the journeys of three women of color in science. Journal of Research in Science Teaching, 48(4), 339-366.

Kanny, M. A., Sax, L. J., \& Riggers-Piehl, T. A. (2014). Investigating forty years of STEM research: How explanations for the gender gap have evolved over time. Journal of Women and Minorities in Science and Engineering, 20(2).

Kern, M. C., Lee, S., Aytug, Z. G., \& Brett, J. M. (2012). Bridging social distance in inter-cultural negotiations:"You" and the bi-cultural negotiator. International Journal of Conflict Management, 23(2), 173-191.

Kessel, C., Poli, F., Ghantous, K., Gorelenkov, N., Rensink, M., Rognlien, T., ... Turnbull, A. (2013). The physics basis for an advanced physics and advanced technology tokamak power plant configuration, ARIES-ACT1. Submitted to Fusion Sci. Tech.

King, N., \& Horrocks, C. (2010). Interviews in qualitative research. Sage.

Kumtepe, A. T., \& Genc-Kumtepe, E. (2013). STEM in early childhood education: We talk the talk. Transforming K-12 Classrooms with Digital Technology, 140. 
Levin, J. S., \& Kater, S. T. (2012). Understanding community colleges. New York, N.Y.: Routledge.

Locke, R. M., \& Wellhausen, R. L. (2014). Production in the innovation economy. MIT Press.

Loo, C., \& Choy, J. (2013). Sources of self-efficacy influencing academic performance of engineering students. American Journal of Educational Research, 1(3), 86-92.

Lorde, A. (2007). Sister outsider: Essays and speeches. Freedom, CA: Crossing Press.

Mahone, E. M., Bruch, M. A., \& Heimberg, R. G. (1993). Focus of attention and social anxiety: The role of negative self-thoughts and perceived positive attributes of the other. Cognitive Therapy and Research, 17(3), 209-224.

Malcom, S. M., Hall, P. Q., \& Brown, J. W. (1976). The double bind: The price of being a minority woman in science. American Association for the Advancement of Science Washington, DC.

Malone, K. R., \& Barabino, G. (2009). Narrations of race in STEM research settings: Identity formation and its discontents. Science Education, 93(3), 485-510.

Maltese, A. V., Potvin, G., \& Florin, D. (2014). 7 STEM and STEM education in the United States. The Age of STEM: Educational Policy and Practice across the World in Science, Technology, Engineering and Mathematics. 
Maltese, A. V., \& Tai, R. H. (2011). Pipeline persistence: Examining the association of educational experiences with earned degrees in STEM among U.S. students. Science Education, 95(5), 877-907.

Mansfield, K. C., Welton, A. D., \& Grogan, M. (2014). "Truth or consequences": a feminist critical policy analysis of the STEM crisis. International Journal of Qualitative Studies in Education, 27(9).

Maricopa Community College. (2014). ATE Projects Impact Report. Tempe, AZ.

Marra, R. M., Rodgers, K. A., Shen, D., \& Bogue, B. (2009). Women engineering students and self-efficacy: A multi-year, multi-institution study of women engineering student self- efficacy. Journal of Engineering Education, 98(1), 2738.

Masten, A. S. (2014). Global perspectives on resilience in children and youth. Child Development, 85(1), 6-20.

Maxwell, J. A. (2005). Qualitative research design (2nd ed., Vol. 41). Thousand Oaks, CA: Sage Publications, Inc.

McClelland, S. I., \& Holland, K. J. (2014). You, me, or her leaders' perceptions of responsibility for increasing gender diversity in STEM departments. Psychology of Women Quarterly, 0361684314537997.

McKinsey \& Company. (2009). The economic impact of the achievement gap in America's schools. New York, NY: McKinsey \& Company. 
Milgram, D. (2013). Analysis exclusive: Forming the complete picture. International Innovation, 102-105.

Miller, K., Gault, B., \& Thorman, A. (2011). Improving childcare access to promote postsecondary success among low-income parents. Washington, D.C.: Institute for Women's Policy Research.

Moss-Racusin, C. A., Dovidio, J. F., Brescoll, V. L., Graham, M. J., \& Handelsman, J. (2012). Science faculty's subtle gender biases favor male students. Proceedings of the National Academy of Sciences, 109(41), 16474-16479.

Moustakas, C. (1994). Phenomenological research methods. Thousand Oaks, CA: Sage Publications Inc.

National Science Foundation. (2001). Program Solicitation NSF 01-52 (p. 26). Washington, D.C.: National Science Foundation.

National Science Foundation. (2006). Investing in America's future: Strategic plan FY 2006-11. Retrieved from http://nsf.gov/pubs/2006/nsf0648/nsf0648.jsp

National Science Foundation. (2012). Program Solicitation NSF 11-692 (p. 16). Washington, D.C.: National Science Foundation.

Oakes, J. (1990). Opportunities, achievement and choice: Women and minority students in science and mathematics. Review of Research in Education, 16, 153-222.

Ong, M., Wright, C., Espinosa, L., \& Orfield, G. (2011). Inside the double bind: A synthesis of empirical research on undergraduate and graduate women of color in 
science, technology, engineering, and mathematics. Harvard Educational Review, 81(2), 172-209.

Packard, B. W.-L., Gagnon, J. L., LaBelle, O., Jeffers, K., \& Lynn, E. (2011). Women's experiences in the STEM community college transfer pathway. Journal of Women and Minorities in Science and Engineering, 17(2).

Patton, M. (2011). ATE Projects Impact Report. Washington, DC: American Association of Community Colleges.

Patton, M., \& Internet Scout Research Group. (2013). ATE@20: Two Decades of Advancing Technological Education (p. 60). Madison, WI: National Science Foundation.

Penner, A. M., \& Paret, M. (2008). Gender differences in mathematics achievement: Exploring the early grades and the extremes. Social Science Research, 37(1), 239 $-253$.

Perkins-Gough, D., \& Duckworth, A. L. (2013). The Significance of GRIT. Educational Leadership, 71(1), 14-20.

Picho, K., \& Brown, S. W. (2011). Can stereotype threat be measured? A validation of the social identities and attitudes scale (SIAS). Journal of Advanced Academics, 22(3), 374-411.

Popper, K. (1959). The logic of scientific discovery. New York, N.Y.: Basic Books.

Prensky, M. (2001). Digital natives, digital immigrants part 1. On the Horizon, 9(5), 1-6. 
President's Council of Advisors on Science and Technology. (2012). Engage to excel:

Producing one million additional college graduates with degrees in science, technology, engineering, and mathematics (p. 103). Washington, D.C.: Executive Office to the President.

Ramsey, L., Betz, D., \& Sekaquaptewa, D. (2013). The effects of an academic environment intervention on science identification among women in STEM. Social Psychology of Education, 1-21.

Redlich-Amirav, D., \& Higginbottom, G. (2014). New emerging technologies in qualitative research. Qualitative Report, 19(26).

Reyes, M.-E. (2011). Unique challenges for women of color in STEM transferring from community colleges to universities. Harvard Educational Review, 81(2), 241263.

Riegle-Crumb, C., King, B., Grodsky, E., \& Muller, C. (2012). The more things change, the more they stay the same? Prior achievement fails to explain gender inequality in entry into STEM college majors over time. American Educational Research Journal, 49(6), 1048-1073.

Riegle-Crumb, \& King, B. (2010). Questioning a white male advantage in STEM examining disparities in college major by gender and race/ethnicity. Educational Researcher, 39(9), 656-664. 
Risman, B. J. (2009). From doing to undoing: Gender as we know it. Gender and Society, $81-84$.

Robelen, E. W. (2012). Gender gaps persist in STEM education. Education Week, 31(35), $17-19$.

Rosenthal, L., Levy, S., London, B., Lobel, M., \& Bazile, C. (2013). In pursuit of the MD: The impact of role models, identity compatibility, and belonging among undergraduate women. Sex Roles, 68(7-8), 464-473.

Rosenthal, L., London, B., Levy, S. R., \& Lobel, M. (2011). The roles of perceived identity compatibility and social support for women in a single-sex STEM program at a co-educational university. Sex Roles, 65(9-10), 725-736.

Saldaña, J. (2013). The coding manual for qualitative researchers (2nd ed). Los Angeles: SAGE.

Sarangee, K. R., \& Echambadi, R. (2014). Firm-specific determinants of product line technology strategies in high technology markets. Strategic Entrepreneurship Journal, 8(2), 149-166.

Scholer, A. M. (1998). Issues of gender and personal life for women in academic biology. Journal of Women and Minorities in Science and Engineering, 4, 69-89.

Schuck, S. (2009). Getting help from the outside: Developing a support network for beginning teachers. The Journal of Educational Enquiry, 4(1). 
Seidman, I. (2006). Interviewing as qualitative research: A guide for researchers in education and the social sciences. New York, NY: Teachers College Press.

Seidman, I. (2013). Interviewing as qualitative research: A guide for researchers in education and the social sciences (Fourth). New York, NY: Teachers College Press.

Seymour, E., \& Hewitt, N. (1997). Talking about leaving. Boulder, CO: Westview Press. Shapiro, J. R., \& Williams, A. M. (2012). The role of stereotype threats in undermining girls' and women's performance and interest in STEM fields. Sex Roles, 66, 175183.

Silverman, D. (2009). Doing qualitative research (Third Edition). Thousand Oaks, CA: SAGE Publications Inc.

Skahill, M. P. (2002). The role of social support network in college persistence among freshman students. Journal of College Student Retention: Research, Theory and Practice, 4(1), 39-52.

Smith, C., Wingate, L., \& Gullickson, A. (2013). Advanced Technological Education Survey 2013 Fact Sheet. Western Michigan University: EvaluATE Evaluation Resource Center. Retrieved from http://evaluate.org/featured_resources/resources/ate_survey_2013_fact_sheet/

Smith, C., Wingate, L., \& Gullickson, A. (2014). Advanced Technological Education Survey 2014 Fact Sheet. Western Michigan University: EvaluATE Evaluation 
Resource Center. Retrieved from http://evaluate.net/downloads/2014\%20Fact\%20Sheet.pdf

Solorzano, D., Ceja, M., \& Yosso, T. (2000). Critical race theory, racial microaggressions, and campus racial climate: The experiences of African American college students. Journal of Negro Education, 60-73.

Spencer, S. J., Steele, C. M., \& Quinn, D. M. (1999). Stereotype threat and women's math performance. Journal of Experimental Social Psychology, 35(1), 4-28.

Starks, H., \& Trinidad, S. B. (2007). Choose your method: A comparison of phenomenology, discourse analysis, and grounded theory. Qualitative Health Research, 17(10), 1372-1380.

Starobin, S. S., Chen, Y. “April,” Kollasch, A., Baul, T., \& Laanan, F. S. (2014). The effects of a pre-engineering project-based learning curriculum on self-efficacy among community college students. Community College Journal of Research and Practice, 38(2-3), 131-143.

Starobin, S. S., \& Laanan, F. S. (2008). Broadening female participation in science, technology, engineering, and mathematics: Experiences at community colleges. New Directions for Community Colleges, 2008(142), 37-46.

Steele. (1997). A threat in the air: How stereotypes shape intellectual identity and performance. American Psychologist, 52(6), 613. 
Steele, C. (2010). Whistling Vivaldi: And other clues to how stereotypes affect us. New York, NY: W.W. Norton.

Stemler, S., \& Bebell, D. (1999). An empirical approach to understanding and analyzing the mission statements of selected educational institutions.

Sullivan, J. R. (2013). Skype: An appropriate method of data collection for qualitative interviews? The Hilltop Review, 6(1), 10.

Tai, R. H., Christine Qi Liu, Maltese, A. V., \& Fan, X. (2006). Planning early for careers in science. Science, 312(5777), 1143-1144.

Tan, E., \& Barton, A. (2008). Unpacking science for all through the lens of identities-inpractice: The stories of Amelia and Ginny. Cultural Studies of Science Education, $3(1), 43-71$.

Thompson, J. J., \& Windschitl, M. (2005). "Failing girls:” Understanding connections among identity negotiation, personal relevance, and engagement in science learning from underachieving girls. Journal of Women and Minorities in Science and Engineering, 11(1), 1-26.

Tolley, K. (2014). The science education of American girls: A historical perspective. Routledge.

Tough, P. (2012). How children succeed: Grit, curiosity, and the hidden power of character. New York, NY: Houghton Mifflin Harcourt. 
Trujillo, G., \& Tanner, K. D. (2014). Considering the role of affect in learning:

Monitoring students' self-efficacy, sense of belonging, and science identity. $C B E$ Life Sciences Education, 13(1), 6-15.

Tsapogas, J. (2004). The role of community colleges in the education of recent science and engineering graduates. InfoBrief NSF, 04-315.

Ungar, M. (2012). The social ecology of resilience. Springer.

U.S. Bureau of Labor Statistics. (2009). The 30 occupations with the largest employment growth 2008-18. U.S. Bureau of Labor Statistics, Employment Projections 20082018.

US News Staff. (2012). The 25 best jobs. U.S. News. Retrieved from http://money.usnews.com/careers/best-jobs/rankings/the-25-best-jobs

Vecchiarelli, T., Taormina, J., Simon, N., \& Anderson, M. (2009). Project esteem: A collaboration on gender equity education in STEM fields. Synergy in STEM: Bringing Mathematics, Physics and Engineering Together, 133.

Von Solms, R., \& Van Niekerk, J. (2013). From information security to cyber security. Computers \& Security, 38, 97-102.

Watermeyer, R. (2012). Confirming the legitimacy of female participation in science, technology, engineering and mathematics (STEM): Evaluation of a UK STEM initiative for girls. British Journal of Sociology of Education, 33(5), 679. 
Wenger, E. (1999). Communities of practice: Learning, meaning and identity. Cambridge: Cambridge University Press.

West, C., \& Zimmerman, D. H. (1987). Doing gender. Gender and Society, 1(2), 125151.

Westine, C. D., Gullickson, A. R., \& Wingate, L. A. (2010). Female participation in ATE-funded programs: A ten-year trend (pp. 1-6). EvaluATE Evaluation Resource Center.

Wilkinson, S. (2013). The influence of intellectual property rights on the international trade of advanced technology products. PSAKU International Journal of Interdisciplinary Research 1, 1 (1), 144-194.

Williams, M. M., \& George-Jackson, C. E. (2014). Using and doing science: Gender, self-efficacy, and science identity of undergraduate students in STEM. Journal of Women and Minorities in Science and Engineering, 20(2).

Wingate, L., Westine, C., \& Gullickson, A. (2010). Advanced Technological Education survey 2010 fact sheet. Western Michigan University, Evaluation Center. Retrieved from http://evaluate.org/app/webroot/files/uploads/2010_ATE_Survey_Fact_Sheet.pdf

Young, D. M., Rudman, L. A., Buettner, H. M., \& McLean, M. C. (2013). The influence of female role models on women's implicit science cognitions. Psychology of Women Quarterly, 37(3), 283-292. 


\section{Appendix A}

Email to Principal Investigators to Request Nominations for Participants

Email Subject Line: Seeking ATE grad nominations

\section{Dear XXXX,}

I am a doctoral student at San Francisco State University's Ed.D. in Educational Leadership program. I am conducting research on women in Advanced Technological Education (ATE) programs in the United States. My study seeks to understand the factors that impact or support women's success in ATE programs. I am looking to interview women graduates of ATE programs and I would appreciate your nominating graduates from your program - those who received an associate's degree within the last ten years. If you or another faculty member have graduates to nominate, please send me their names and contact information by Xxxxx XX, 201X? My contact information can be found below. In addition, if you have questions or concerns about this study, you are welcome contact Dr. XXXXXX the Principal Investigator on the NSF-ATE grant. Thank you for your consideration.

Respectfully, Courtney Paulger

San Francisco State University 


\section{Appendix B}

\section{Recruiting Email to Potential Participants}

Email Subject Line: We want to learn about ATE from you!

\section{Dear XXXX,}

I am a doctoral student from San Francisco State University and am doing a study on successful women graduates of Advanced Technological Education (ATE) programs. We're trying to learn why some women do well in advanced technological education programs, while most women do not do very well. Can I talk with you about why you are doing so well? Dr. XXXXXX recommended you as a person from whom we can learn about women successes. Just email me back, and we'll set times to talk that are good for your schedule. I am available days and nights and really look forward to talking with you.

Respectfully, Courtney

San Francisco State University 


\section{Appendix C}

\section{Extensive Participant Demographics}

Table Al

Demographic Data of Study Participants

\begin{tabular}{|c|c|c|c|c|c|c|c|c|}
\hline Pseudonym & $\begin{array}{l}\text { Sub- } \\
\text { bacculaureate } \\
\text { degree - area of } \\
\text { study }\end{array}$ & $\begin{array}{l}\text { Date of } \\
\text { degree }\end{array}$ & $\begin{array}{l}\text { Relationship } \\
\text { status }\end{array}$ & $\begin{array}{l}\text { Self- } \\
\text { identified } \\
\text { race/ } \\
\text { ethnicity } \\
\end{array}$ & $\begin{array}{l}\text { Number } \\
\text { of } \\
\text { children }\end{array}$ & $\begin{array}{l}\text { Age } \\
\text { (years) }\end{array}$ & \begin{tabular}{|l|} 
Self- \\
identified \\
religion
\end{tabular} & $\begin{array}{l}\text { Approximate } \\
\text { average } \\
\text { household } \\
\text { income }\end{array}$ \\
\hline Roxanne & $\begin{array}{l}\text { Industrial } \\
\text { Maintenance }\end{array}$ & 2012 & $\begin{array}{l}\text { Single, never } \\
\text { married }\end{array}$ & White & None & 23 & Christianity & $\begin{array}{l}\$ 75,000- \\
\$ 99,999\end{array}$ \\
\hline Nena & \begin{tabular}{|l} 
Energy \\
Management
\end{tabular} & 2013 & Divorced & $\begin{array}{l}\text { Black or } \\
\text { African- } \\
\text { American }\end{array}$ & None & 39 & $\begin{array}{l}\text { Christianity; } \\
\text { Inter/Non- } \\
\text { denominationa }\end{array}$ & $\begin{array}{l}\$ 25,000 \\
\$ 49,999\end{array}$ \\
\hline Betty & $\begin{array}{l}\text { Power Plant } \\
\text { Technology }\end{array}$ & 2005 & Married & White & 2 & 52 & $\begin{array}{l}\text { Protestantism; } \\
\text { Christianity }\end{array}$ & $\begin{array}{l}\$ 150,000- \\
\$ 174,999\end{array}$ \\
\hline Audra & Biotechnology & 2011 & $\begin{array}{l}\text { Single, } \\
\text { cohabiting } \\
\text { with partner }\end{array}$ & $\begin{array}{l}\text { White \& } \\
\text { Mexican- } \\
\text { American }\end{array}$ & None & 29 & Christianity & $\begin{array}{l}\$ 25,000- \\
\$ 49,999\end{array}$ \\
\hline Kyla & Biotechnology & 2005 & $\begin{array}{l}\text { Single, never } \\
\text { married }\end{array}$ & $\begin{array}{l}\text { Black or } \\
\text { African- } \\
\text { American }\end{array}$ & 2 & 48 & Catholicism & $\begin{array}{l}\$ 50,000- \\
\$ 74,999\end{array}$ \\
\hline Sula & $\begin{array}{l}\text { Architectural } \\
\text { Technology }\end{array}$ & 2011 & $\begin{array}{l}\text { Single, never } \\
\text { married }\end{array}$ & $\begin{array}{l}\text { From } \\
\text { multiple } \\
\text { races- Black } \\
\text { \& White }\end{array}$ & None & 30 & $\begin{array}{l}\text { No self- } \\
\text { identified } \\
\text { religion }\end{array}$ & $\begin{array}{l}\$ 50,000- \\
\$ 74,999\end{array}$ \\
\hline
\end{tabular}

